\title{
الصراع السياسي الفلسطيني الداخلي \\ بين النشأة والتطور والحاضر
}

د.*.* علي حساه الدين البغدادي"

أولًا - الإجراءات المنهجية للبحث:

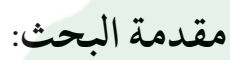

تعتبر إشكالية الصراع السياسي الداخلي في دولة فلسطين المشكلة الكبرى داخـل

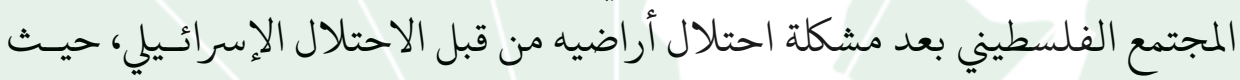

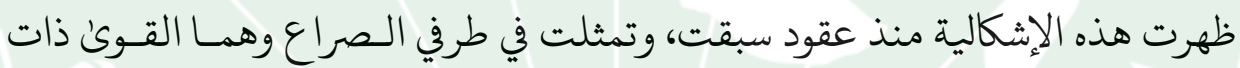

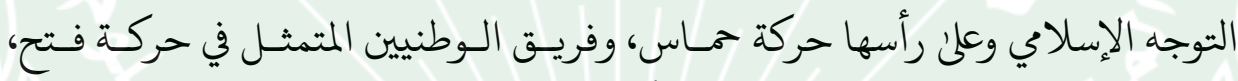

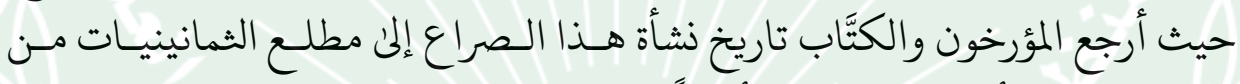

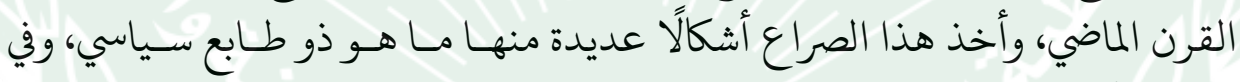

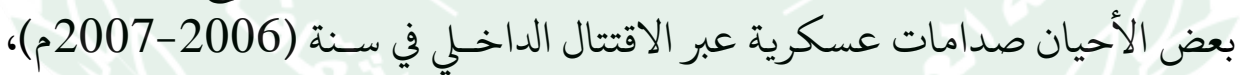

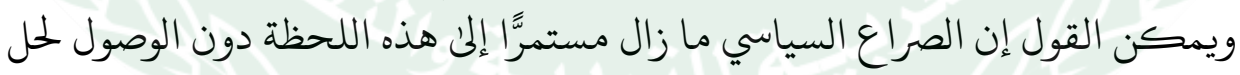
ينهي هذه الإشكالية داخل المجتمع الفلسطيني.

ويصنف المجتمع الفلسطيني ضمن الدول التي تعاني من أزمات إنسانية وسياسية

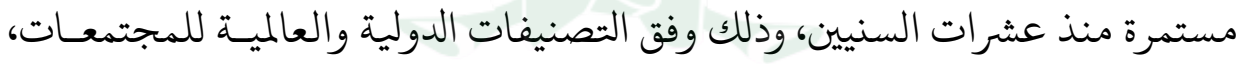

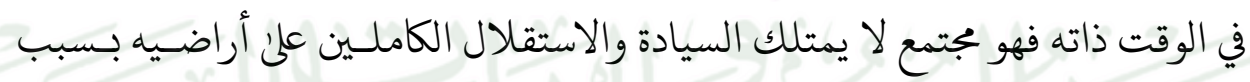

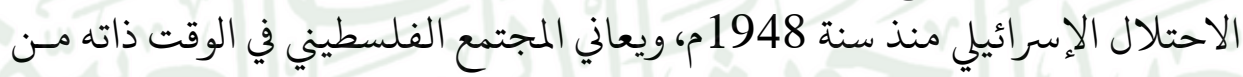

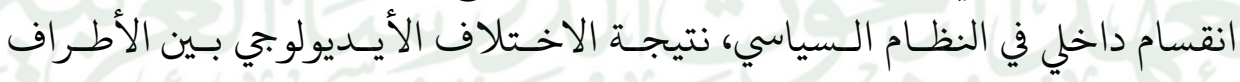

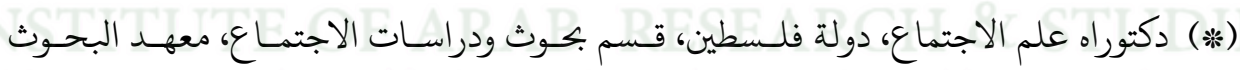

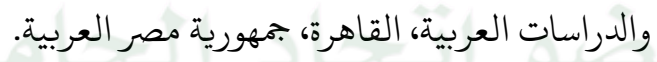


المتصارعة علئ الحكم والمتمثلة في حركتي فتح وحماس، حيث تسيطر حركة فتح مثثلـة

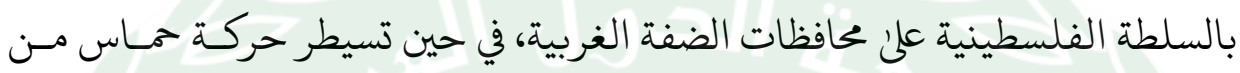

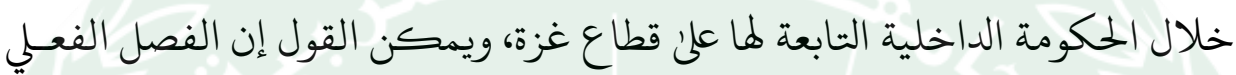

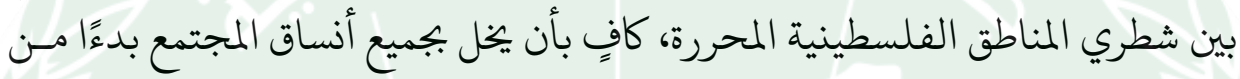

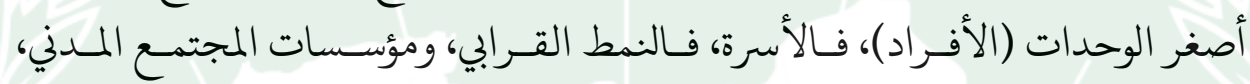

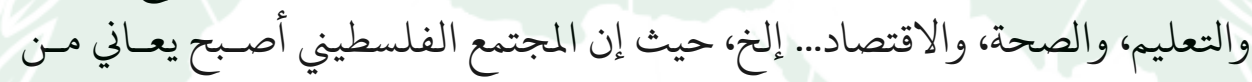
تفشي ظواهر عديدة لم تكن تعرف سابقًا بهذا الحجم والأثر.

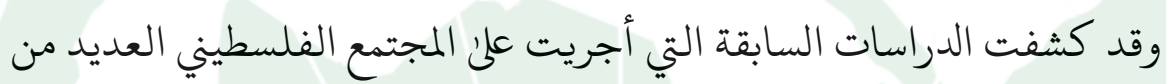

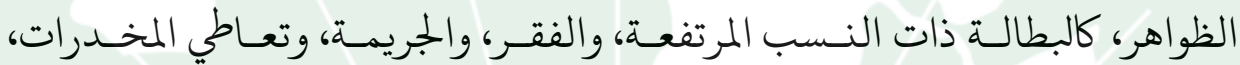

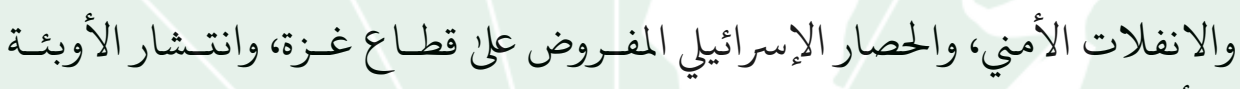
والأمراض التي لم تكن تعرف سابقًا.

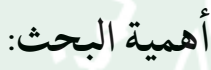

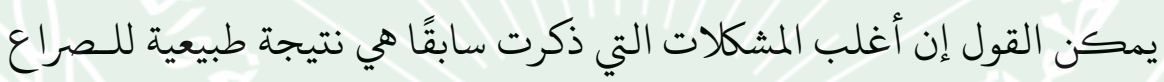

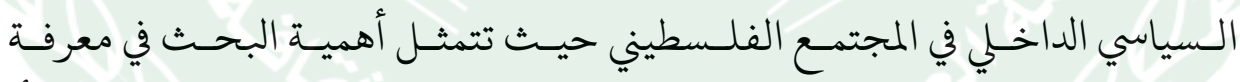

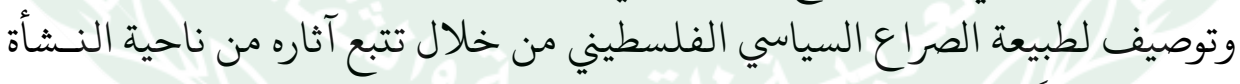

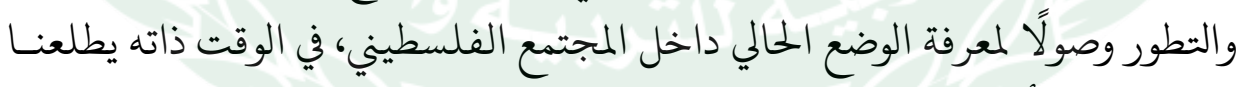

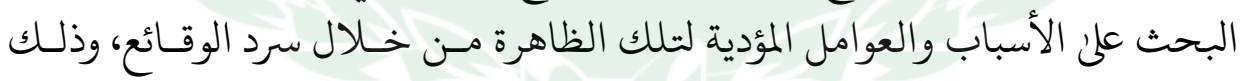

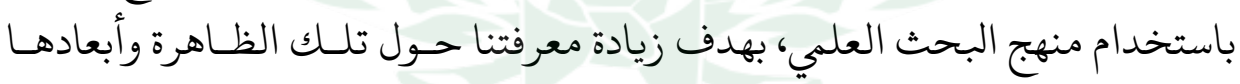
وأسبابها الموضوعية وتاريخها التطوري، البحي،

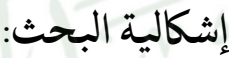

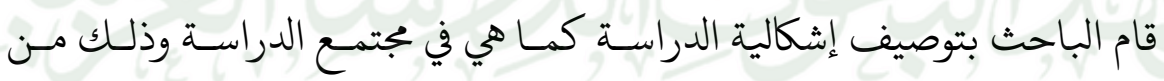

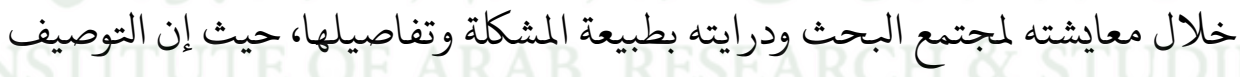

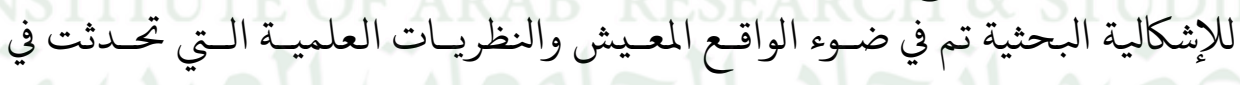


موضوع الصراع، وأيضًا في ضوء الدراسات السابقة ذات الـصلة بالإثـكالية موضـوع

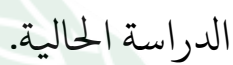

وقد تجسدت إشكالية الدراسة الحالية في تغيير حالة الصراع الـسياسي الداخلي

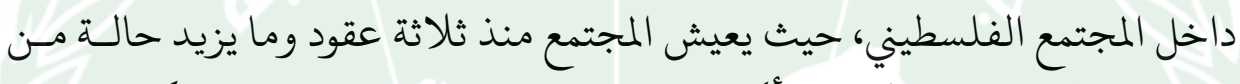

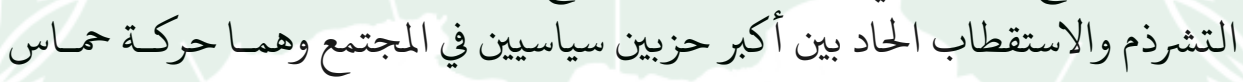

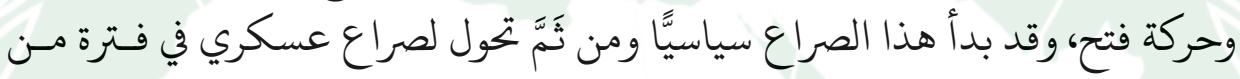

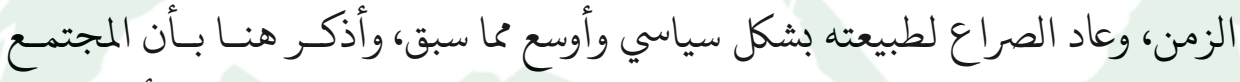

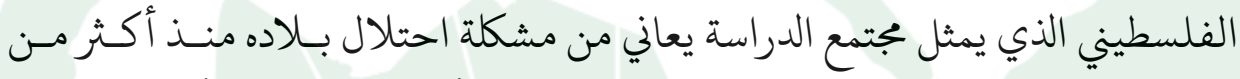

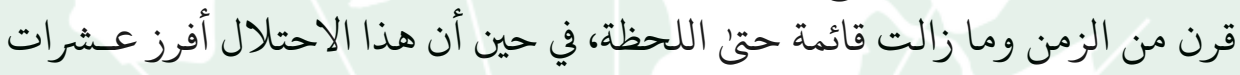

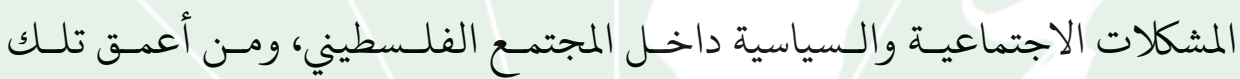

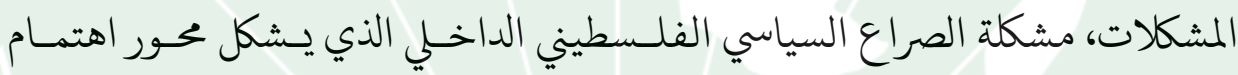

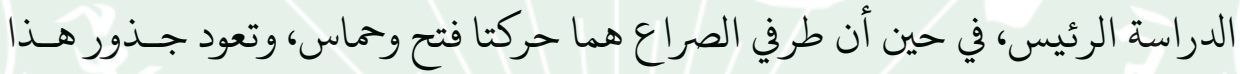

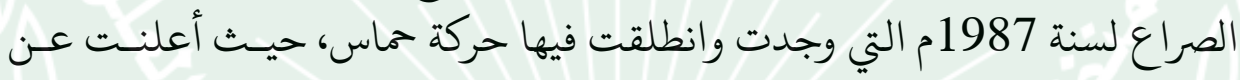

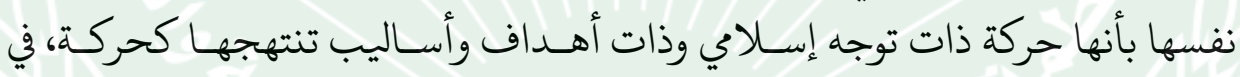

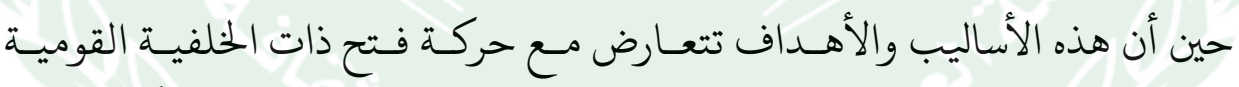

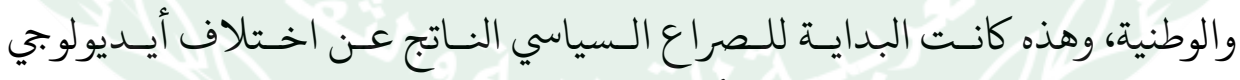
وبرنامجين مختلفين بين التنظيمين الأكبرين شعبية وقوة داخل مجتمع الدراسة.

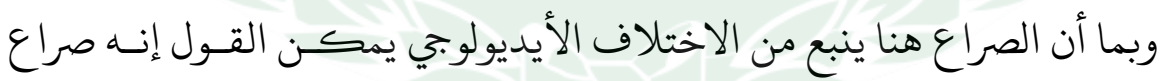

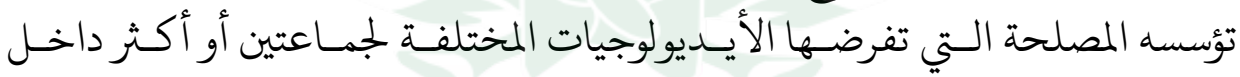

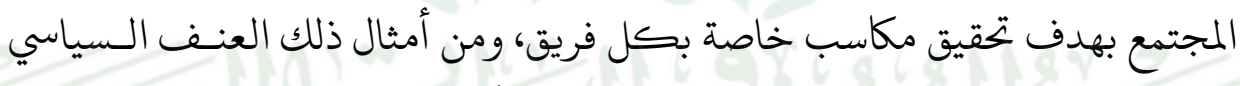

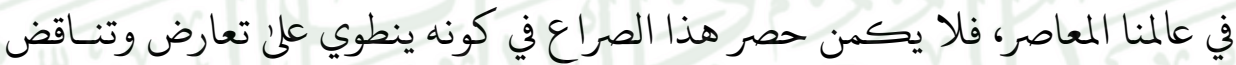

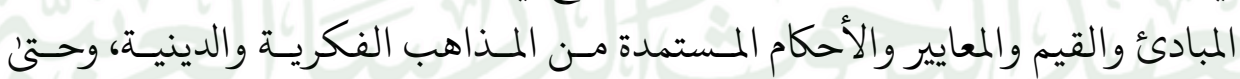

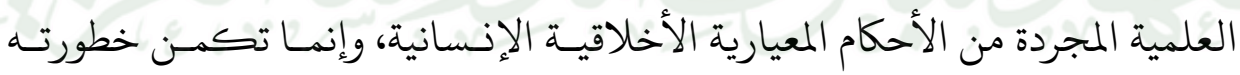

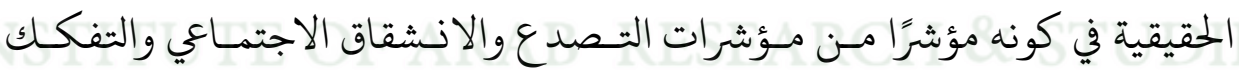

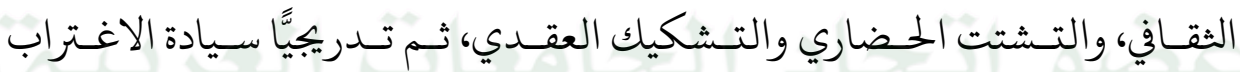


الاجتماعي الذي يعكس بدوره أخطر ظاهرة اجتماعيـة تهـد الكيـان الإنساني مـن حيث إنه كيان متميز عن غيره (1).

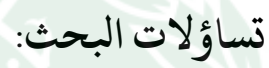
- ما تاريخ نشأة الصراع السياسي الداخلي وطبيعته؟

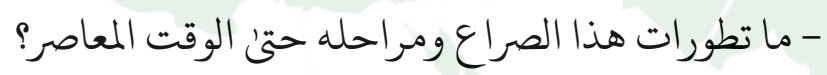

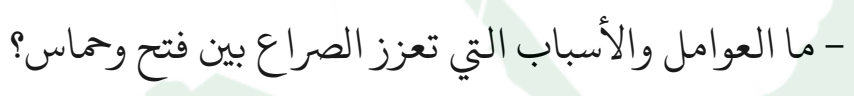

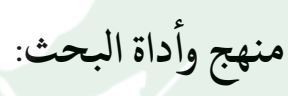

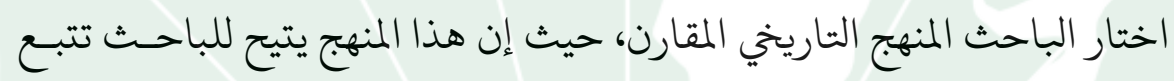

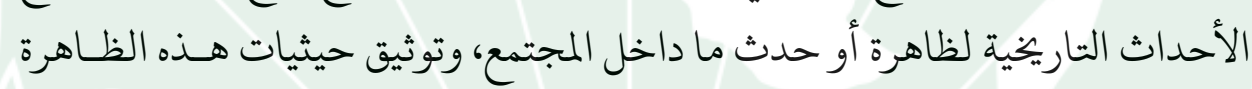

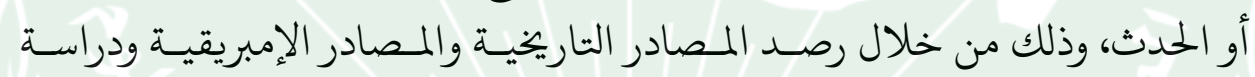

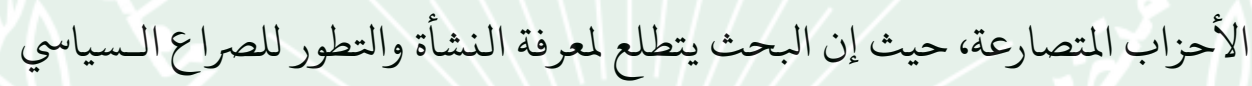

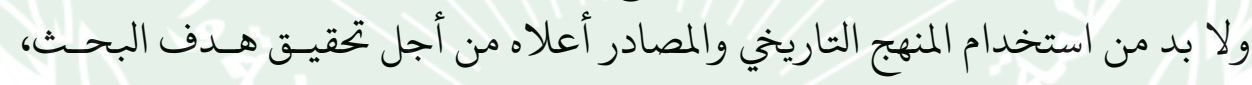

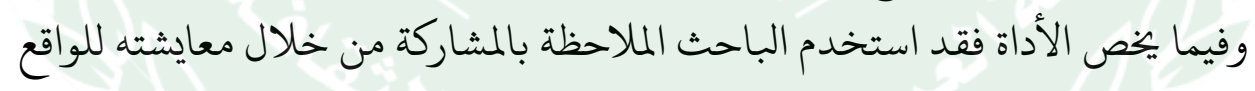

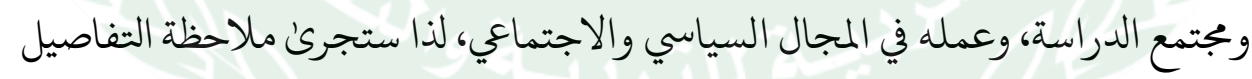
المتعلقة بموضوع الصراع كافة وذكرها ضمن البحث.

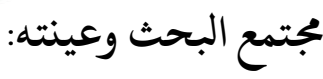

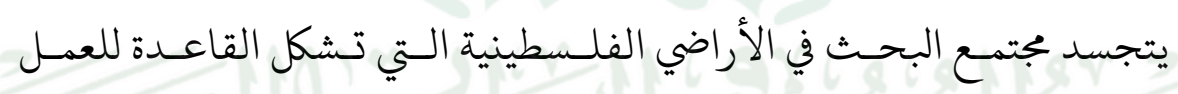

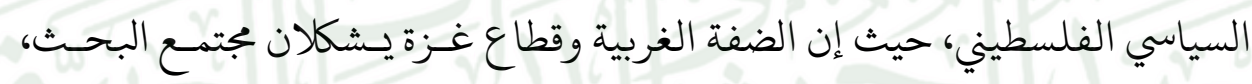

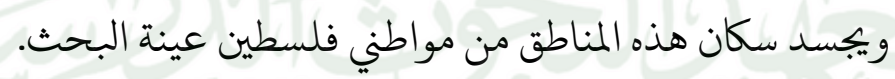

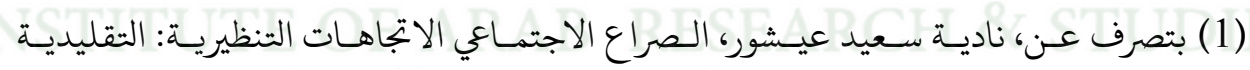

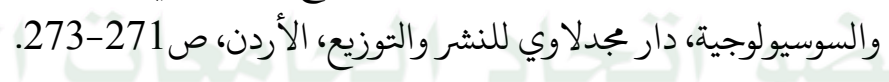




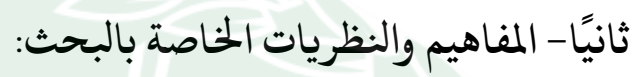

مفاهيم البحث:

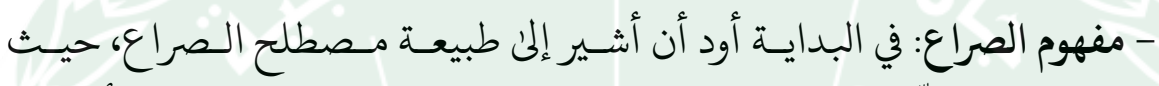

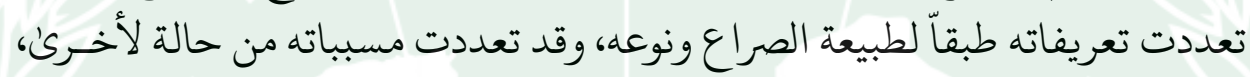

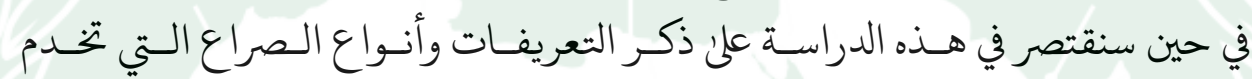
موضوع الدراسة.

أ- تعريف الصراع اصطلاحًا: يمكن تعريف الصراع من وجهة نظر إدارية بأنه:

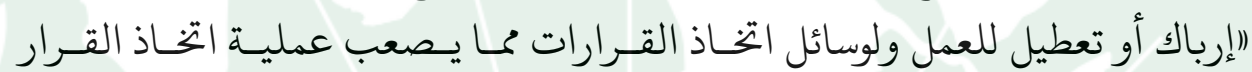

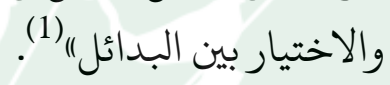

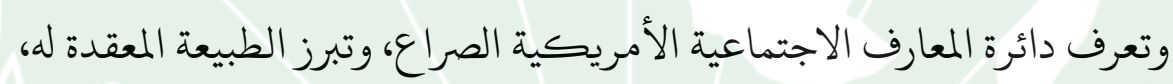

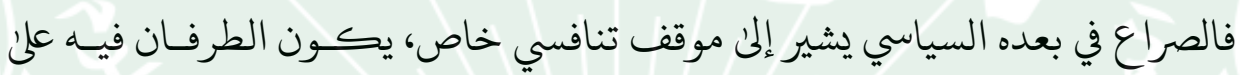

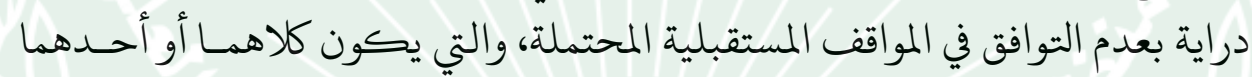

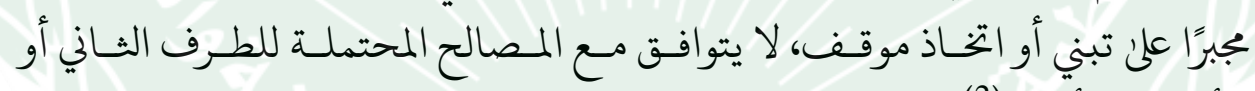
الأطراف الأخرى' (2).

- ويعرف الصراع في قـاموس "لونجمـان) بأنـه: ("حـاله مــن الاخــلاف أو عـدم الاتفاق بين جماعات ناتج عن تعارض في المبادئ والأفكار ||(3).

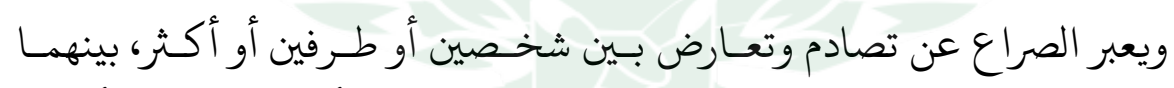

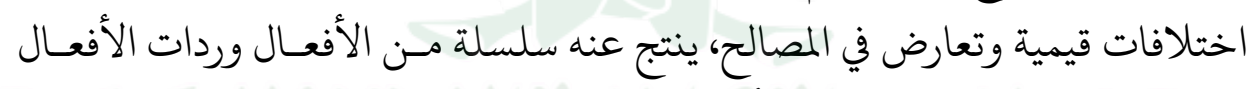

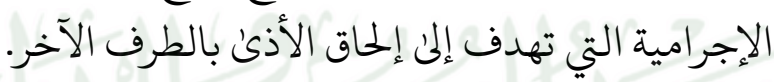

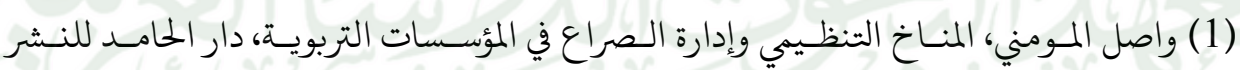

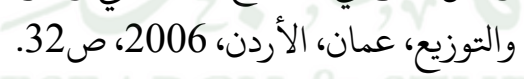

(2) Edward J. Murray, "Conflict: The Psychological Aspects", in IESS, pp. 220-225.

(3) محمود بدوي، مفهوم الصراع، مجلة دراسات مستقبلية، عدد 3، جامعة أسيوط، 1991، ص37. 
ب- التعريف الإجرائي للصراع حسب موضوع البحـث: الصراع بوجـه عام هـو

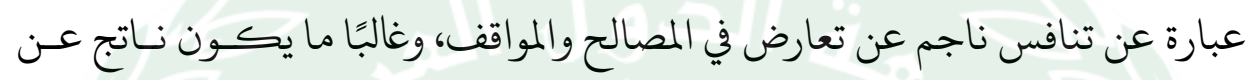

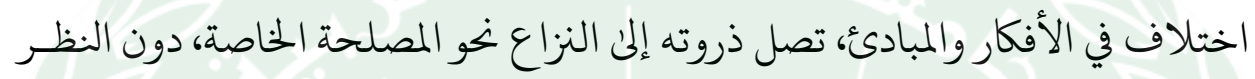

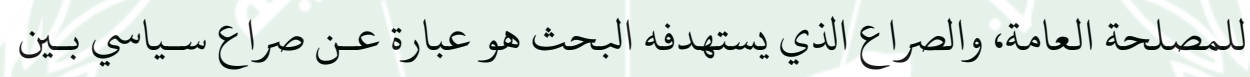

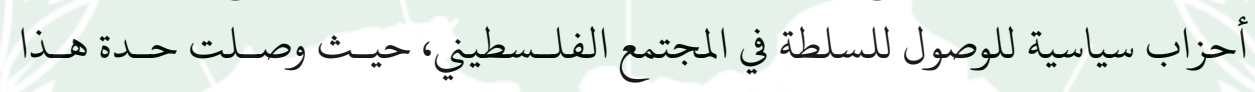

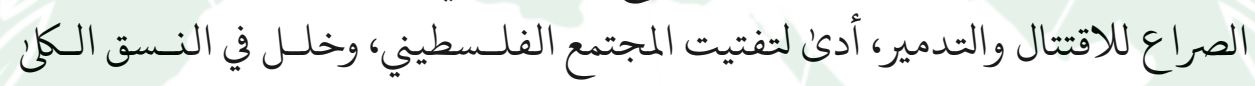

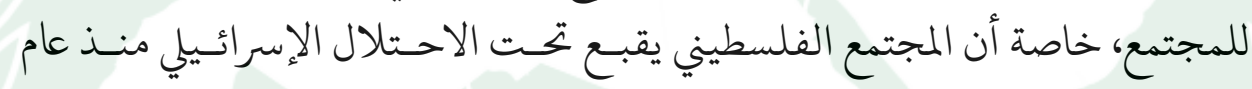

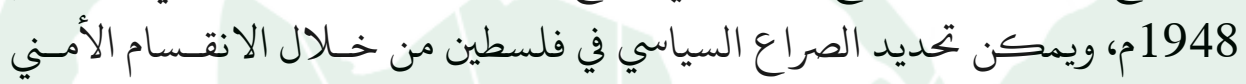

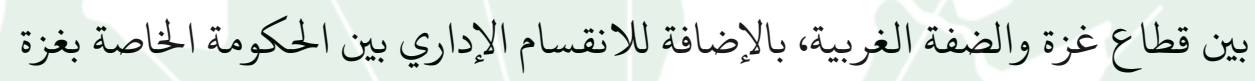

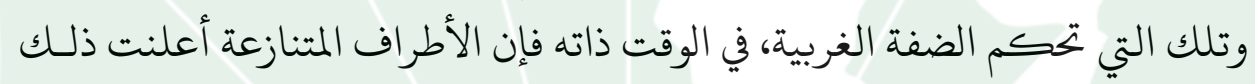
تكرارًا وبشكل علني أمام العالم بأكمله سواء من خلال الأقوال أو الأفعال.

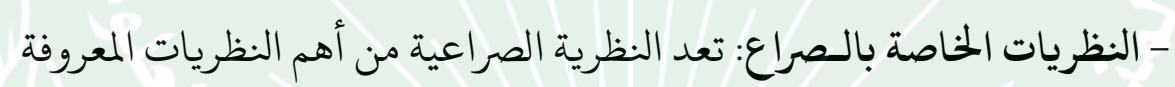

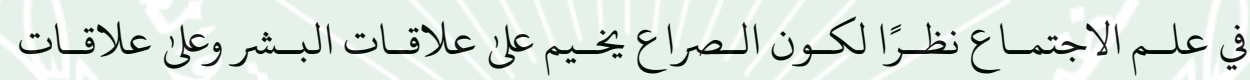

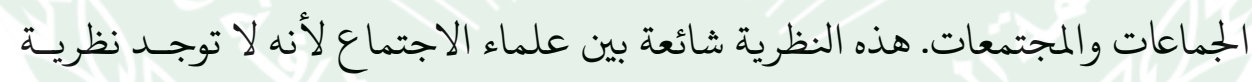

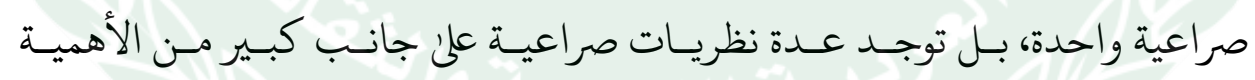

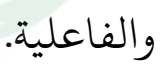

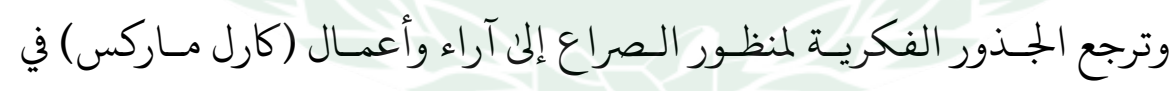

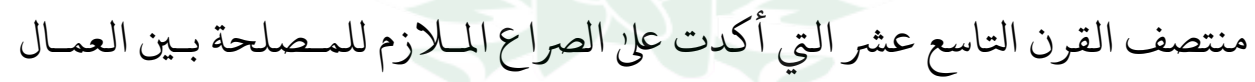

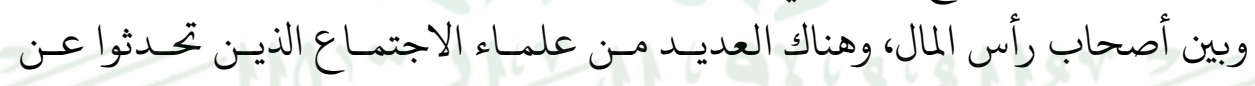

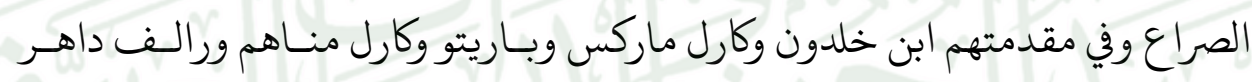

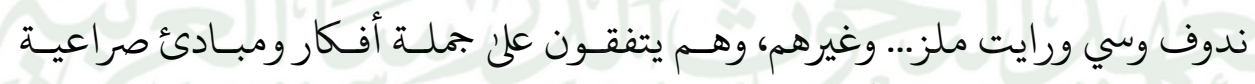
بسبب الحياة التي نعيشها (1).

(1) عبد العزيز بن على الغريب، نظريات علم الاجتماع، جدة، المطبعة للنشر، 2009، ص134. 
1- نظرية الصراع عند كارل ماركس: كارل ماركس اشـتهر بنظريته الصراعية

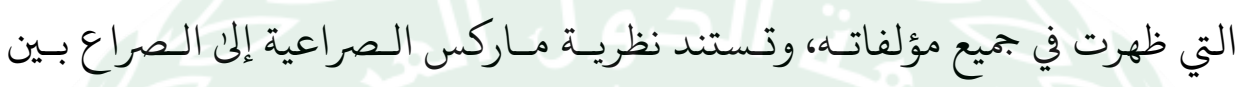

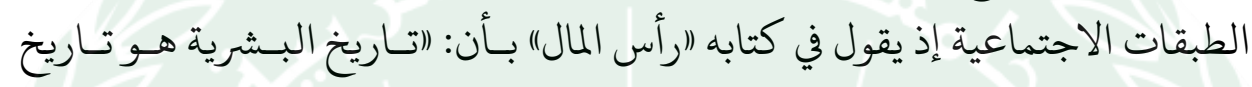

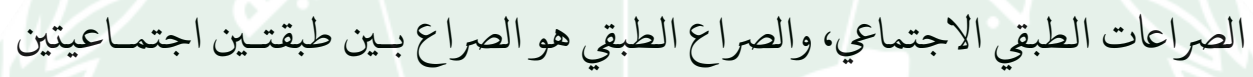

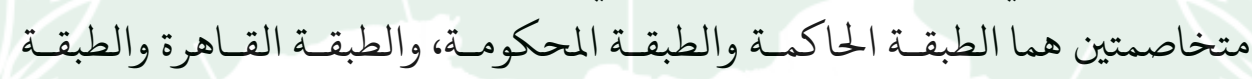

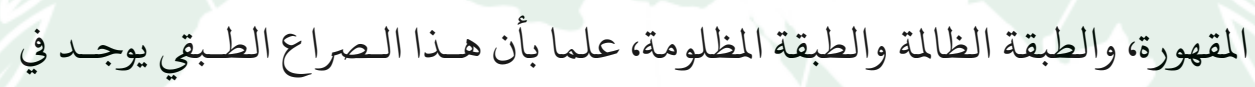

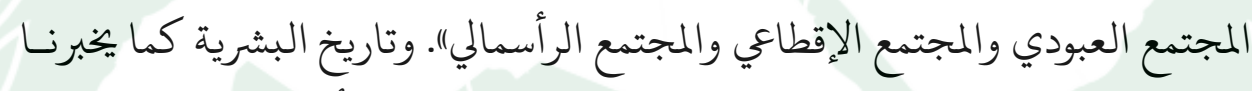

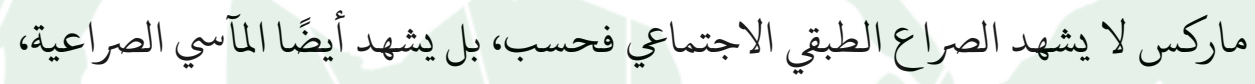

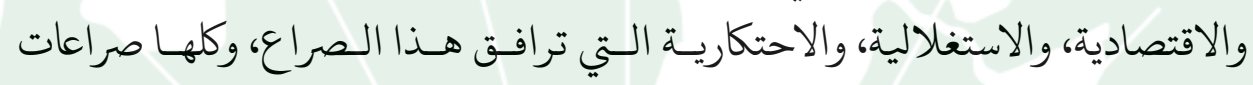

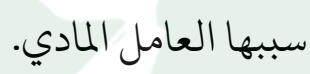

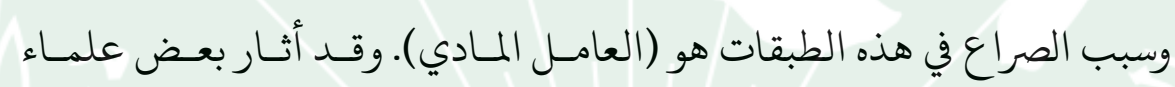

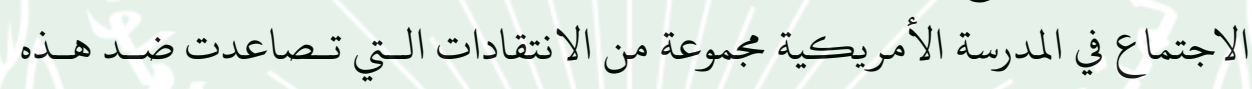

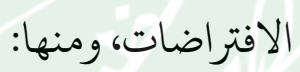

- أن المجتمعات أكبر من مجرد انعكاس لتنظيمات اقتصادية أو أشكال الملكية. - لا ترتبط المصالح دائمًا داخل المجتمع بطبقة اجتماعية واحدة. - نادرًا ما يدور الصراع الاجتماعي داخل المجتمع بين قطبين فقط. - لا تعكس علاقات القوة في أي مجتمع مباشر بنظام الملكية.

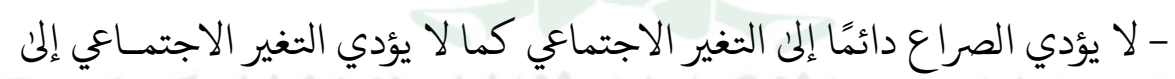
الصراع) وأيضًا يعتبر الصراع الطبقي طبقًا لرأي ماركس هو نتيجة حتمية لحركة التاريخ، (1) طلعت إبراهيم لطني، النظرية المعاصرة في علم الاجتماع، القاهرة، دار غريب للطباعة والنشر، ط2، 2009، ص16. 
حيث يرئ أن نمو وعي وإدراك طبقة العمـال (البروليتاريـا) باسـتغلال طبقـة المـلاك

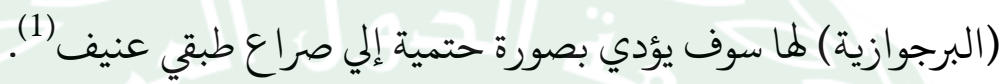

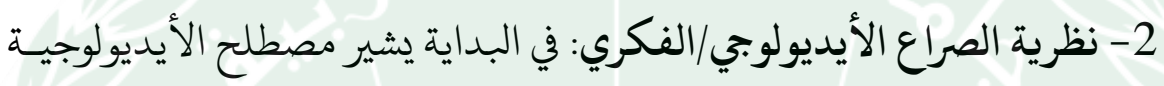

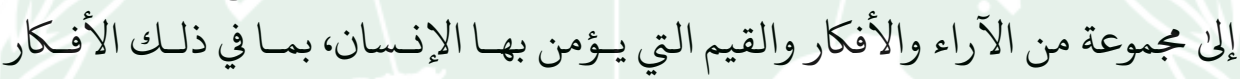

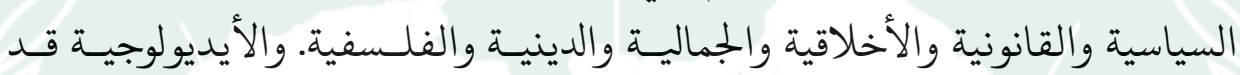

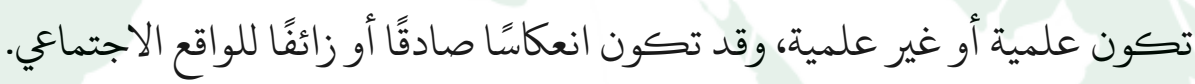
ويمكن القول إن الصراع الأيديولوبي صراع تؤسسه المـصلحة الـتي تفرضهـا

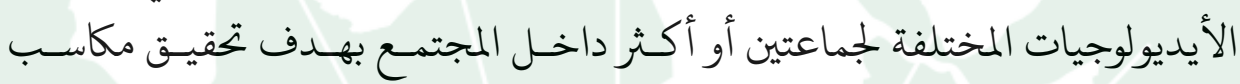

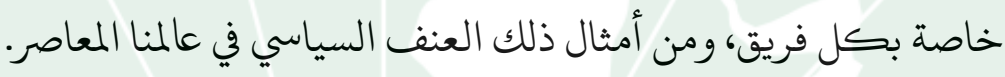
ولا يكمن خطر هذا الصراع في كونه ينطوي على تعارض وتنساقض المبـادئ والقسيم

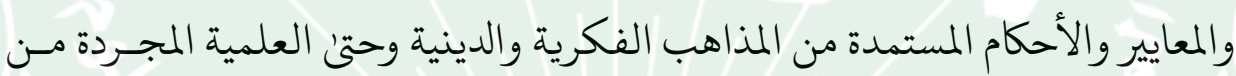

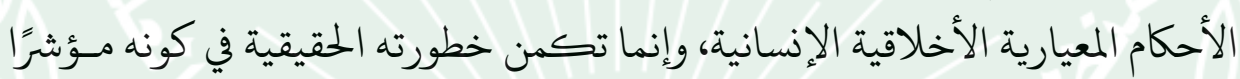

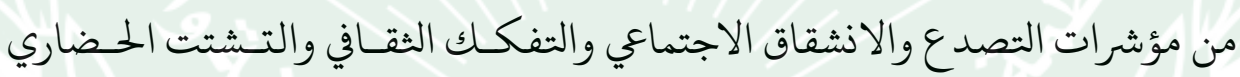

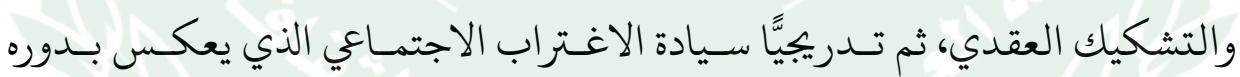

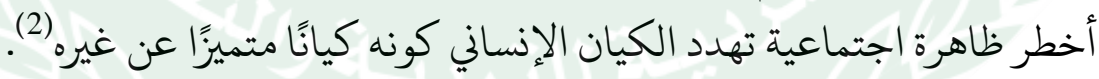
ولقد حاول دارندورف إجراء نوع من التوليف بين بعض الطروحـات الوظيفيـة

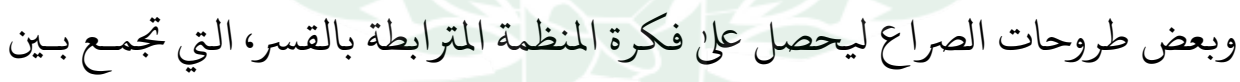

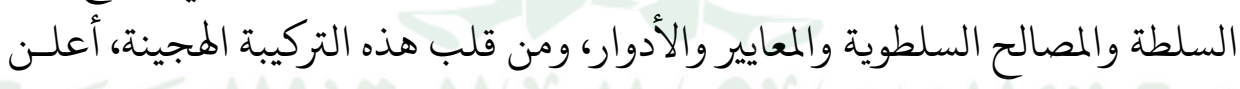

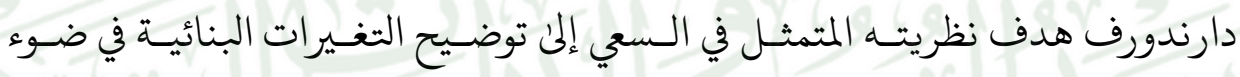
صراعات الجماعات التي يصفها علئ النحو التالي:

(1) حمد الجوهري، وعدلي السمري، المشكلات الاجتماعية، مركز البحوث والدراسات الاجتماعية،

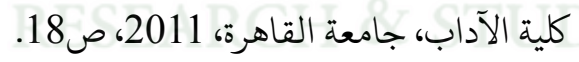

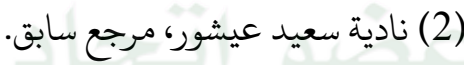


- في كل منظمة مترابطة بالقسر هناك نوعان من المواقتع المحتـشدة همـا المواقع المسيطرة والمواقع الخاضعة.

- يوصف كل تجمع من خلال مصالح كامنة عامة وتجمعات الأفراد الـتي تتحقـق بموجبها تشكلات شبه جماعات.

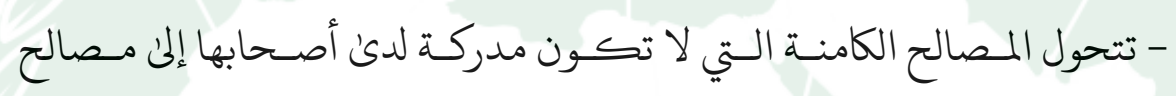

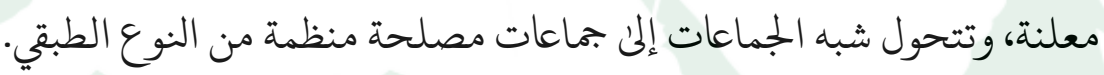

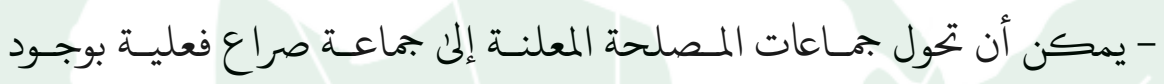

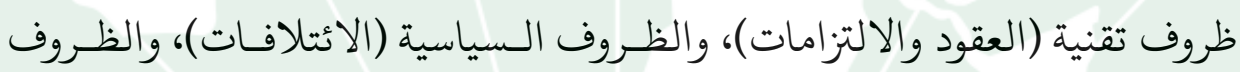
الاجتماعية (الاتصال)، والظروف السيكولوجية (استدماج مصالح الدور).

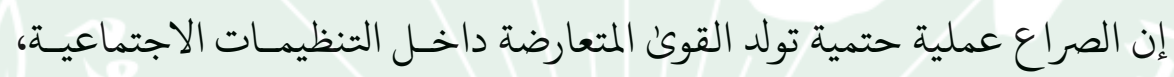

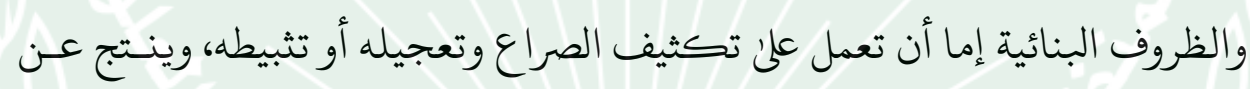

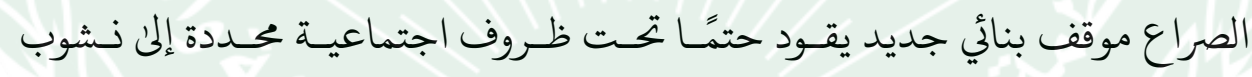

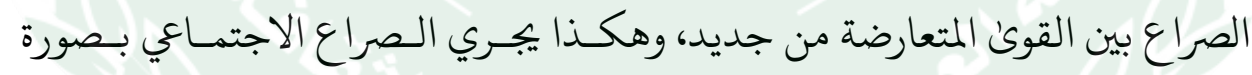

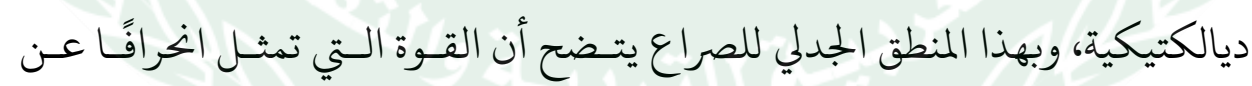

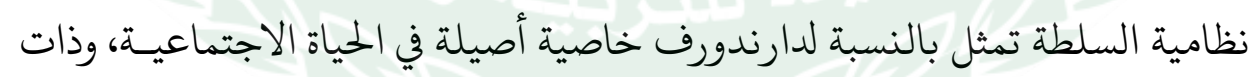

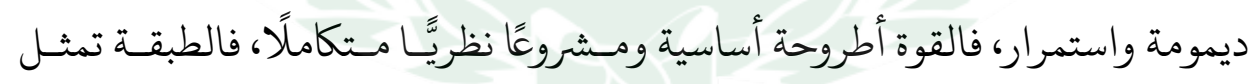

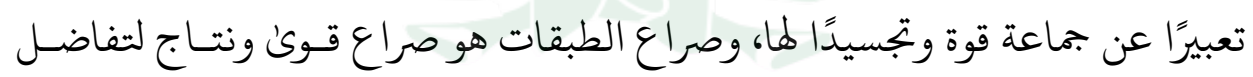

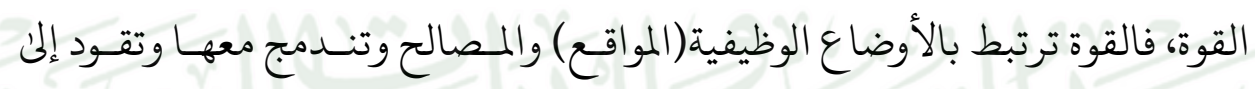

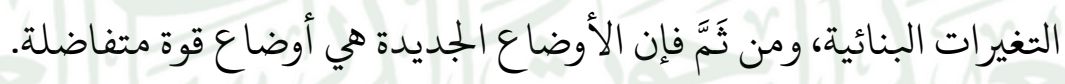

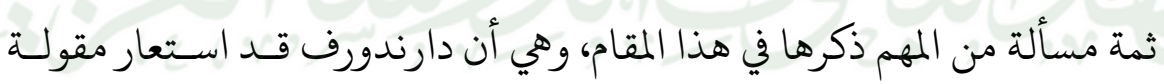

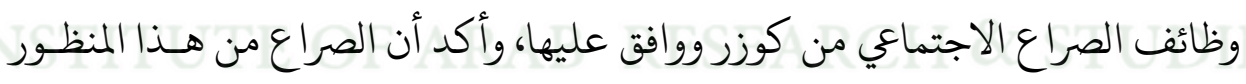




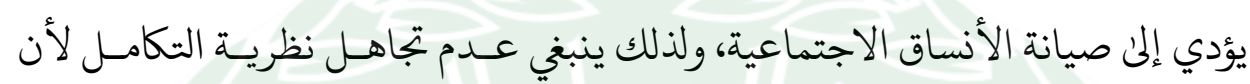
ظاهرة الصراع ترتبط بمحددات الدور وبالتنشئة والحراكئك(1).

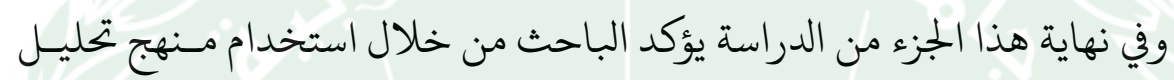

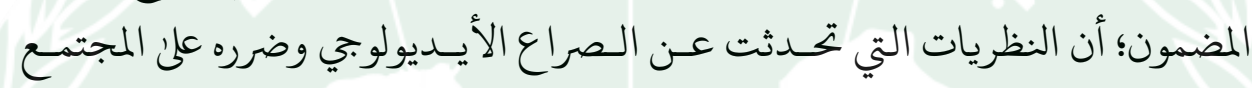

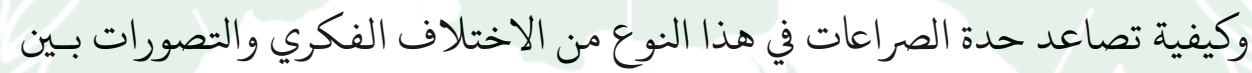

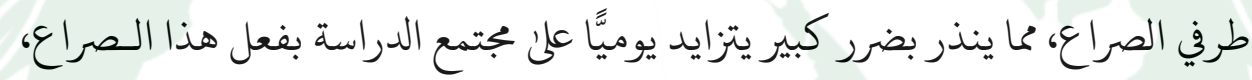

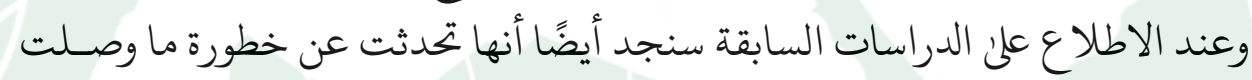

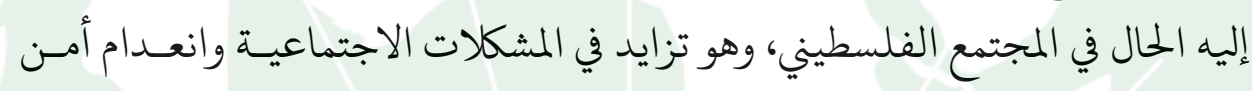

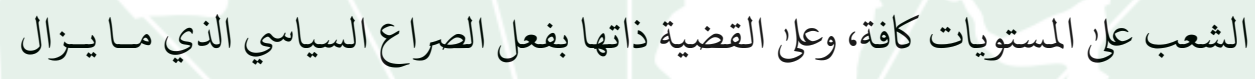
قائمًا بين فتح وحماس.

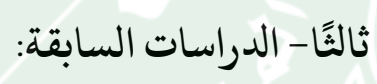
المحور الأول: الدراسات التي اهتمت بالصراع من حيث نشأته وعوامله: - دراسة عنات كورتس (2008م): بعنوان (الثورات الفلسطينية بين الـنزاعات الداخلية والحرب ضد إسرائيل). ناقشت الدراسـة الصراع علن جبهتـين: الثورات الفلـسطينية بـين الـنزاعات

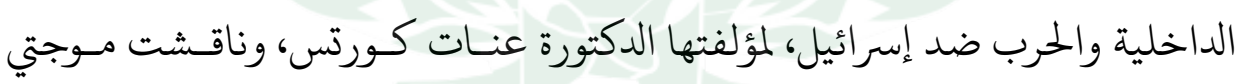

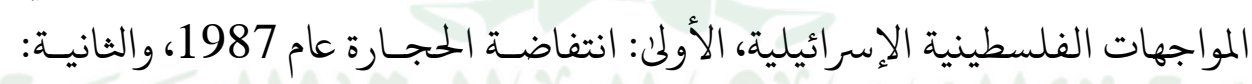

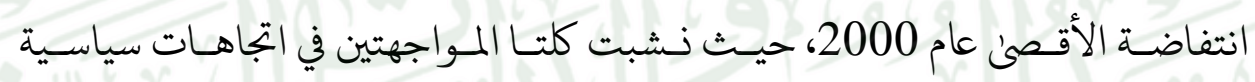
مختلفة، ومتعارضة في الكثير من الأحيان. وكشفت الدراسة عن نتائج أهمها:

(1) محمد الحوراني، النظرية المعاصرة في علم الاجتماع التوازن الثفاضلي صيغة توليفية بين الوظيفة

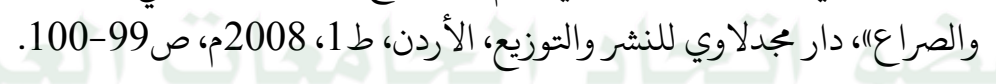


- أن الانتفاضة أسفرت عن تغيرات جوهرية كبـيرة على الـساحة الفلسطينية،

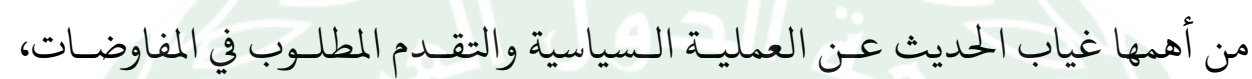
إضافة إلنى انهيار السلطة الفلسطينية في قطاع غزة.

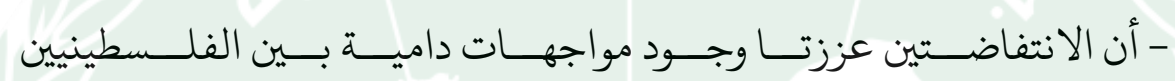

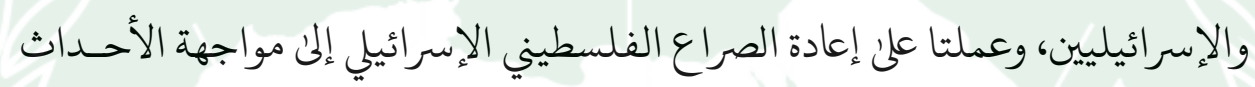
على الساحة الدولية.

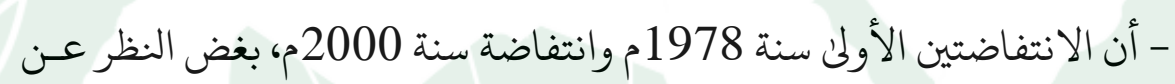

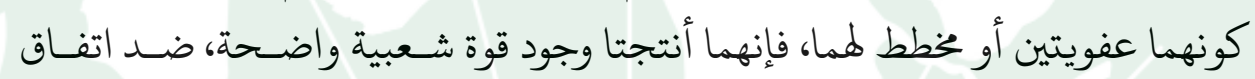

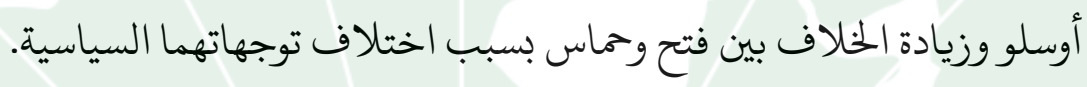
- فشل الحوارات واللقاءات كافة التي جرت بهـدف إنهاء الخلافـات الـسياسية

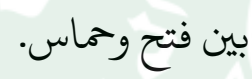

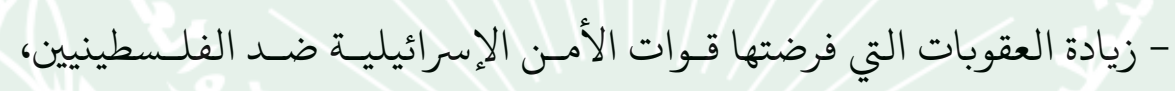

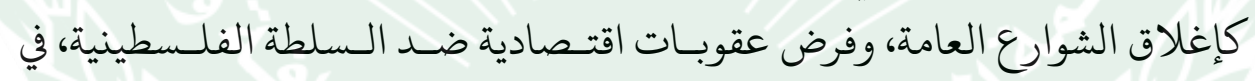

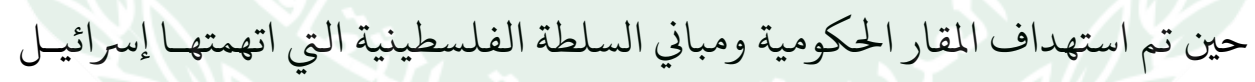
بالوقوف خلف اندلاع الانتفاضة، ومحاولة تثويرها أكثر فأكثر.

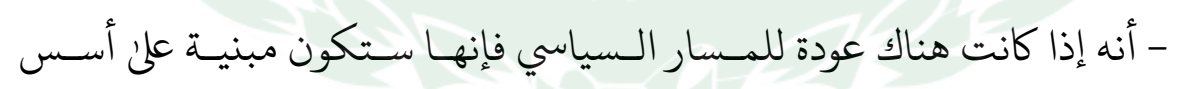

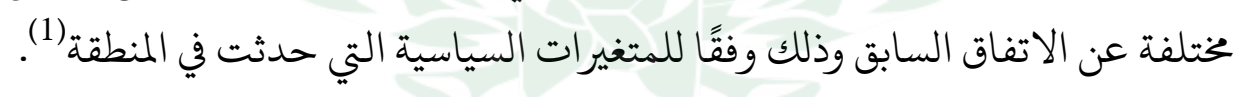
- دراسة مريم عيتاني (2008م): بعنوان (الصلاحيات بين فتح وحماس في إدارة السلطة الفلسطينية).

هدفت هذه الدراسة إلى معرفة الخلل في إدارة الصلاحيات بين الـسلطة الوطنيـة

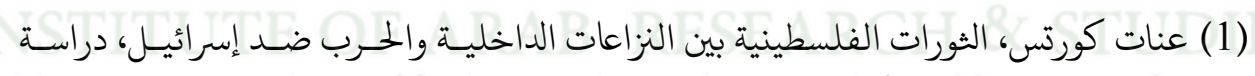

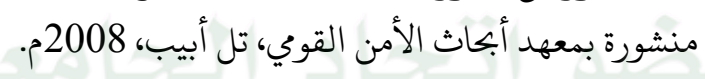




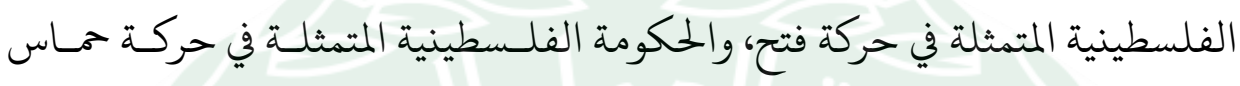
بعد فوزها بالانتخابات التشريعية عام 2007م، وصراع واع الصلاحيات فيما بينهما.

$$
\text { في حين كشفت الدراسة عن النتائج التالية: }
$$

- ظهر صراع الصلاحيات بعد فوز حماس بالانتخابات سنة 2006م.

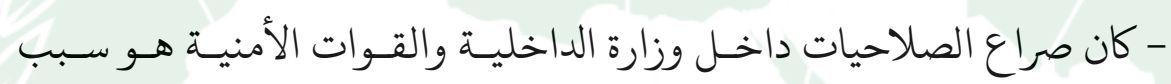

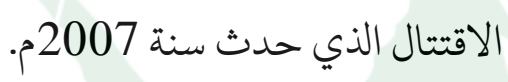

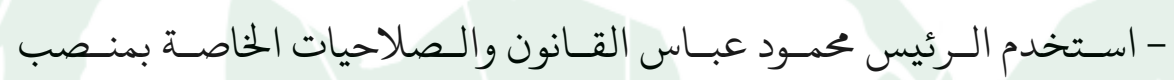
الرئيس.

- قام الرئيس الفلسطيني محمود عباس بحل الحكومة التي شكتها ماس وأعلـن

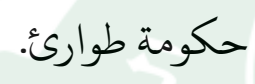

- أدئ الصراع بوجه عام بين فتح وحماس لتغييب القانون وعدم العمل بـهـ رغـم

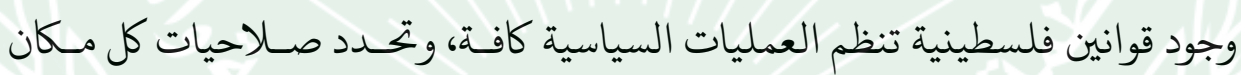
داخل النظام السياسي بوجه عام.

- وجود اختلال وانقسام في التمثيل السياسي للحكـومتين أمـام دول العـالم مــا أدىن لضعف الطرفين سياسيًّا في الداخل والخارج.

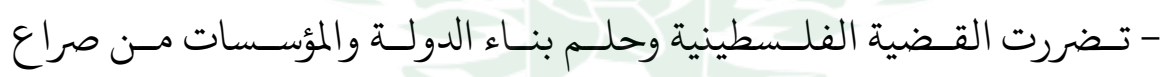

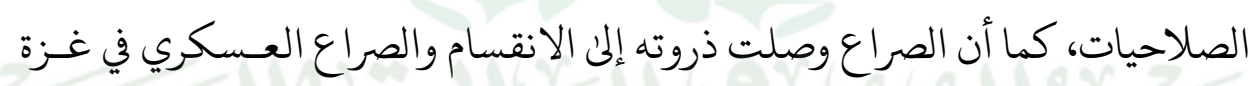

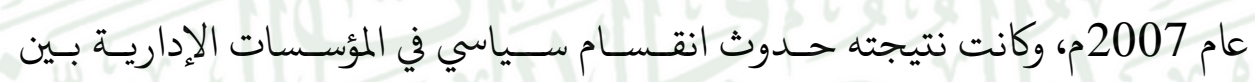
الضفة وغزة) (1)

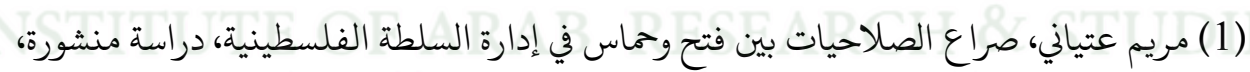
مركز الزيتونة للدراسات والاستشارات، بيروت، 2008 في مرات 
- دراسة ماجد كيـالي (2009م): بعنسوان (الصصراع علئ السياسة والسلطة في الساحة الفلسطينية المقدمات والثداعيات وما العمل).

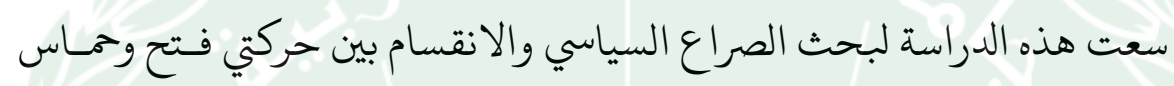

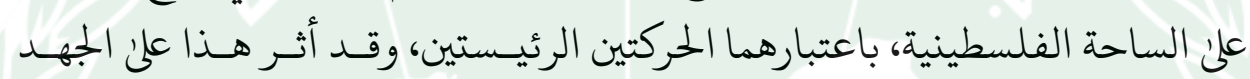

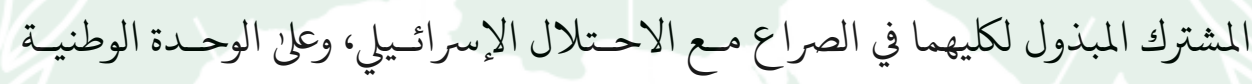

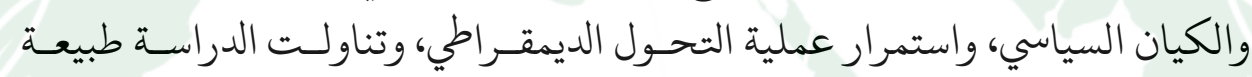
الأزمة بين الحركتين من ناحية أسبابها ونتائُها. وقد كشفت الدراسة عن نتائج أهمها:

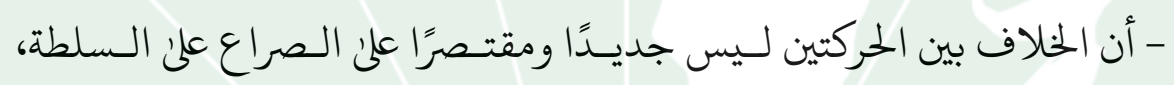

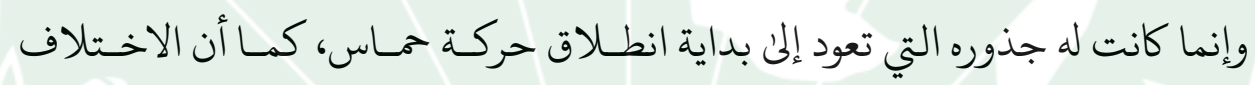

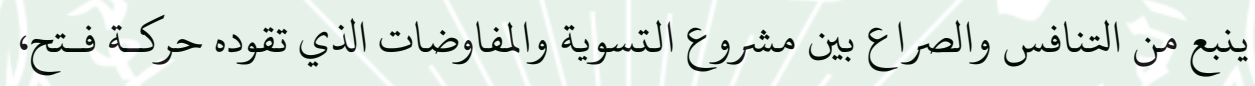

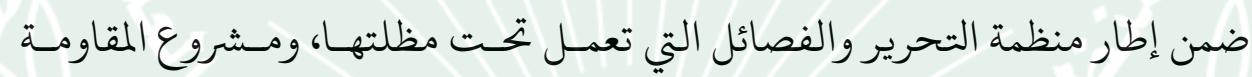
الذي تقوده حركة حماس ومن معها من الفصائل.

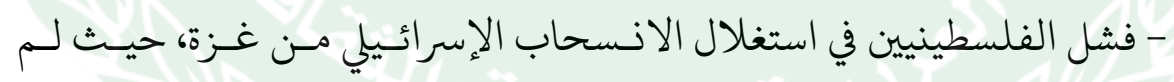

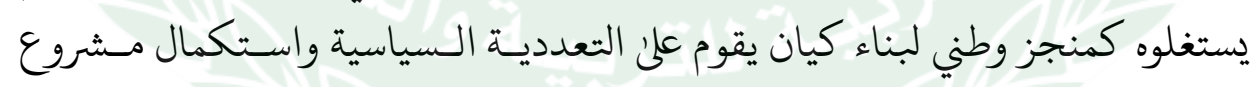
التحرر.

- أصاب خلل كل مؤسسات الدولـة الفلـسطينية والنظـام السياسي وتعطلـت

$$
\text { العملية الديمقراطية منذ سنوات عديدة. }
$$

- زيادة الاعتمادية علي المعونات الدولية في توفير احتياجات الشعب الفلسطيني

$$
\text { أكثر من السابق. }
$$

- ضعف حركتي فتح وماس أمام الاحتلال الإسرائيلي بسبب صراعهما الداخسلي وتراجع تأثيرهما على حالة الصراع مع المحتل. 


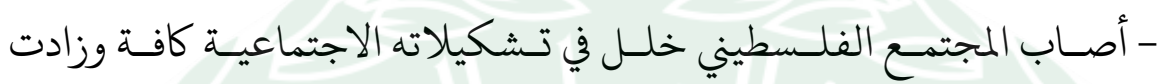
الأزمات المختلفة، وزاد الحصار على غزة، وتغول الاحتلال في الضفة.

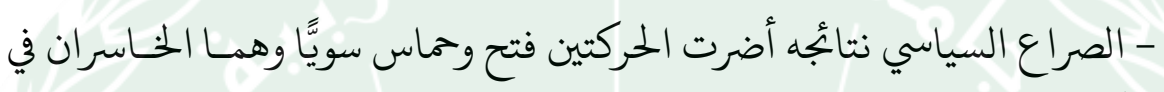
نهاية الأمر.

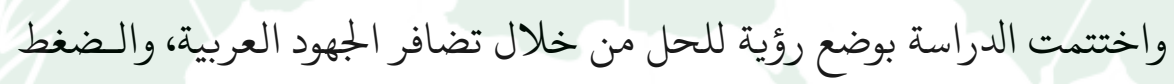

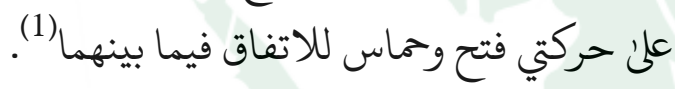

المحور الثاني: الدراسات التي اهتمت بنتائج الصراع على المجتمع:

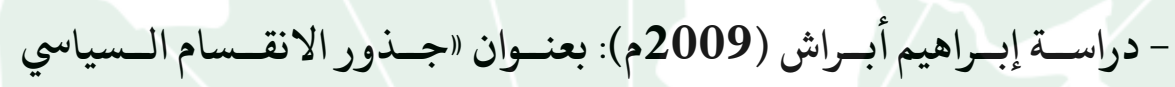

الفلسطيني ومخاطره علي المشروع الوطني".

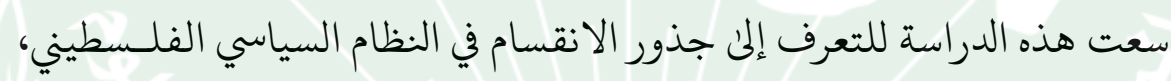
ودراسة أثثه علي المشروع الوطني الفلسطيني.

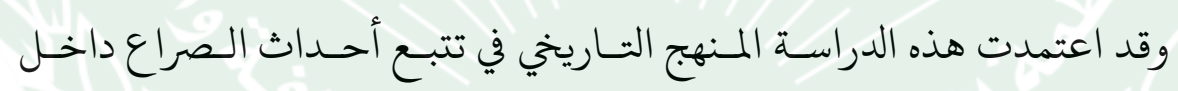

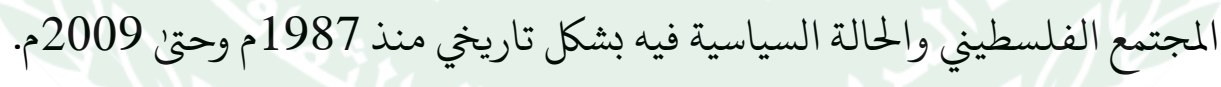

$$
\text { وكشفت الدراسة عن نتائج أهمها: }
$$

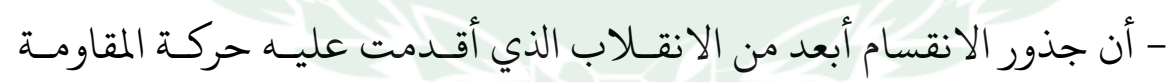

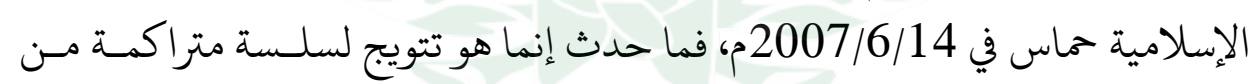

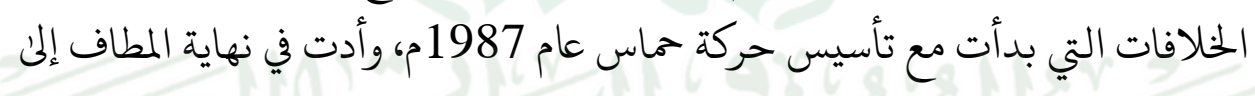
انقسام النظام السياسي الفلسطيني.

- أن الصراع السياسي أفضئ لوجود حكومتين متنـاحرتين تحست الاحتبلال مـا

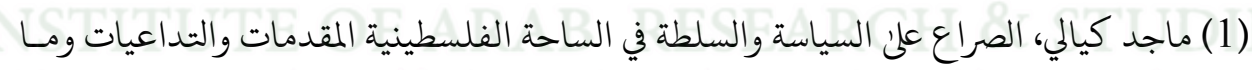

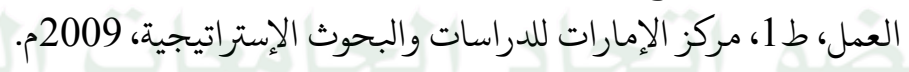


أضعف الحالة السياسية، وأدى لتشتت وضعف الجهود المبذولـة تجـاه عمليـة الـسلام وحصول الفلسطينيين علن حقوقهم وفق الاتفاقات الموقعة مع الاحتلال.

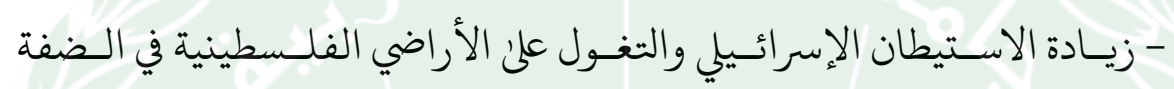
الغربية وتنكرهم لقرارات الشرعية الدولية. - تحول القضية الفلسطينية من شعب يسعن للتحريــر إلن صراع حـول السلطة

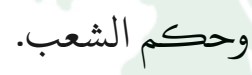

- لم يتوقف الانقسام عند الحد السياسي بل امتد جغرافيًّا واجتماعيَّا وقانونيَّـا

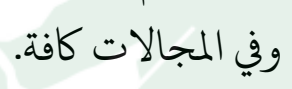

- زيادة التـدخلات الخارجيـة في الـشأن الفلـسطيني الداخلي ومسـار أحداثـه

السياسية(1).

- دراسـة إبـراهيم قـشطة (2008م) : بعنـوان (الـصراع التنظـيمي وأثـره على الأوضاع والعلاقات الاجتماعية الفلسطينية).

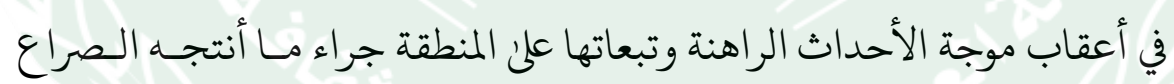

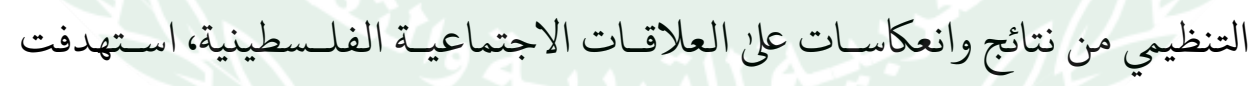

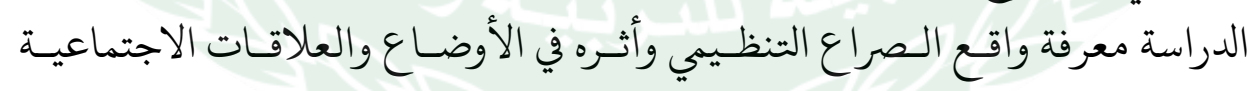

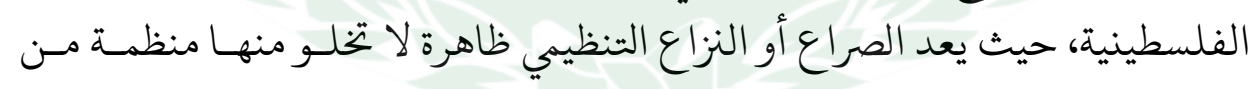

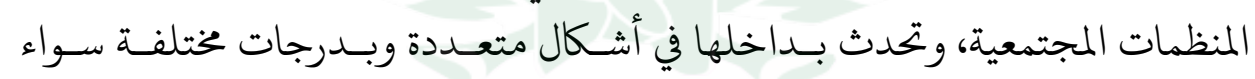

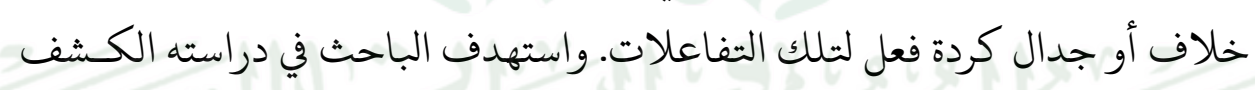

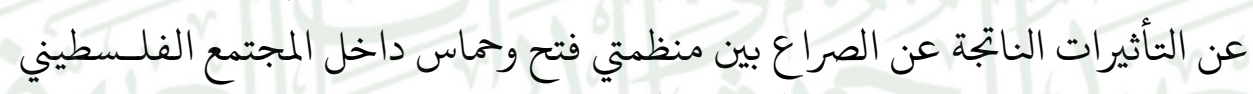

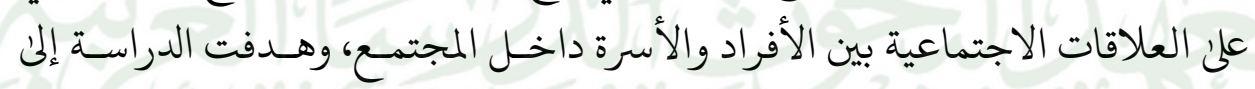

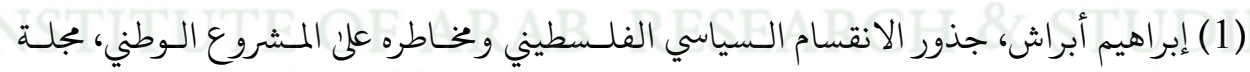

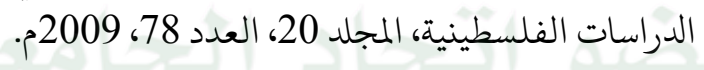


معرفة الظواهر الاجتماعية السلبية التي برزت بفعل بـسبب الصراع التنظيمي بـين حماس وفتح.

$$
\text { وقد كشفت الدراسة عن نتائج أهمها: }
$$

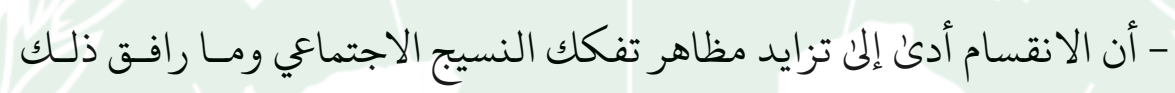

$$
\text { من انقسام اجتماعي داخلي في غزة. }
$$

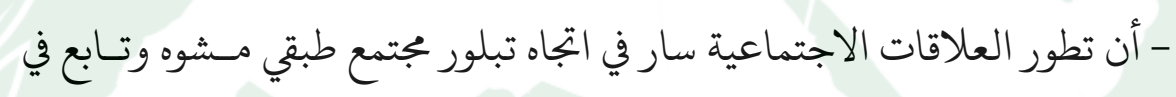

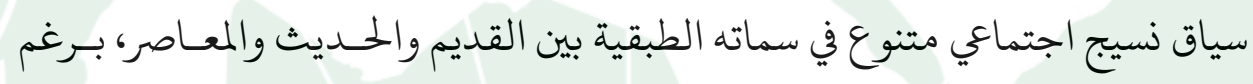

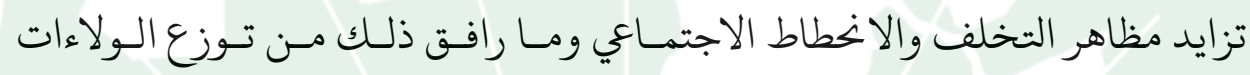

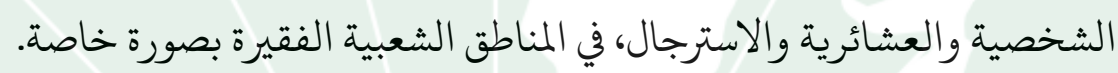

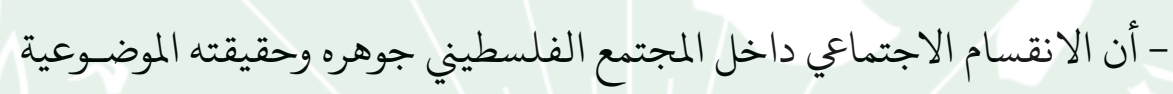

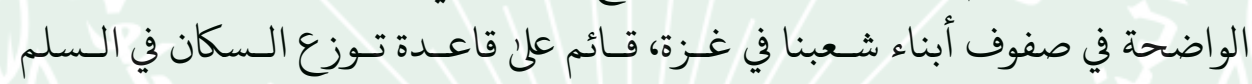

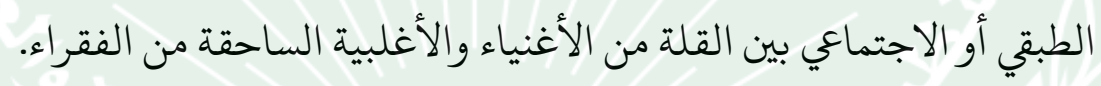

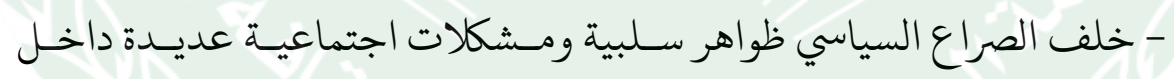

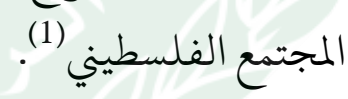

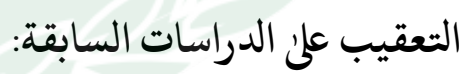

كشفت هذه الدراسات عن نتائج عديدة حول الصراع الداخلي وكيفيـة نشأته

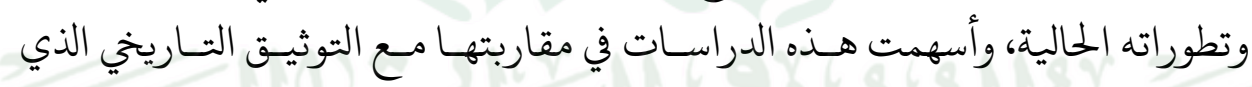

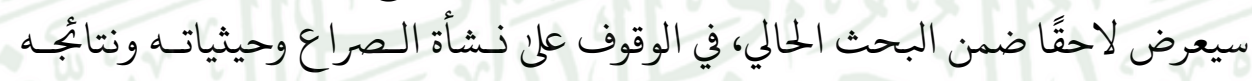

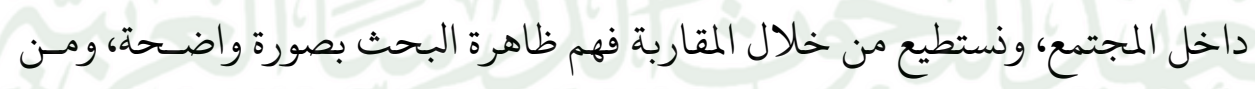

(1) إبراهيم قشطة، الصراع الثنظيي وأثره على الأوضاع والعلاقات الاجتماعية الفلسطينية، دراسة

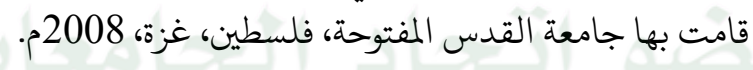


خلال استخدام تحليل المضمون لما سبق من النظريات والدراسات، وإجراء مقارنة بمـا

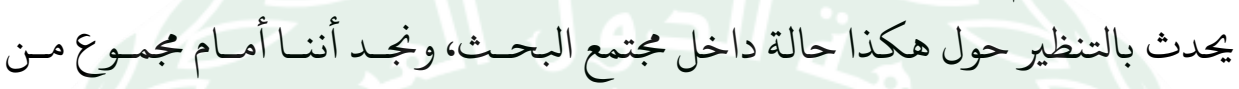

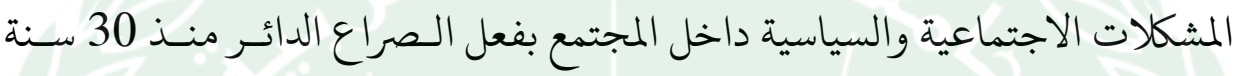

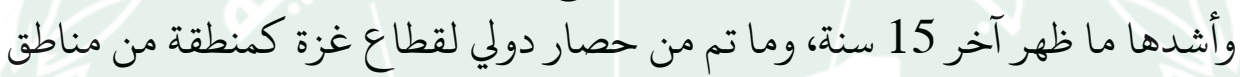

$$
\text { مجتمع البحث. }
$$

رابعًا - طبيعة الصراع السياسي الداخلي وتطوراته:

\section{1- النسق السياسي للمجتمع الفلسطيني (الأحزاب السياسية):}

عند الحديث عن النسق السياسي فإننا نعني النظام السياسي القائم وكل تشكيل

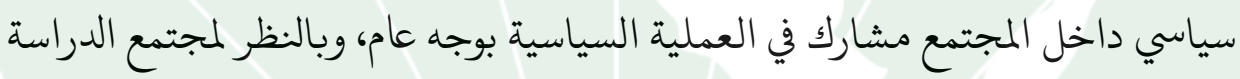

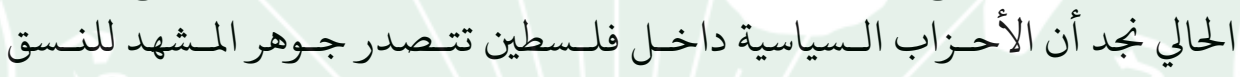

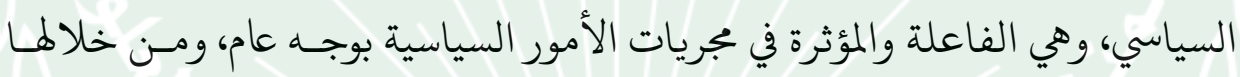

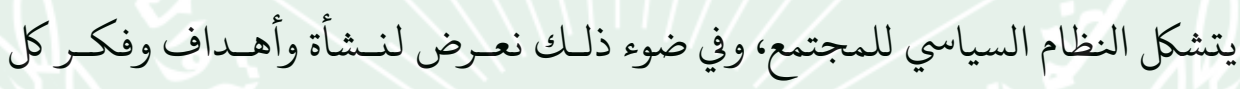

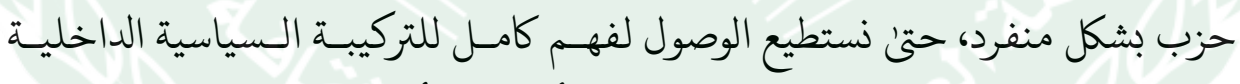

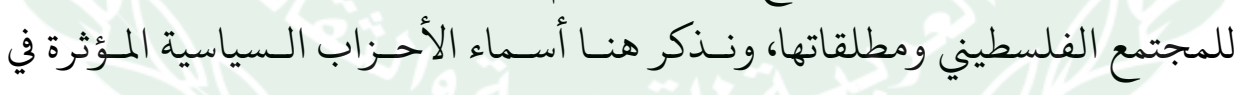

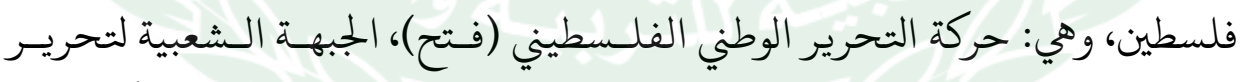

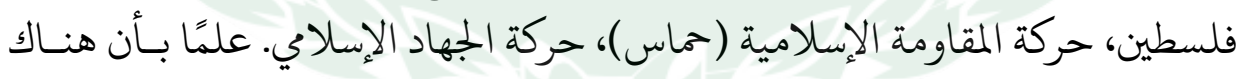

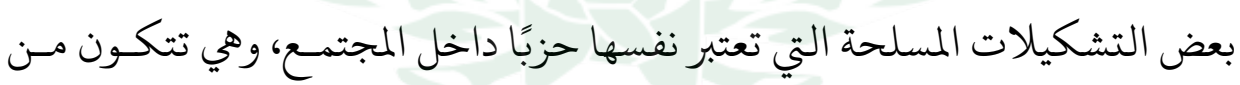

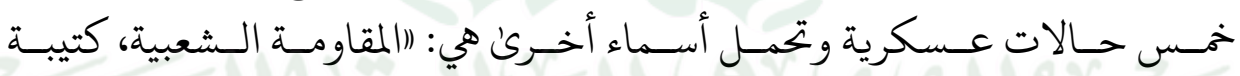

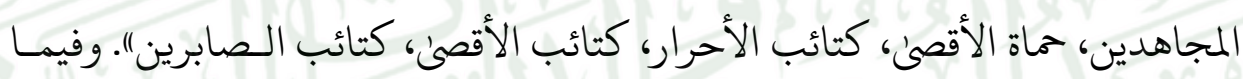

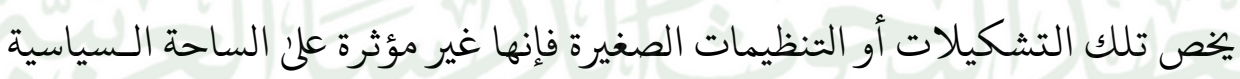

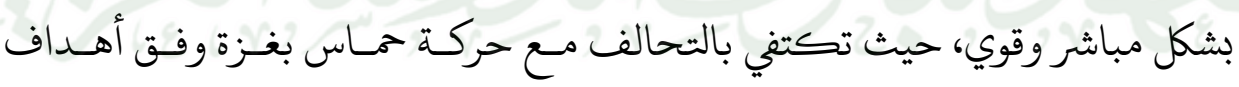

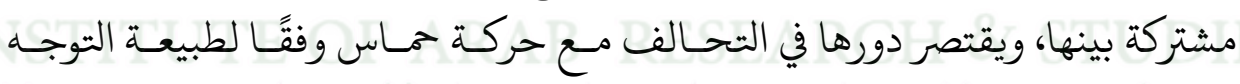




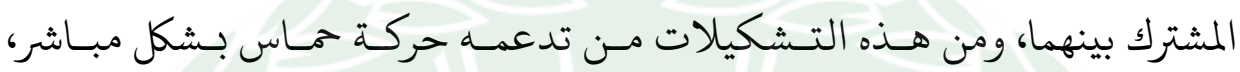

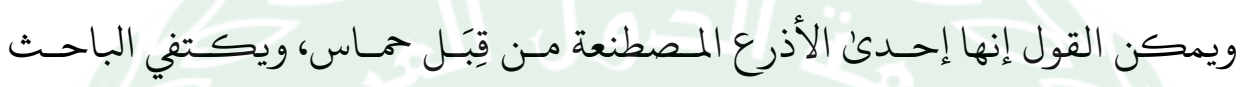

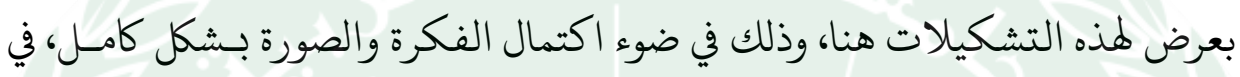

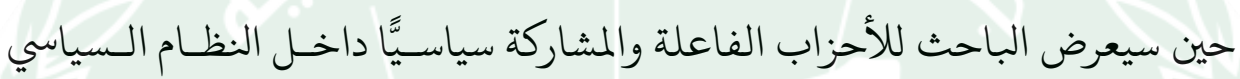
الفلسطيني، والتي لها تأثير مباشر في مجريات الأحداث السياسية بشكل مفصل.

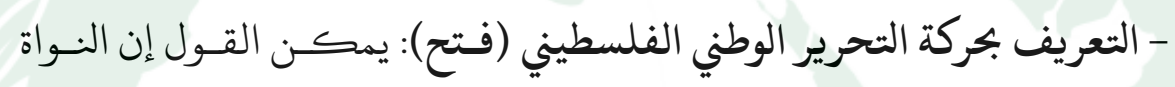

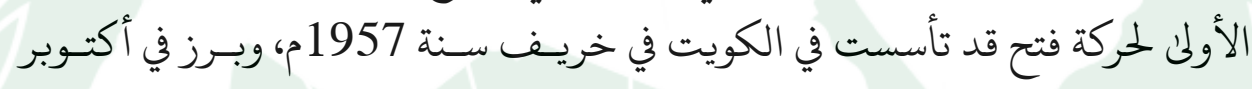

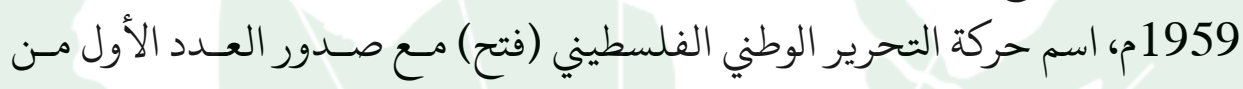

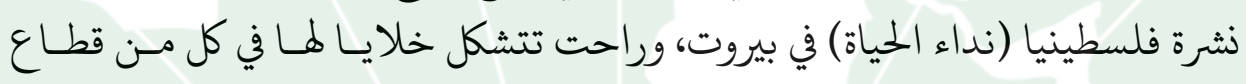

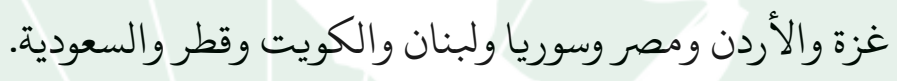

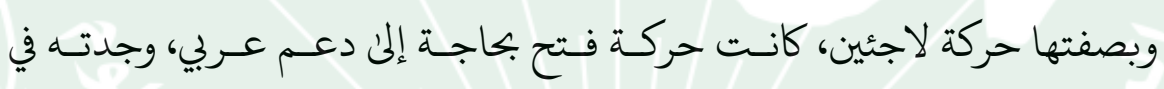

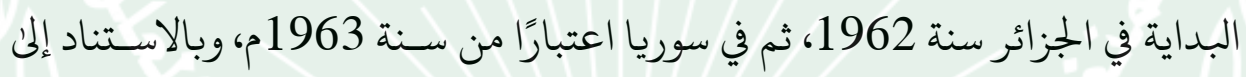

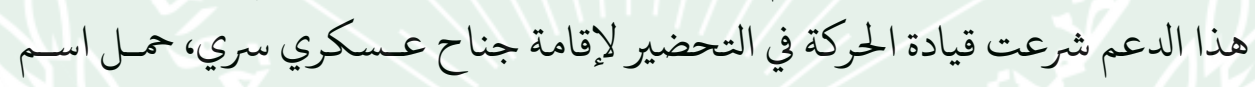

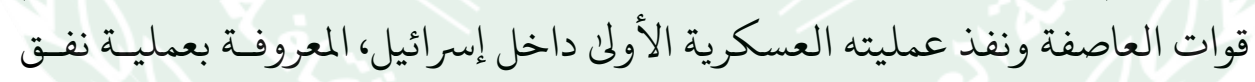

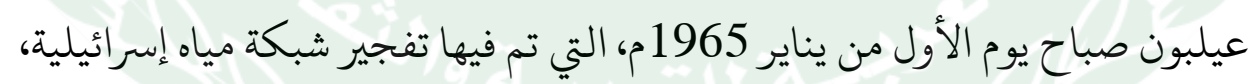
وسقط فيها أول شهيد للحركة هو أحمد محمد موسني سلامة.

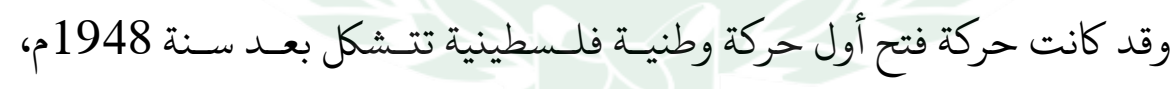

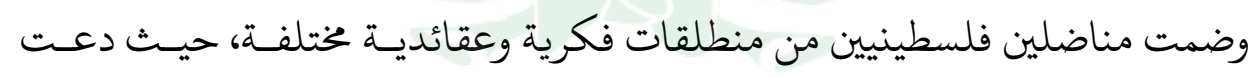

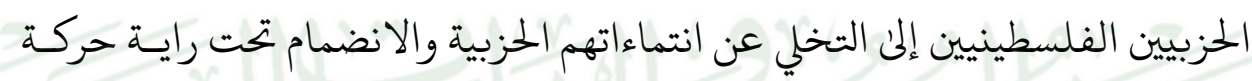

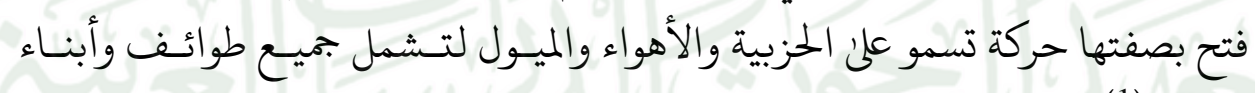
الشعب (1).

(1) بكر أبو بكر، حركة فتح في موسوعة المصطلحات والمفاهيم الفلسطينية، المركز الفلسطيني

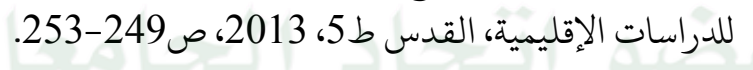


وخلافًا للشعار القوي السائد آنذاك الوحدة العربية هي طريق تحريـر فلسطين،

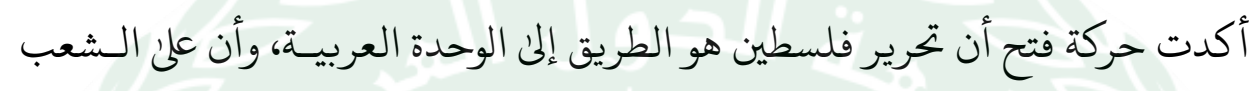

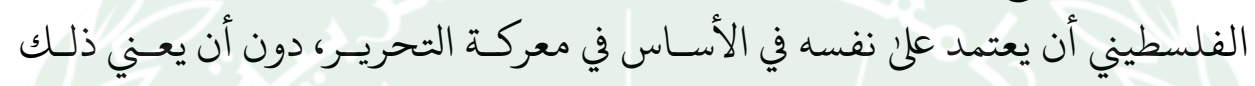

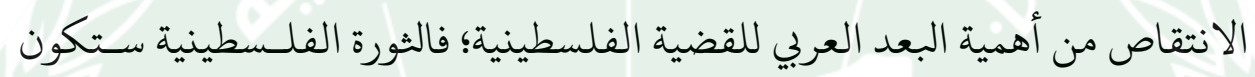
فلسطينية في أصلها، عربية في تطورها. واقتداء بتجارب بعض الثورات، ولا سيما بتجارب الثورات الجزائرية والفيتنامية

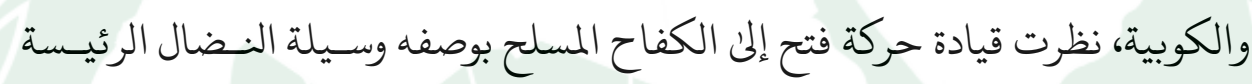

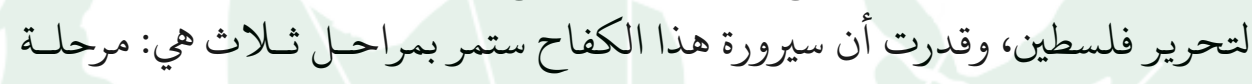
العمل الفدائي، ومرحلة حرب العصابات، ومرحلة الحرب الشعبية.

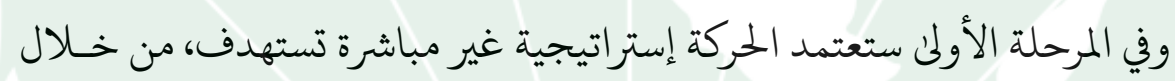

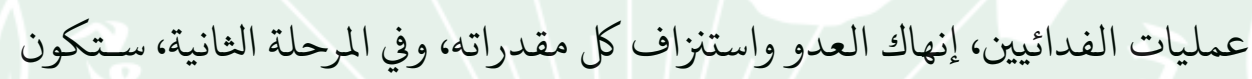

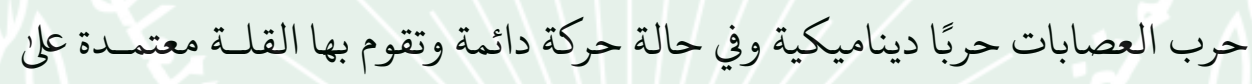

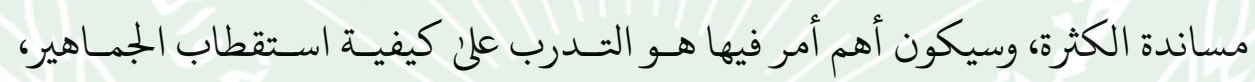

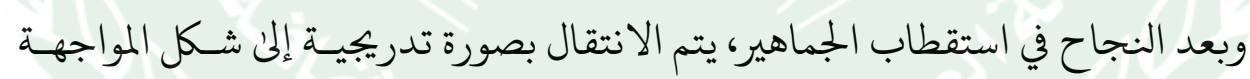

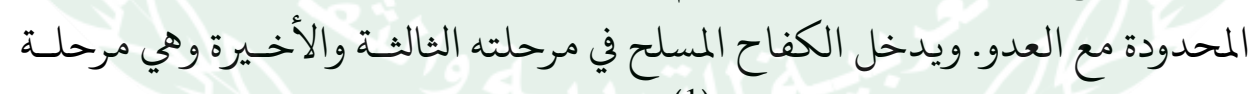
حرب التحرير الشعبية الطويلة المدىن (1).

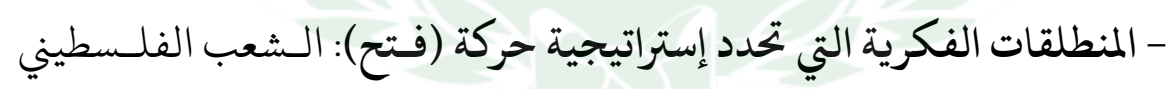

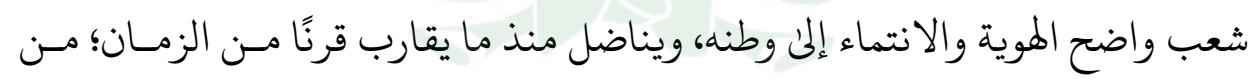

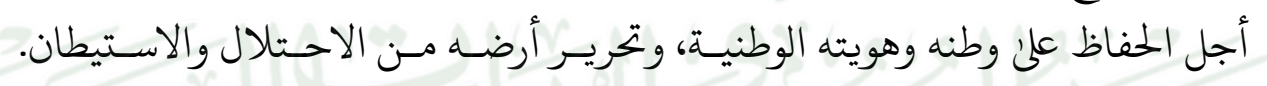

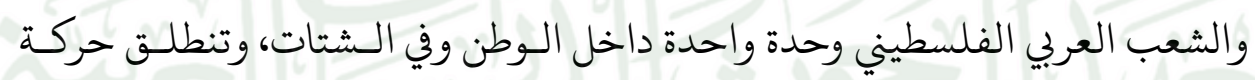
فتح من أن الشعب الفلسطيني شعب عربي، وجزء لا ينفصل من الأمة العربية.

(1) صقر أبو فخر، حركة التحرير الوطني الفلسطيني فتح، قافلة التيه الفلسطيني الطويل، السفير، بيروت، العدد 9941، 5 تشرين الثاني 2005، صرئ النئ 
وتستند حركة فتح في مبادئها علن أن فلسطين أرض للفلسطينيين جميعًا، وهي

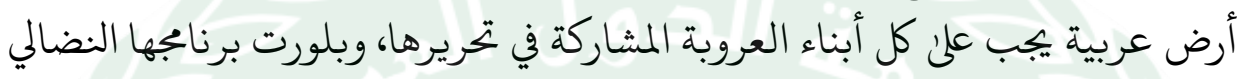

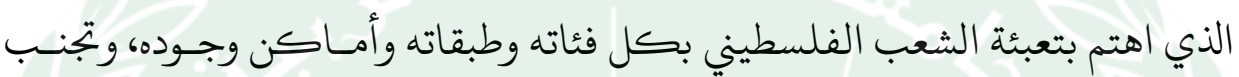

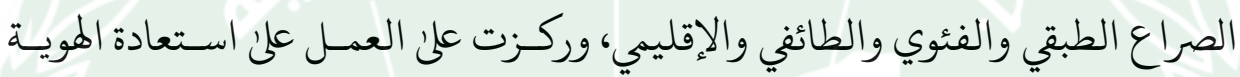

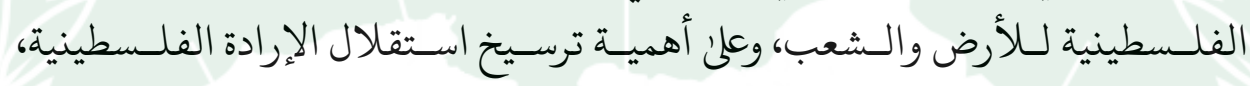
وتعظيم ارتباطها بالأمة العربية، واستقطاب دعمها وحمايتها.

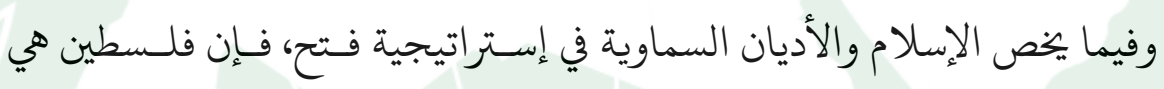

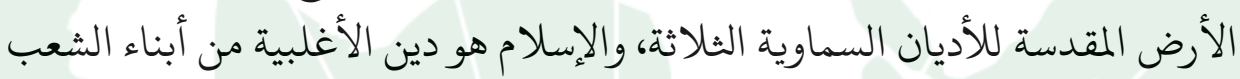

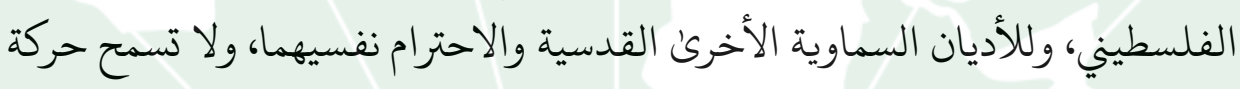

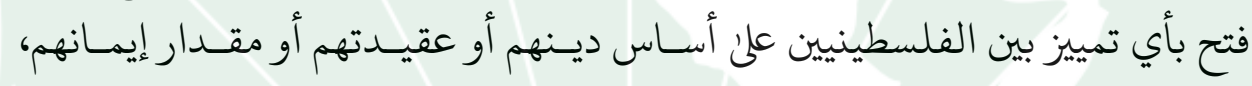
وتحترم حرية العبادة للجميع.

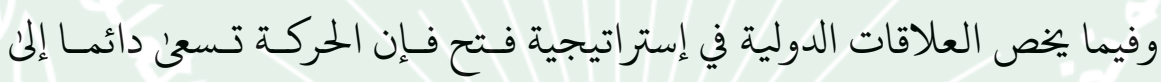

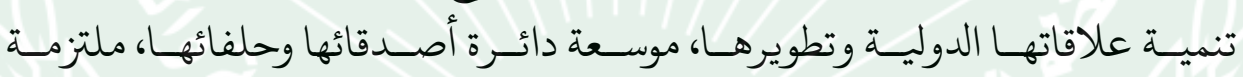

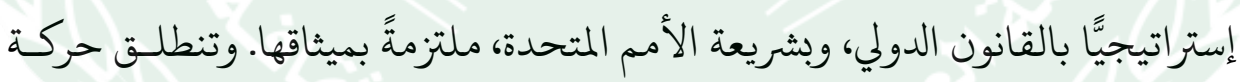

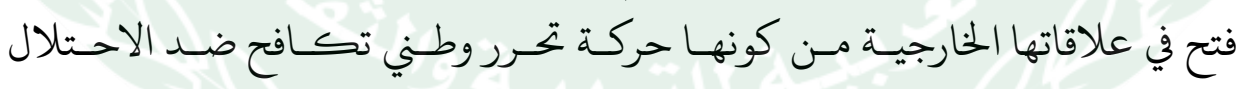

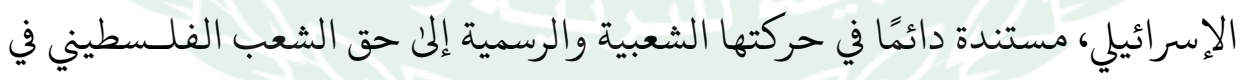

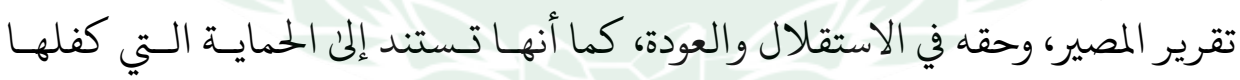

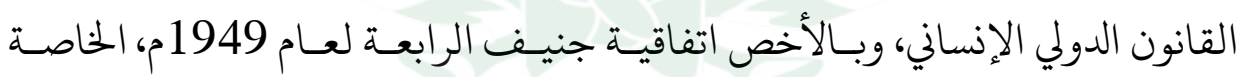

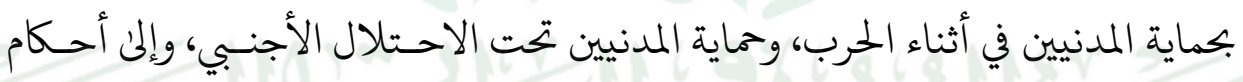

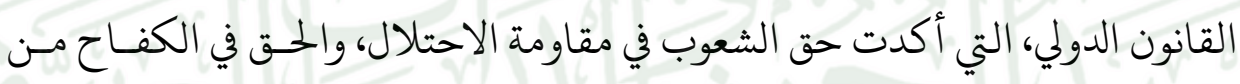

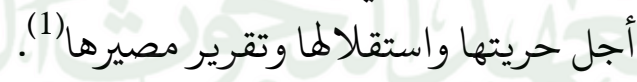

(1) الموقع الرسي لمنظمة النحرير الفلسطينية، مقالات نبذة عن الثنظيمـات الفلسطينية. تـاريخ

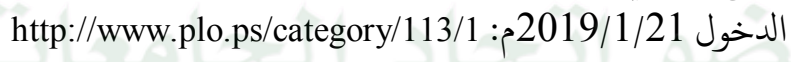




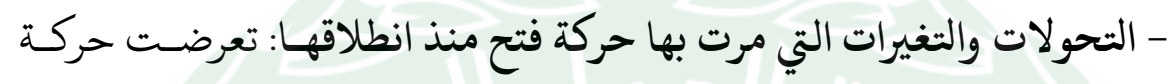

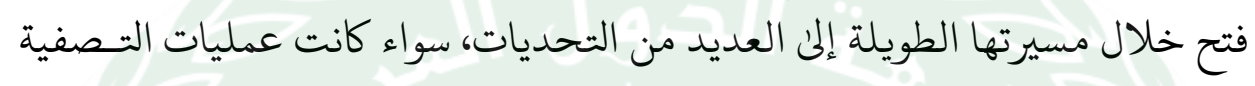

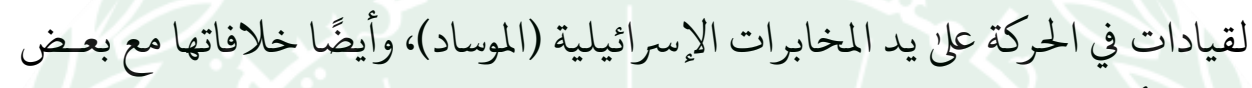
الدول، أو الانشقاقات داخل الحركة.

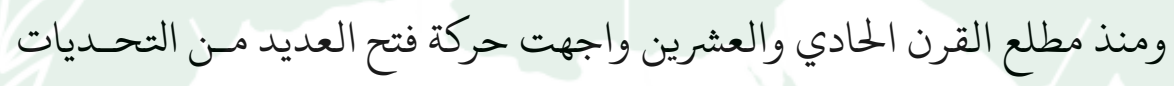

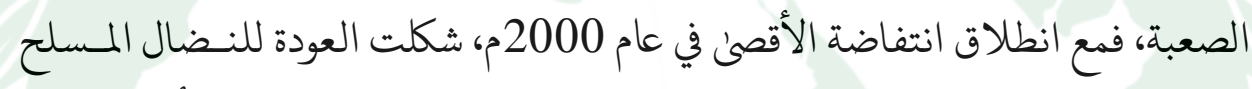

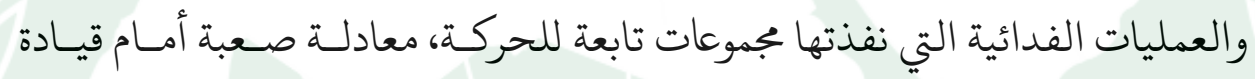

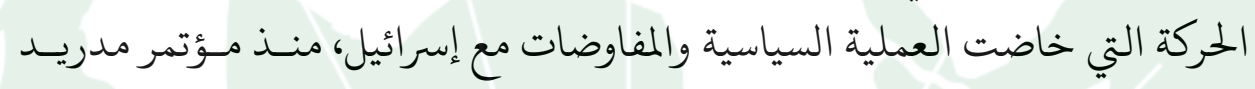

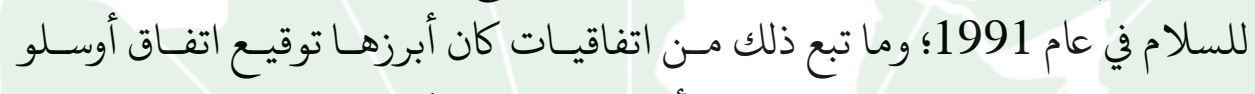
1993م، وما ترتب عليه من التزامات أمنية من قبل الحركة.

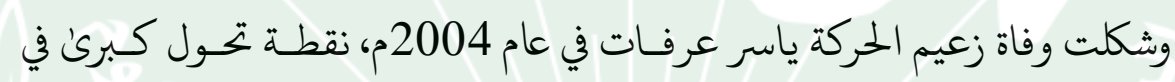

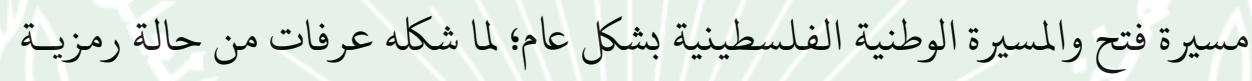

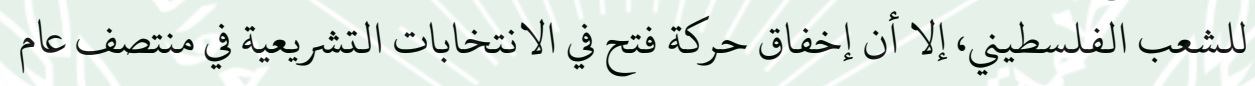

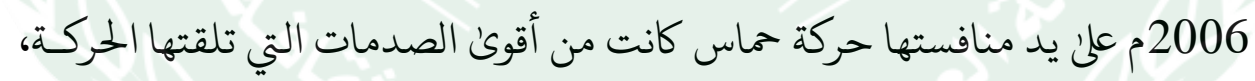

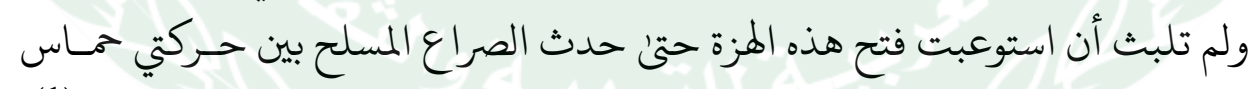

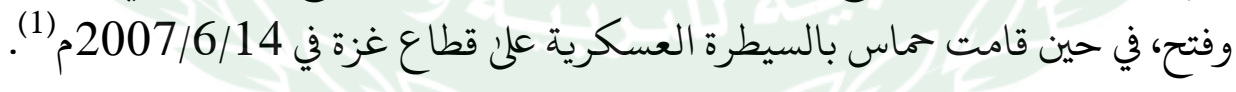
- موقف حركة فتح من الصراع السياسي الداخلي: تعتبر حركة فتح طرفَّا رئيسًا

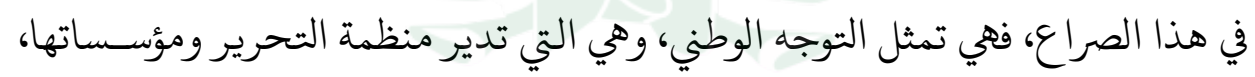

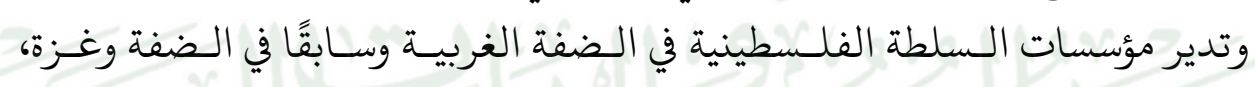

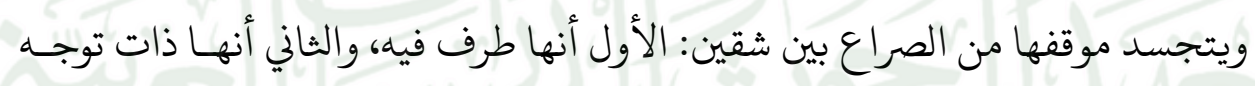

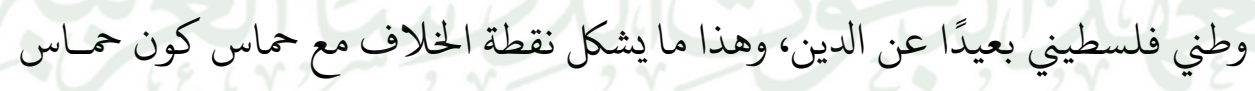

(1) ماجد كيالي، فتح 50 عاماً قراءة نقدية في مآلات حركة وطنية، بحث منشور، المركز الفلسطيني لأبحاث السياسات والدراسات الإستراتيجية، البيرة، 2016مات مركات 


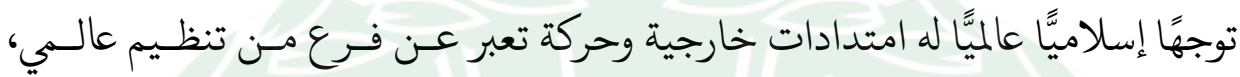

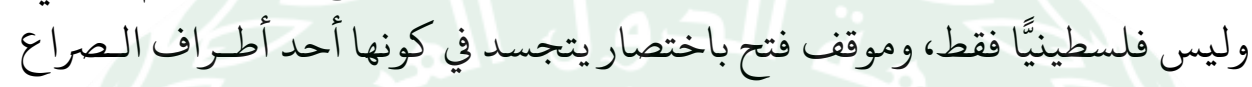

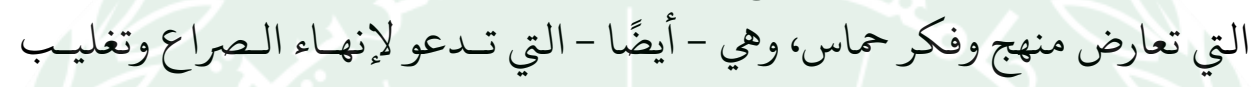

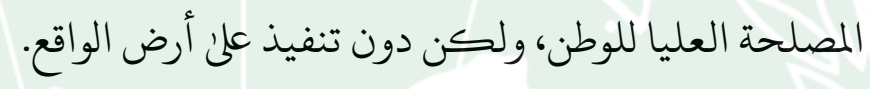

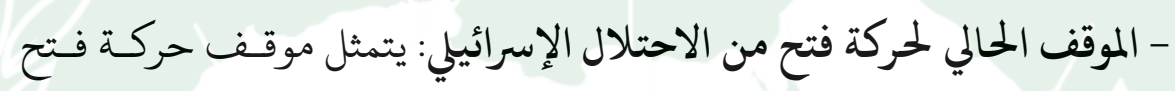

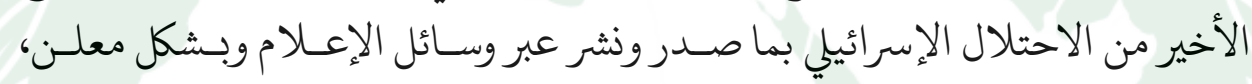

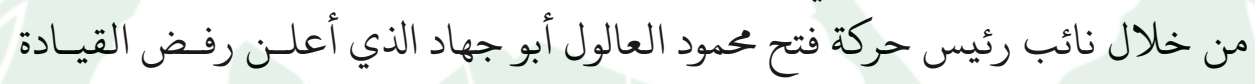

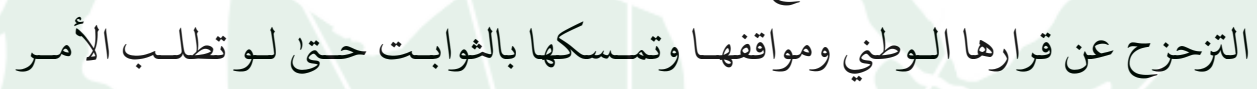
الثضحية.

واعتبر قرار القيادة بإيقاف التعامل مع الاتفاقيات الموقعة مع الجانب الإسرائيلي

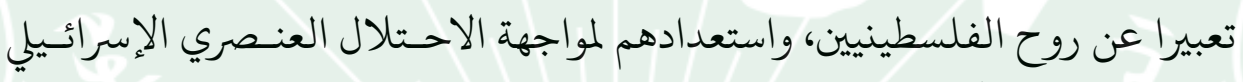

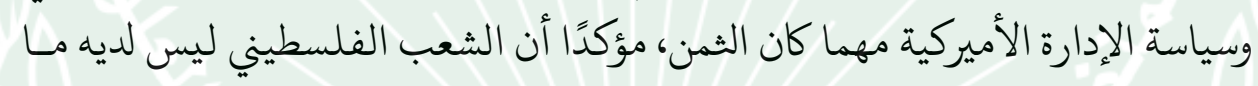

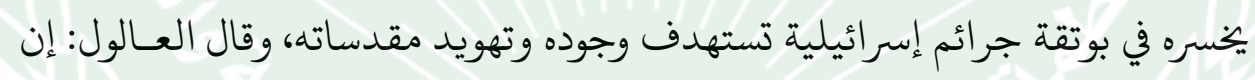

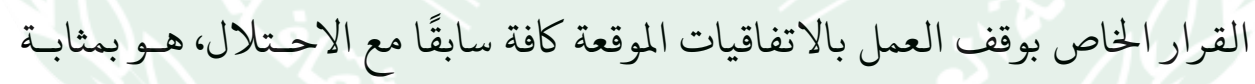

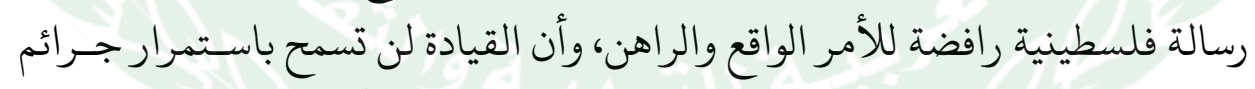

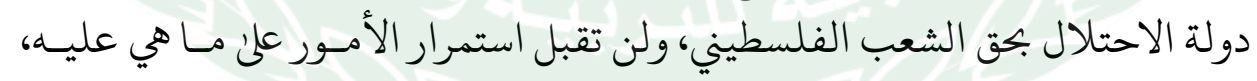

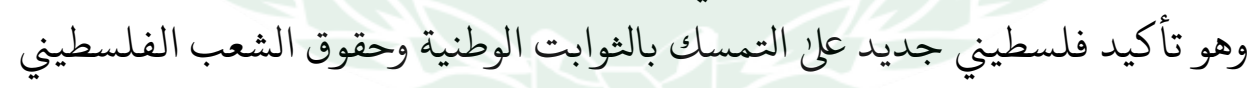

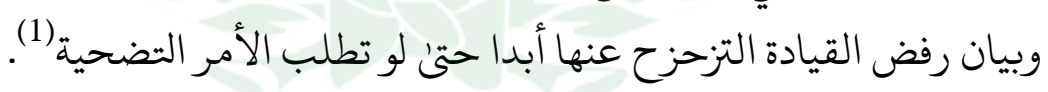

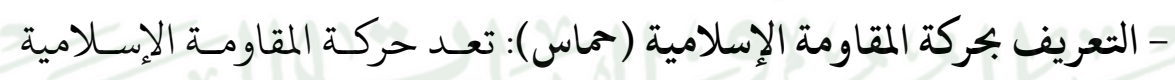

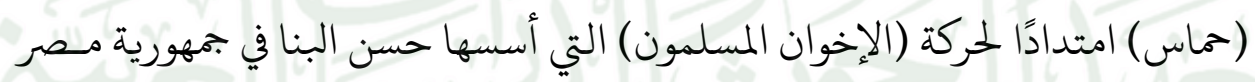

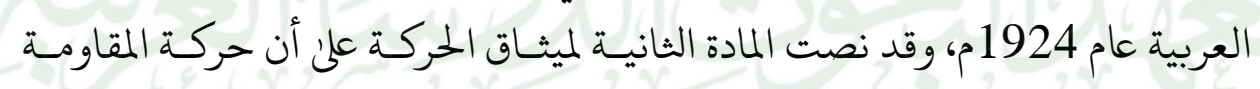

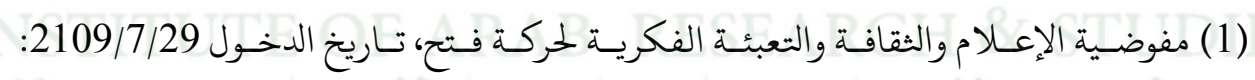
https://www.fatehmedia.ps/page-69882.html 
الإسلامية جناح من أجنحة الإخوان المسلمين بفلسطين، وحركة الإخـوان المسلمون

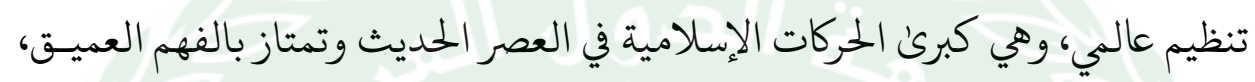

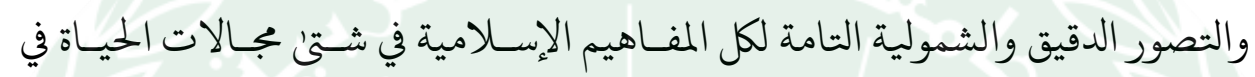

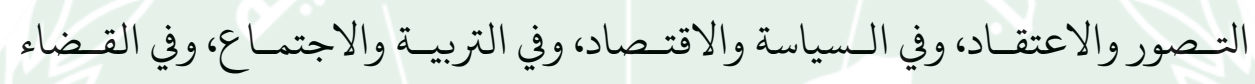

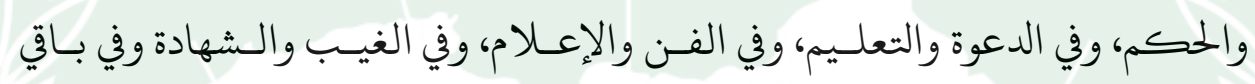
مجالات الحياة (1).

في حين لعبت حركة الإخوان المسلمين منذ النكبة وحستن مـا قبـل قيـام حركة

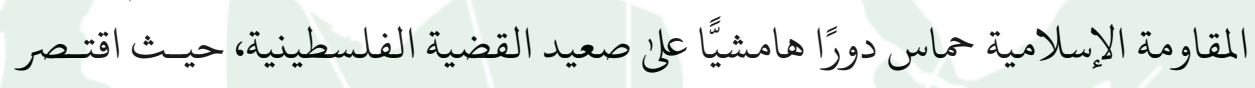

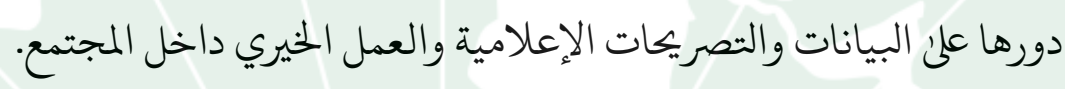

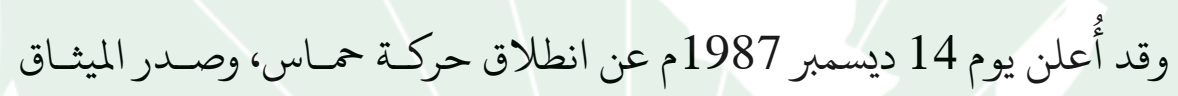

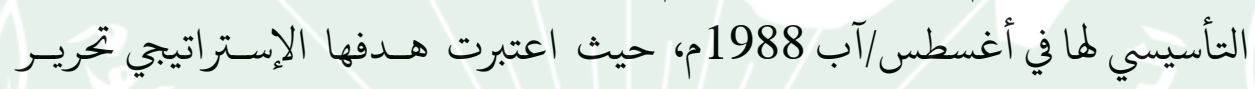

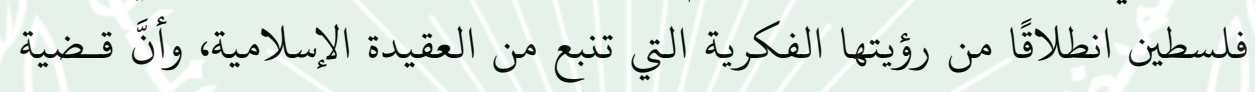

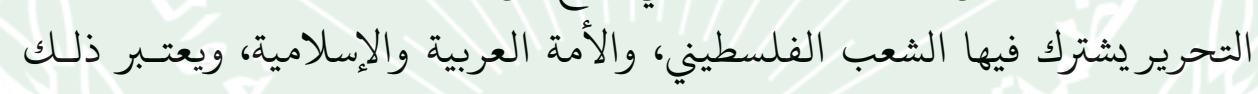

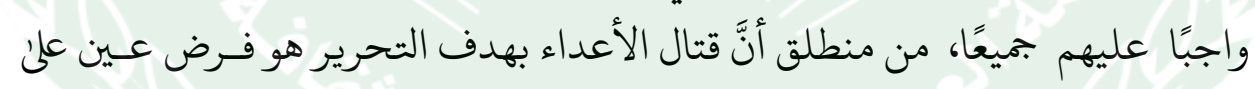

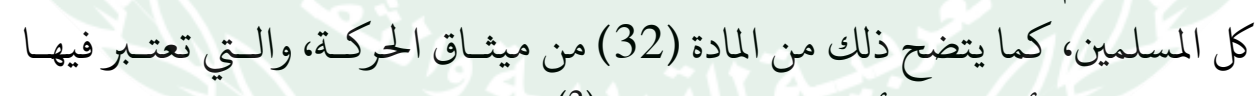

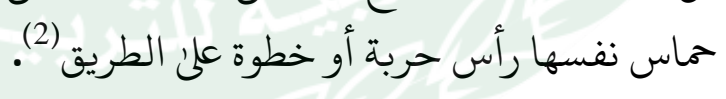

وبعد فشل مفاوضات "كامب ديفيد) عام 2000م الخاصة بـاململف الفلـسطيني،

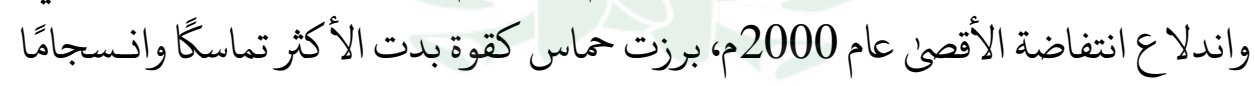

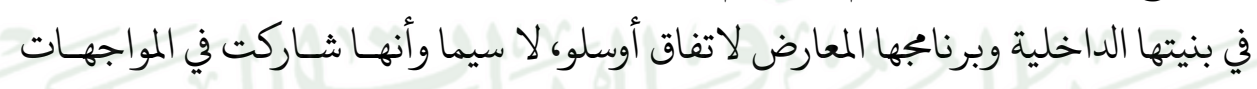

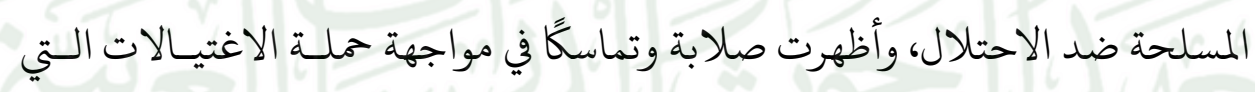

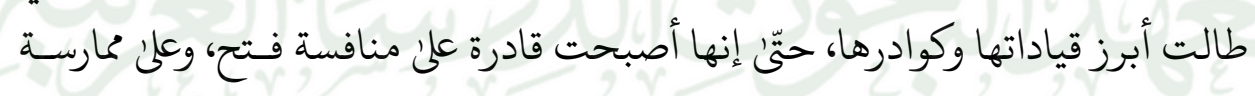
(1) المادة الثانية من ميثاق حركة حماس 1988م. (2) جواد الحمد، المدخل إلن القضية الفلسطينية، مركز دراسات الشرق، عمان، 1997م، ص384. 
إستراتيجيتها الخاصة بالمقاومة وفي التعامل مع السلطة الفلسطينية(1). وقد تزامن هذا المسار مع ضـعف شـعبية قـوى اليسـار وحركـة فـتح والسلطة

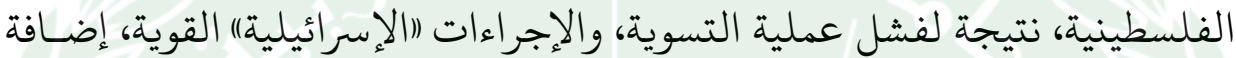

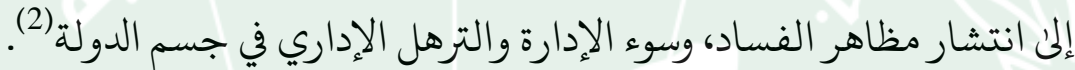
وقد تمثلت مواقف ماس تجاه التعامل مع الاحتلال من خلال بعـض المـشاريع

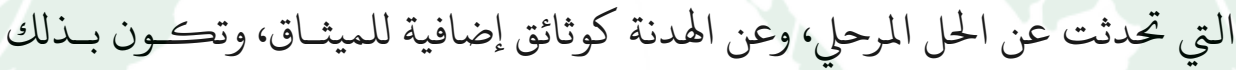

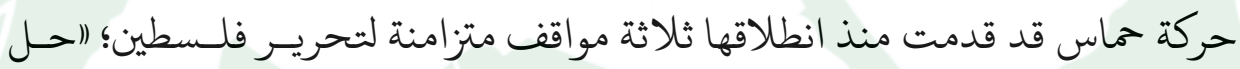

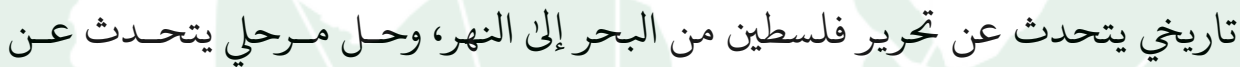

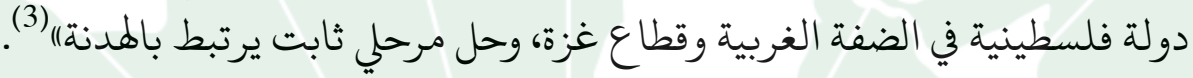

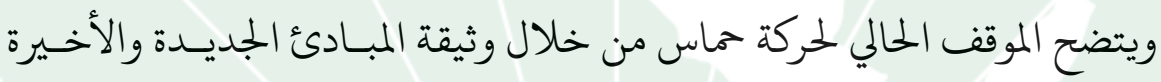
التي صدرت مؤخرًا، حيث أعلنت حماس في عام 2017م ما أسمته وثيقتها السياسية خدية

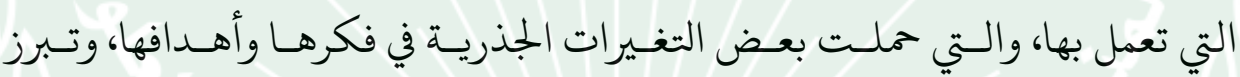

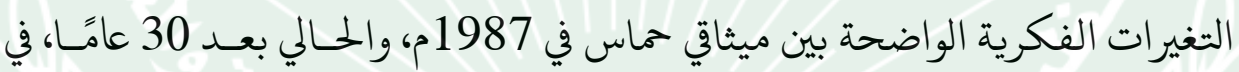

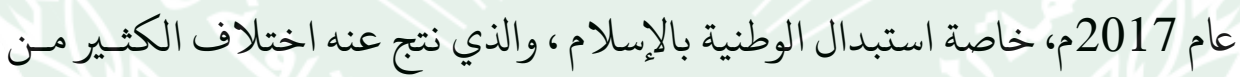

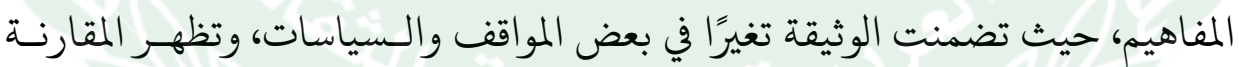

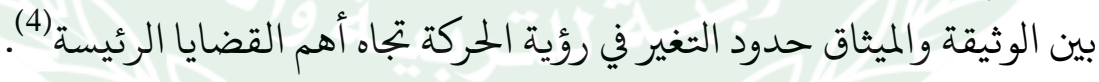
وبينما غاب عن الميثاق السابق مفهوم الدولة الوطنية، وركز علن أن الحركة حركـة

(1) جميل هلال، النظام السياسي الفلسطيني بعد أوسلو، دراسة تحليلية نقدية، مؤسسة الدراسات

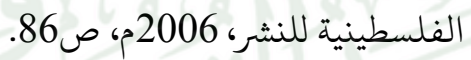

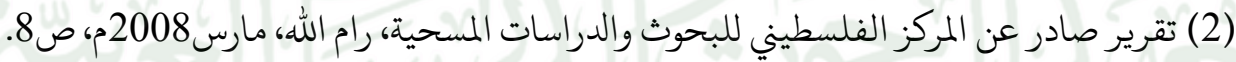

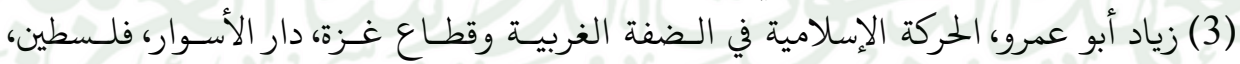

$$
\text { 1989م، ص.93 زباد عبرو، الحرك }
$$

(4) سليم الزعنون، الوثيقة الجديدة لحركة حاس البراغماتية وحدود الثغير السياسي، مركز الروابط

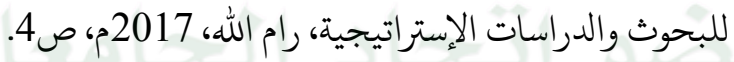




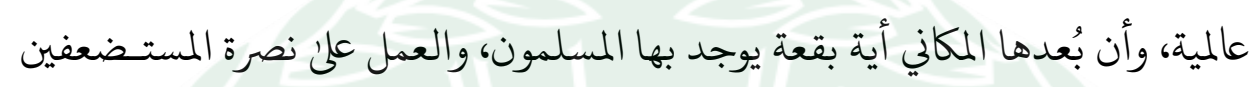

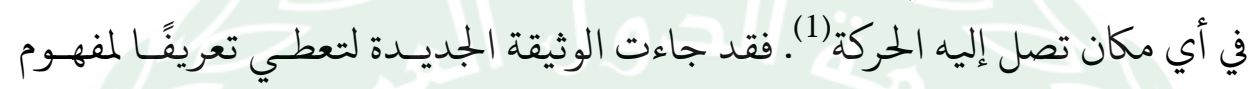

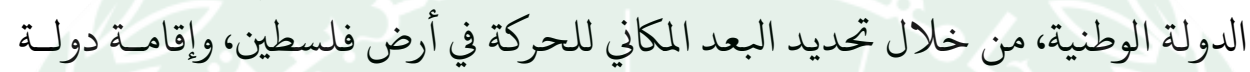

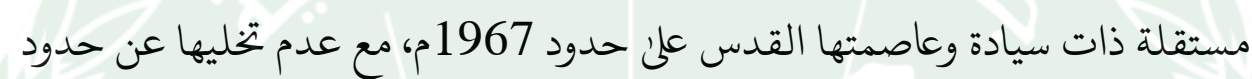

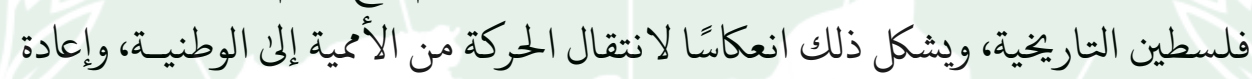
تعريف ذاتها ودورها (2).

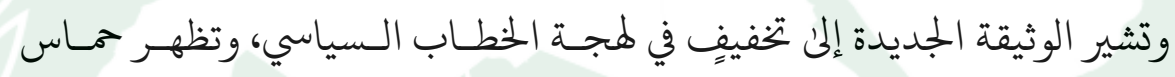

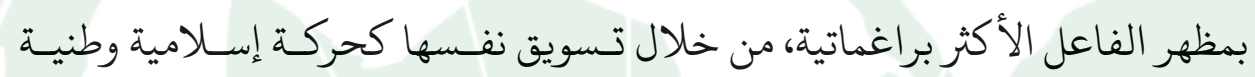

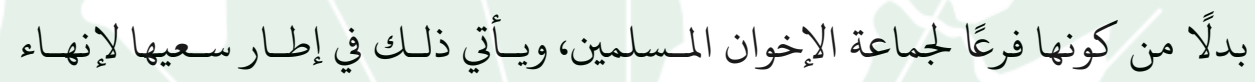

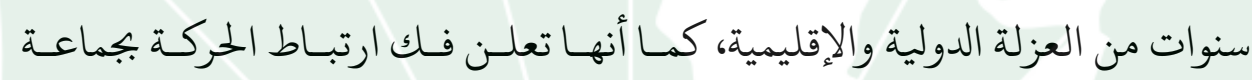

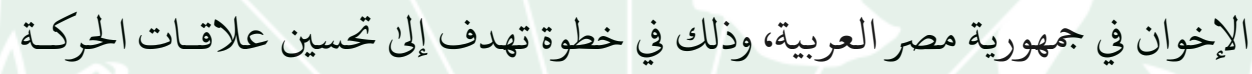

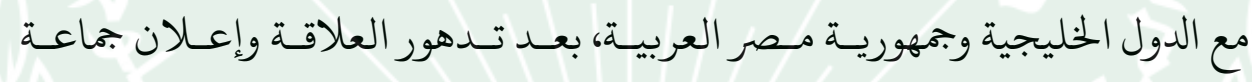

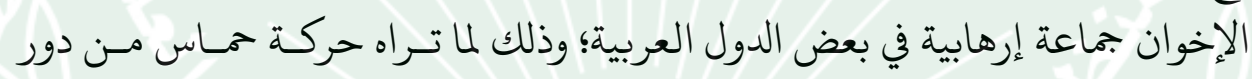

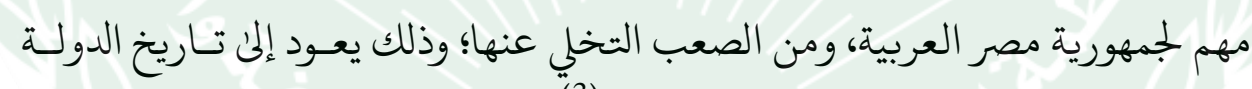

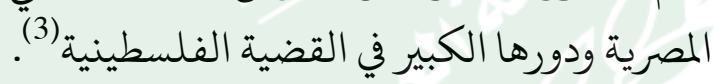

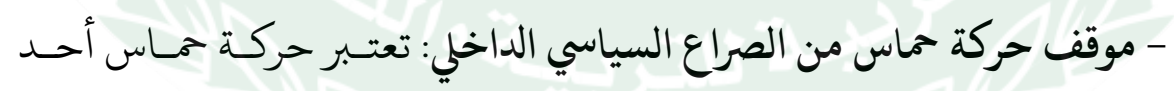

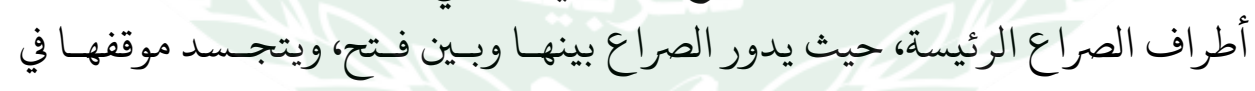

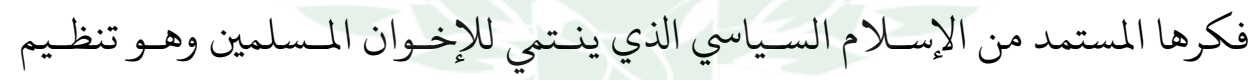

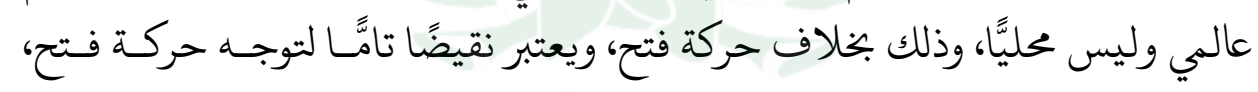

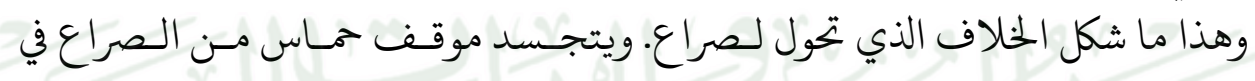

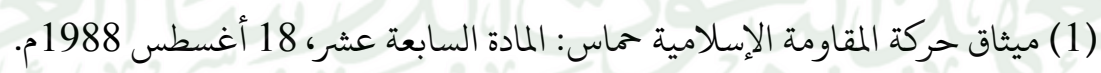
(2) حركة المقاومة الإسلامية حماس: وثيقة المبادئ والسياسات العامة، مرجع سبق ذكره، 2017م،

$$
\text { صليم الزعنون، مرجع سبق ذكر، ص6. }
$$


فرض رؤيتها على المجتمع أمام معارضة فتح للفكرة ذاتها، وموقفها من الصراع بشكل

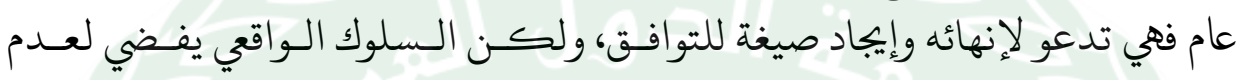

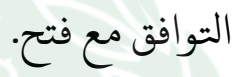

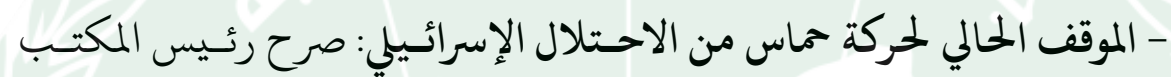

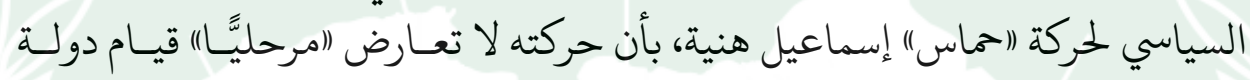

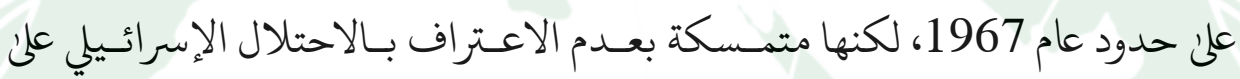

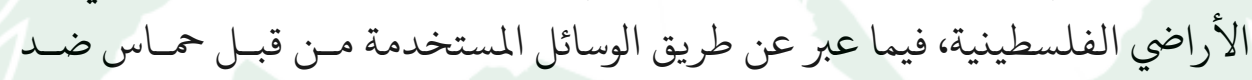

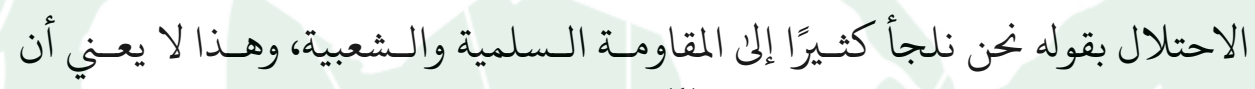

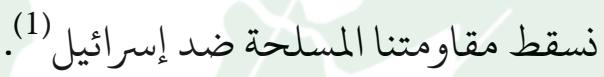

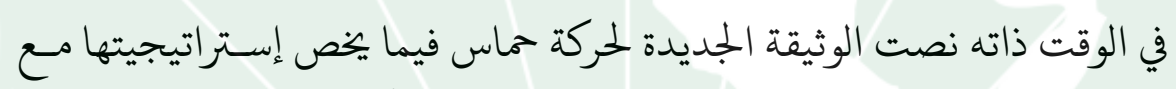

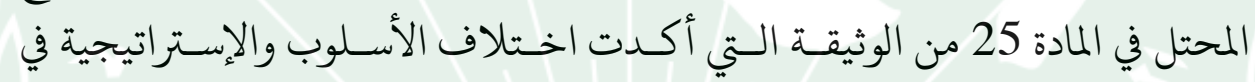

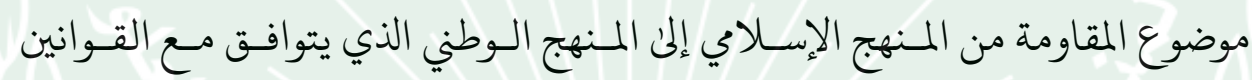

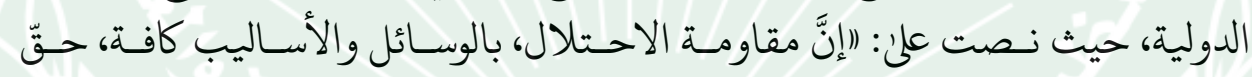

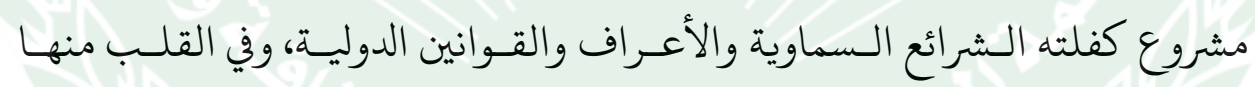

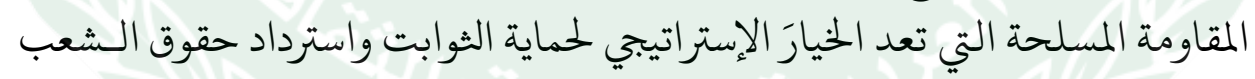
الفلسطيني" (2). 2- ماهية الصراع السياسي الداخلي تاريخيًّا وحاليَّا:

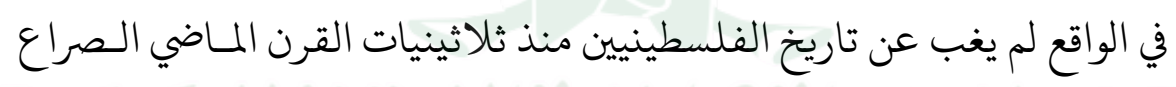

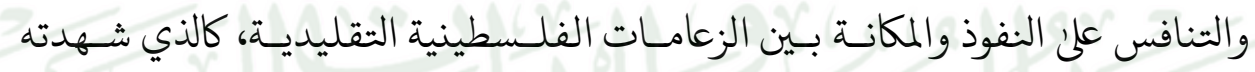

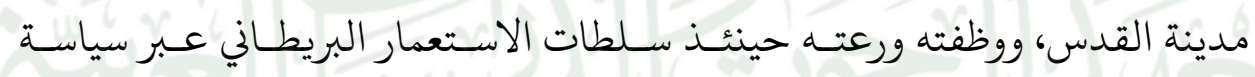

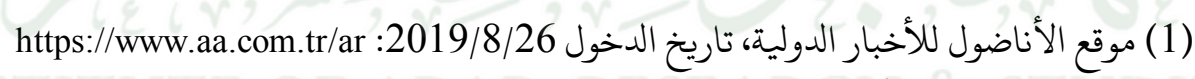

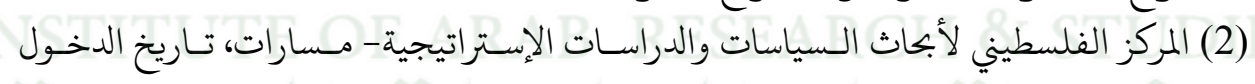
https://www.masarat.ps/article/4610:2019/8/26 
التعيينات، فقد جاء التنازع على شكل مخاصمة بين شخصين من الأسر المقدسية، وهما

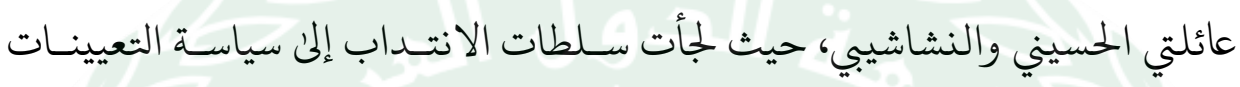

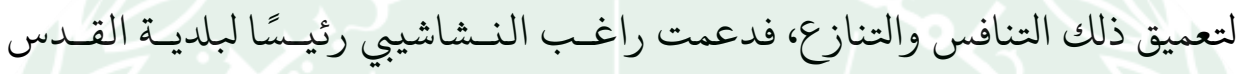

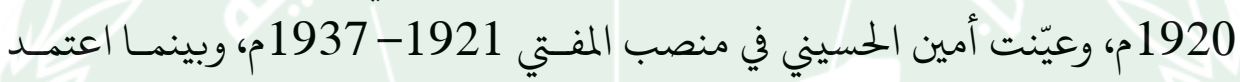

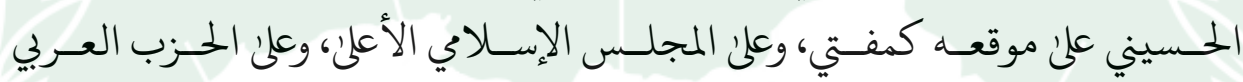

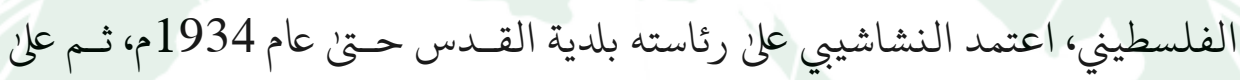

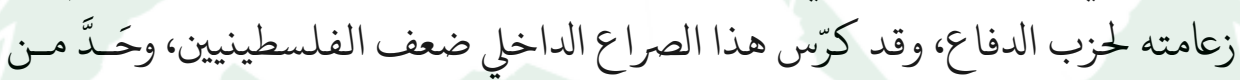

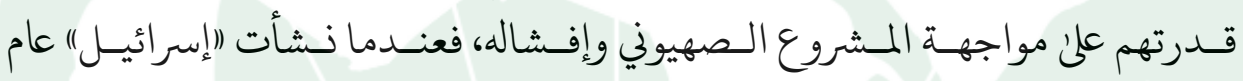

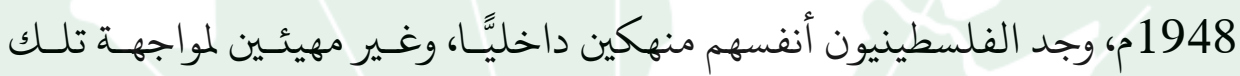

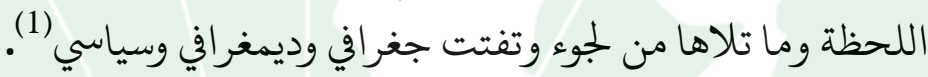

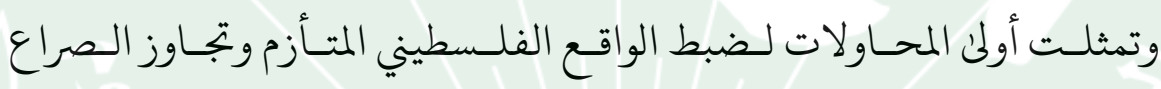

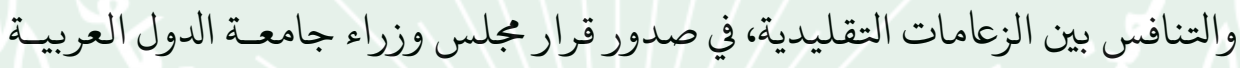

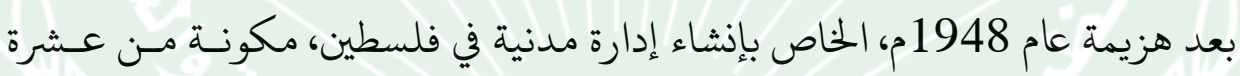

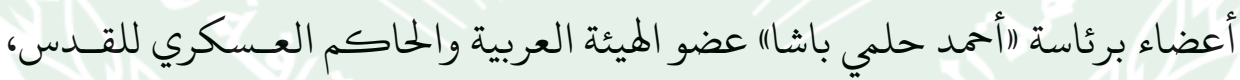

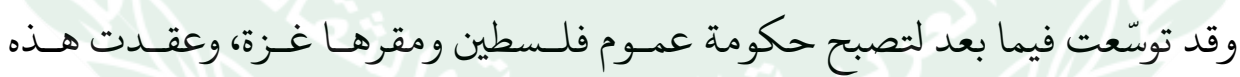

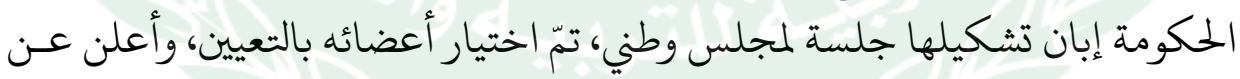

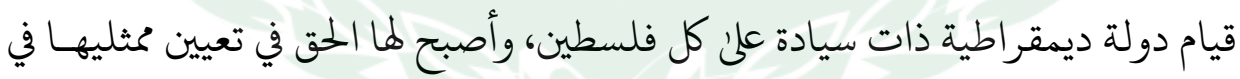

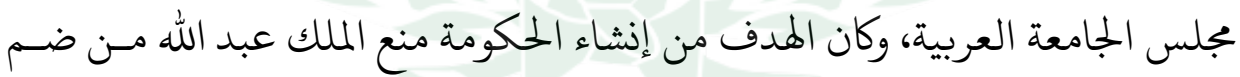

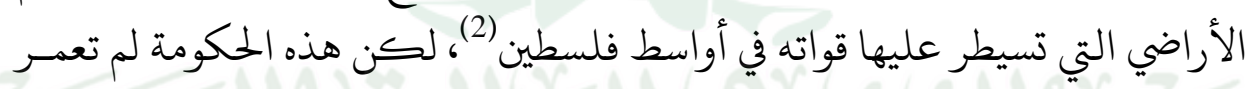

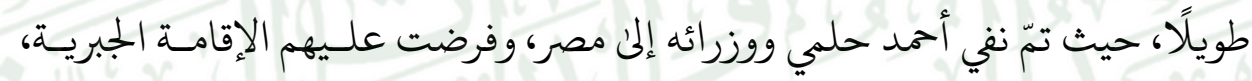

(1) أكرم زعيتر، الحركة الوطنية الفـسطينية، 1939-1935م، مؤسسة الدراسـات الفلسطينية،

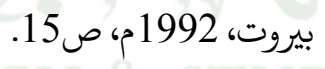

(2) الموسوعة الفلسطينية، ط1، المجلد الثاني، هيئحة الموسـوعة الفـسطينية، دمـشق، 1984م،

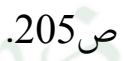




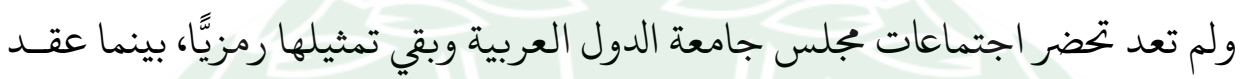

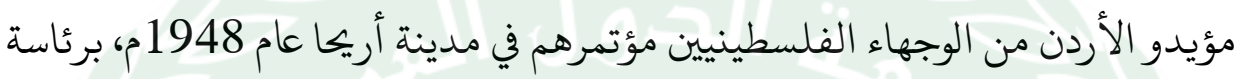

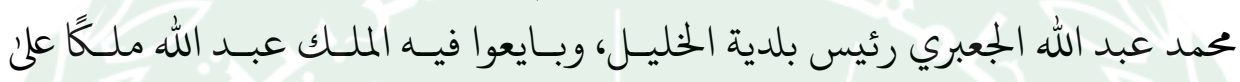

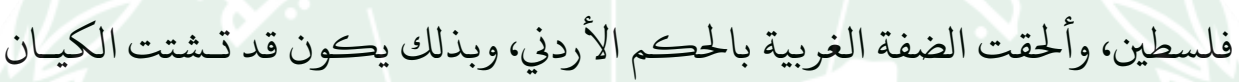

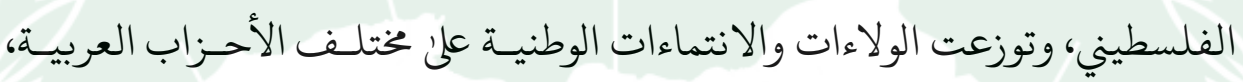

$$
\text { سواءً الإسلامية أو القومية (1). }
$$

وكان من نتائج هذا الانقسام ضرب الحركة الوطنية الفلسطينية وانخراف الجهـود إنفات

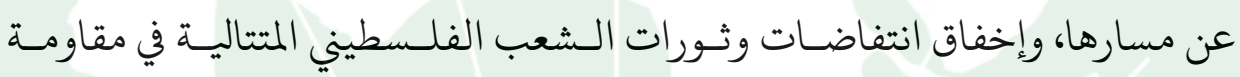

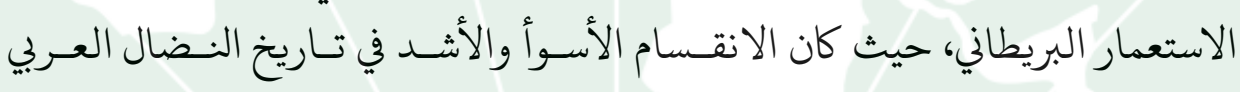

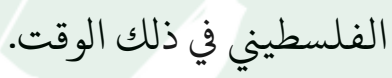

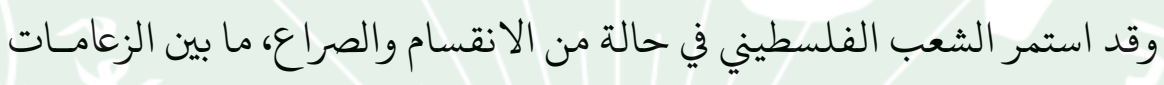

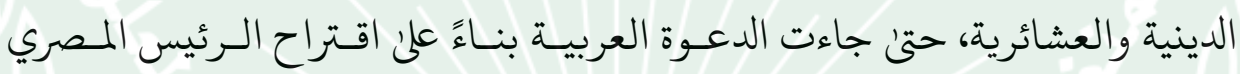

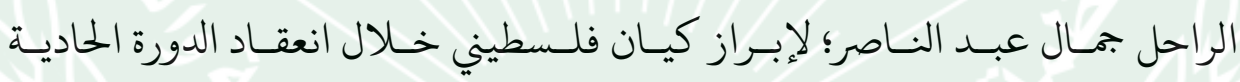

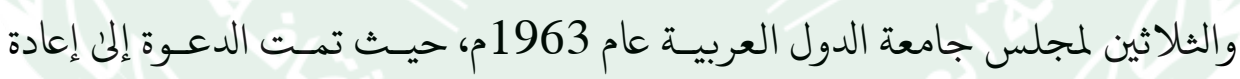

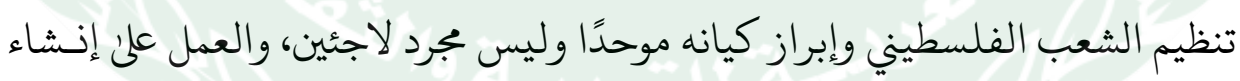
جيش فلسطيني في الدول العربية المضيفة (2). في حين تدارس مؤتمر القمة العربي الأول الذي انعقد في القاهرة في كانون الثـاني

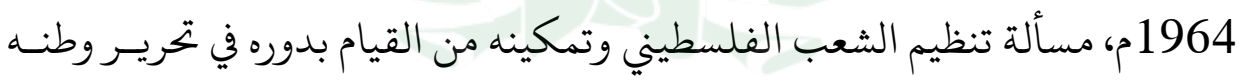

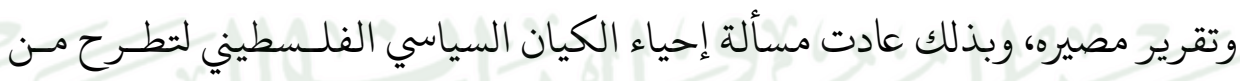

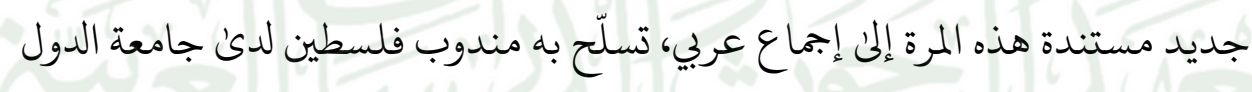

(1) صالح محسن، المجلس الوطني الفلسطيني، إعادة التشكيل وعدالة التمثيل في منظمة التحرير

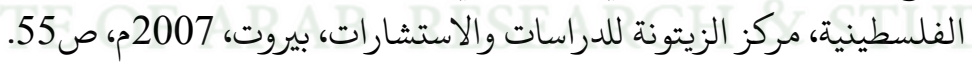

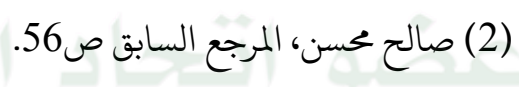


العربية أحمد الشقيري ليَمضي قُدمًا على طريق تنفيذ المهمة التي أوكلت إليه (1).

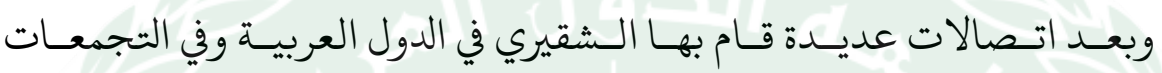

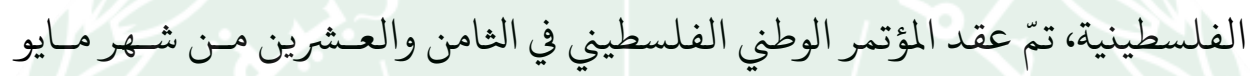
1964م، الذي أعلن عن قيام منظمة التحرير (2).

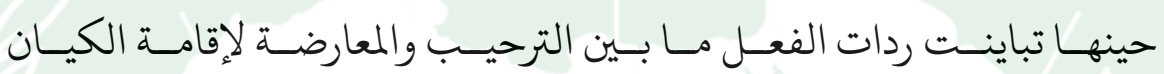
الفلسطيني، وتمثل الترحيب في الأوساط الشعبية خاصة في غزة، وفي الأوساط الحزبية

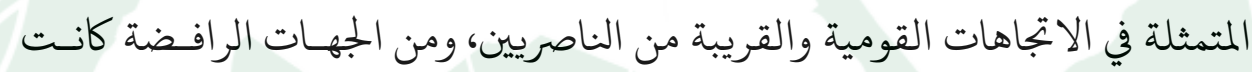

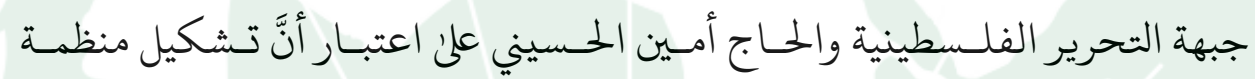
التحرير من شأنه ضرب الحركة الثورية الفلسطينية الوليدة(3).

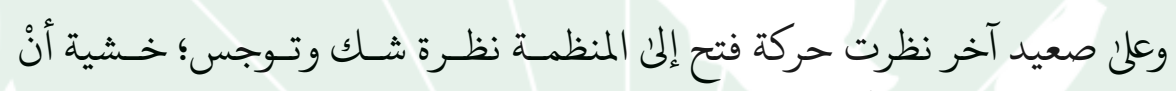

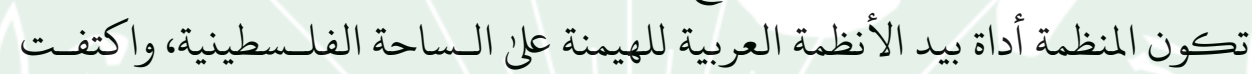

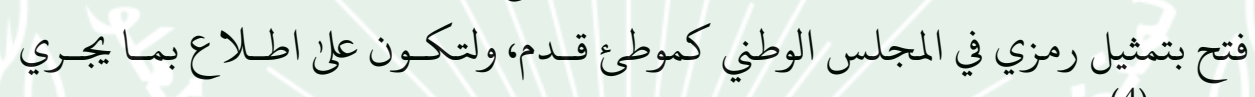

داخلها (4)

وقد شكلت الدورة الرابعة للمجلس الوطني الفلسطيني عام 1968م، محطة مهمة

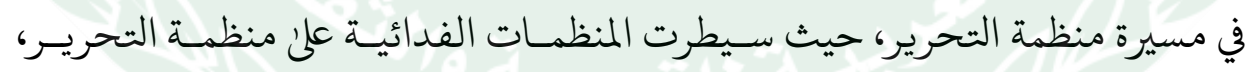

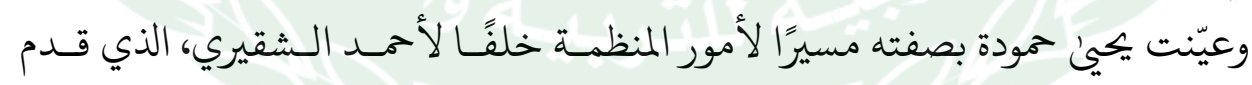

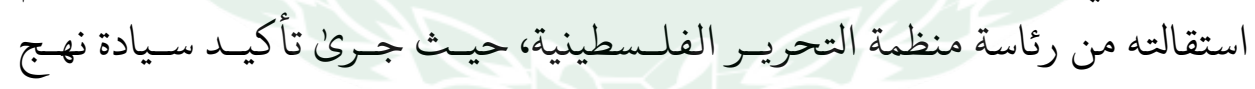

(1) ماهر الشريف، البحث عن كيان -دراسة الفكر الـسياسي الفلـسطيني، طا، مركـز الأبحاث

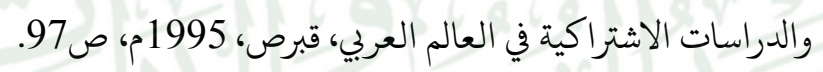

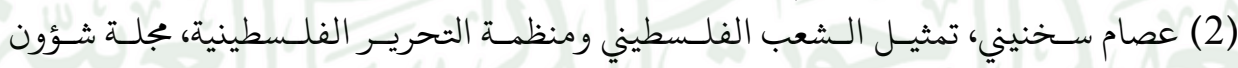

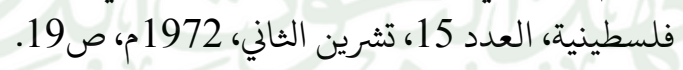

(3) صلاح الدين البحيري، المدخل إلى القضية الفلسطينية، مركز دراسات الشرق الأوسط، عمان،

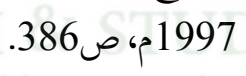

(4) صلاح الدين البحيري، مرجع سبق ذكره، ص387. 


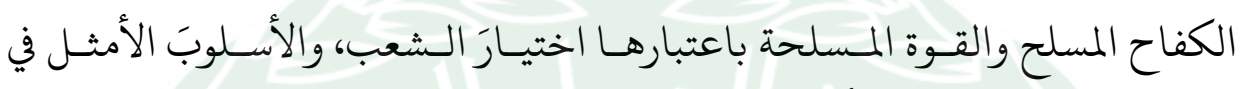

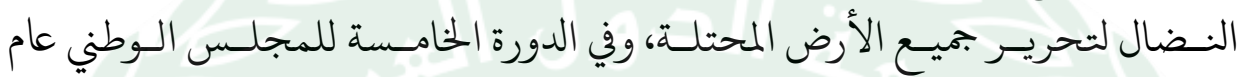

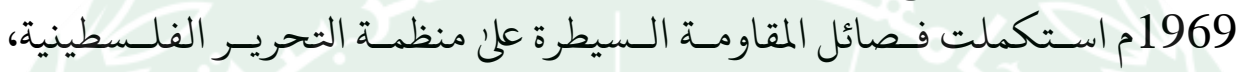

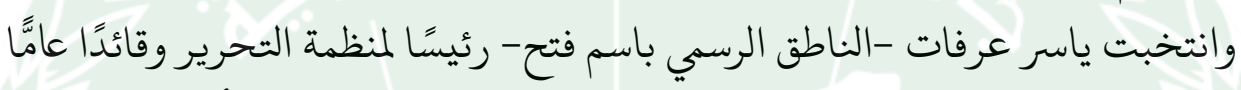

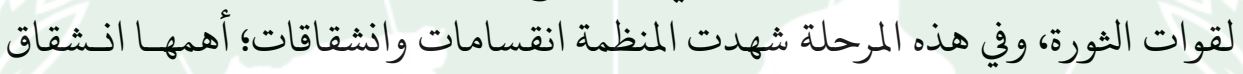

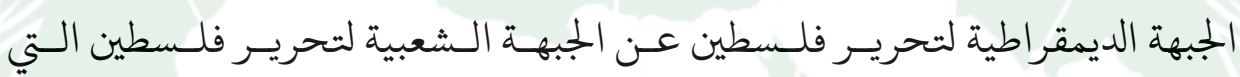

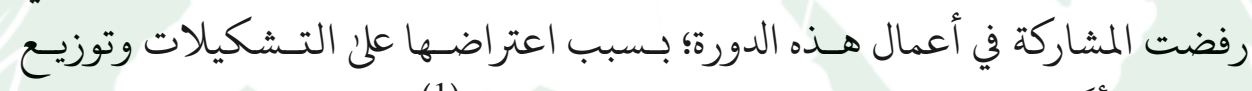

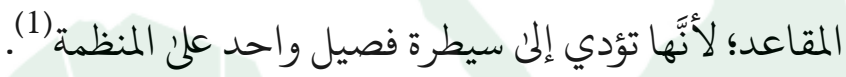

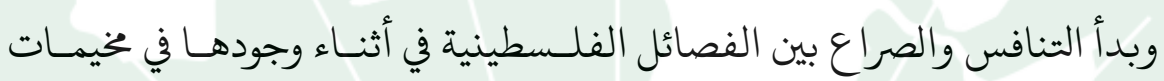

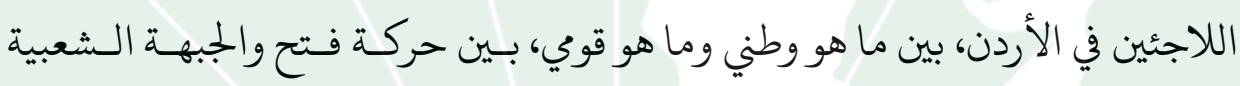

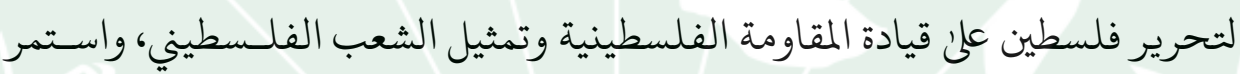

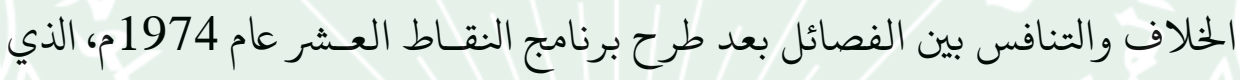

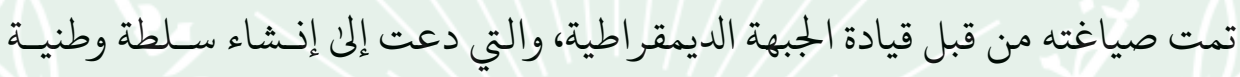

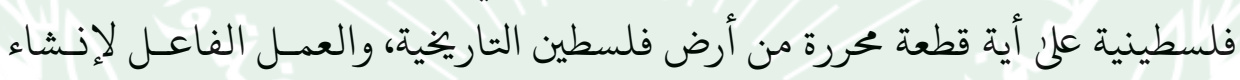

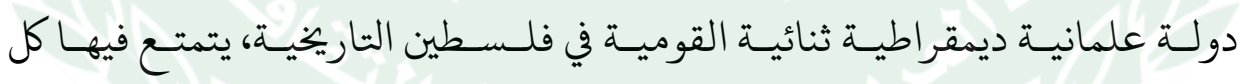

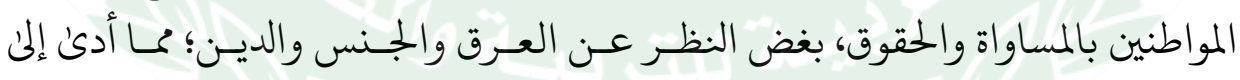

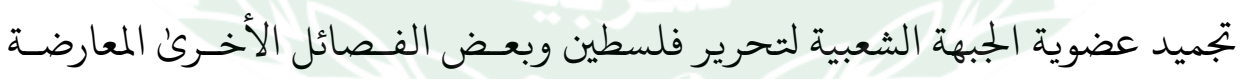

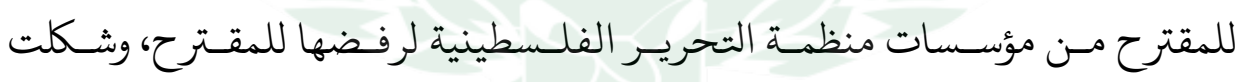

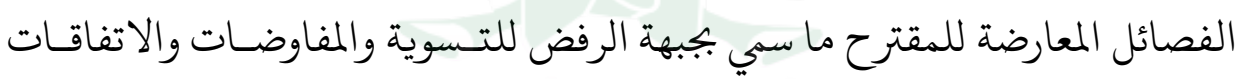

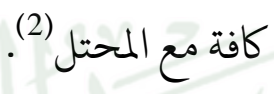

(1) حممد الحوراني، أمد نوفل، وآخرون: خو نقلة نوعية في عمل منظمة التحرير الفلسطينية، مركز

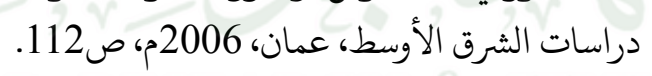

(2) منير شفيق، في معالجة الانقسام الفلسطيني، فلسطين اليوم، 19 يوليو 2015م. (تاريخ الدخول

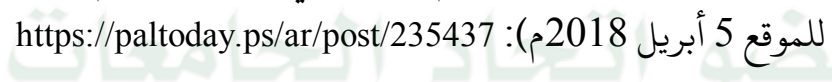


وبعد حصار طـرابلس عام 1983م، والاتفـاق على خـروج يـاسر عرفـات مـن ئن

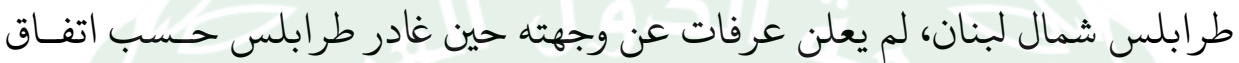

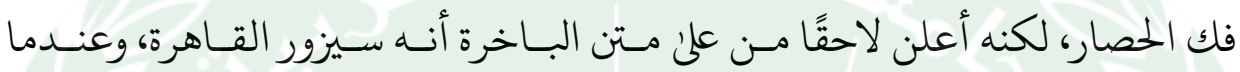

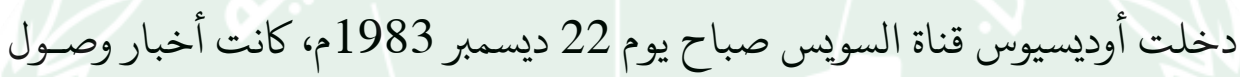

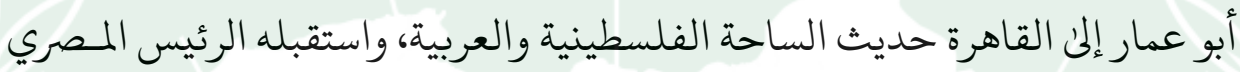

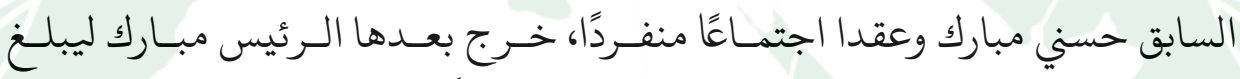

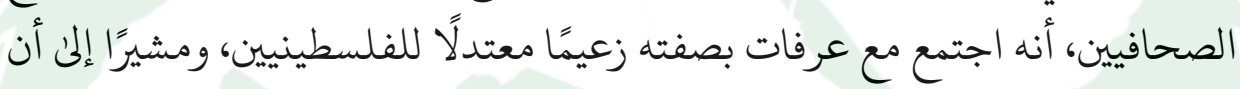

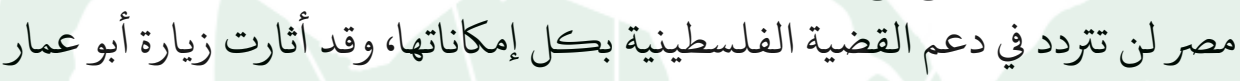

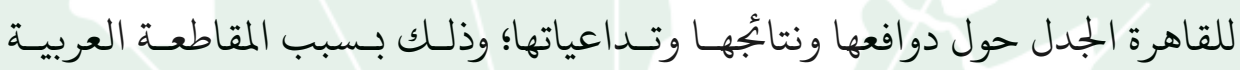

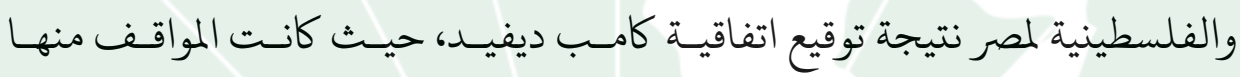

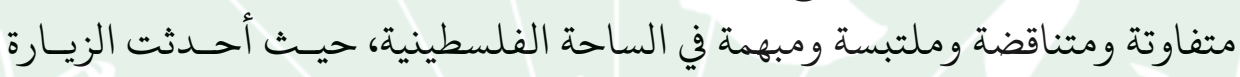

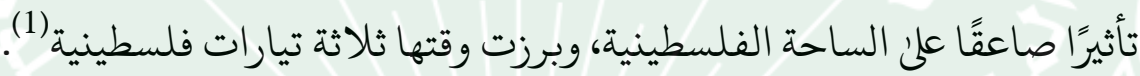

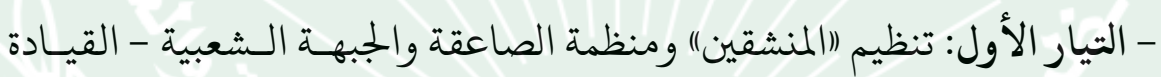

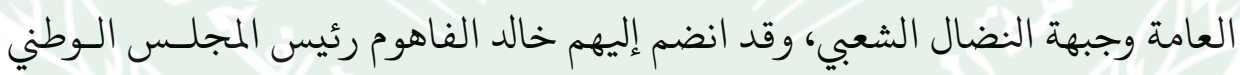

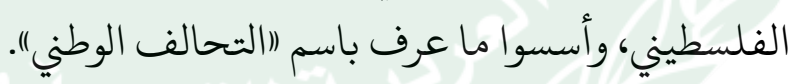

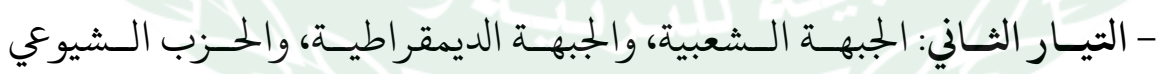

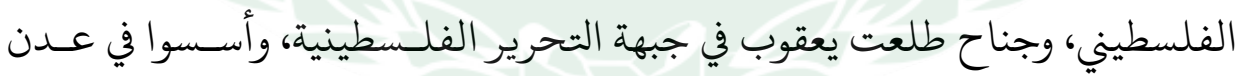
بتاريخ 1984/3/26 (التحالف الديمقراطي).

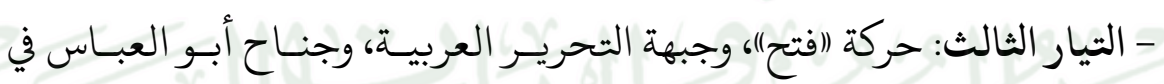

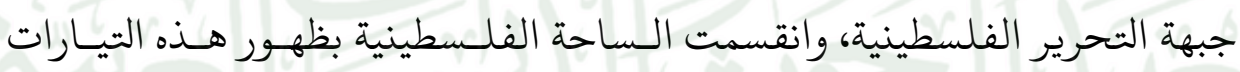

(1) محطات تاريخية ما بين العامين 1968-1987م، وكالة الأنباء والمعلومات الفلسطينية وفـا، 15 http://info.wafa.ps/ar_page.aspx?id=9102

$$
\text { فبراير 2014م. (تاريخ الدخول للموقع } 10 \text { يناير 2018): }
$$




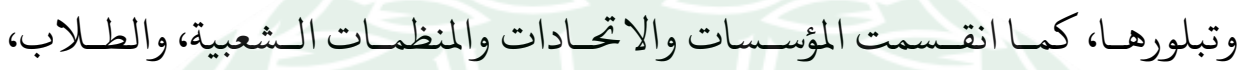

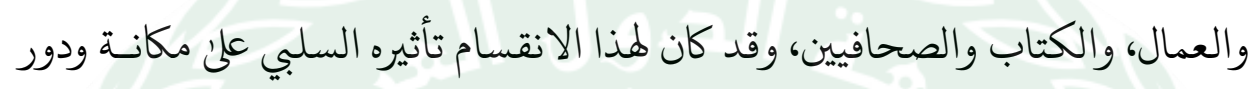
منظمة التحرير الفلسطينية في المحافل العربية والإقليمية والدولية.

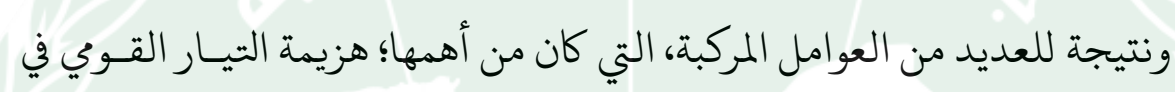

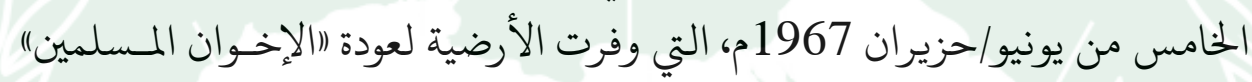

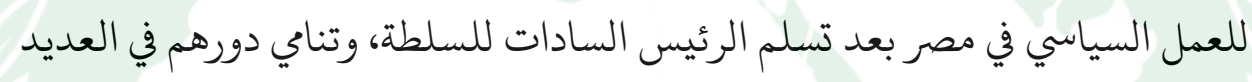

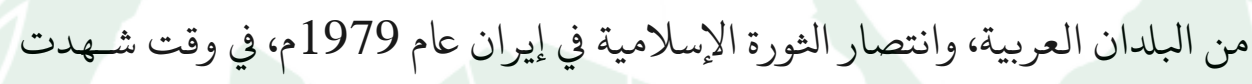

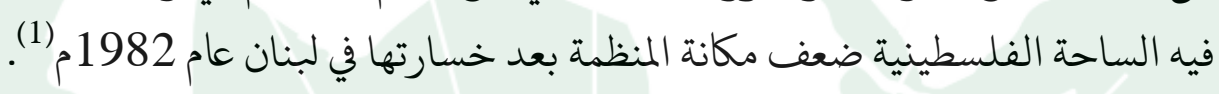

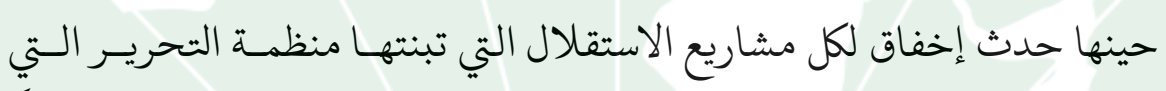

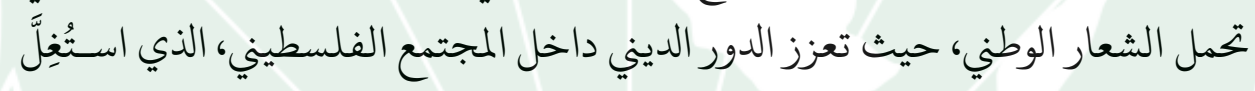

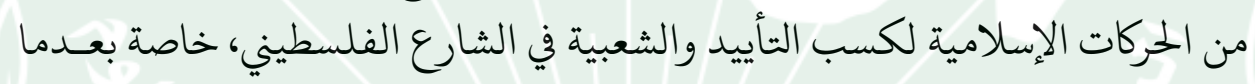

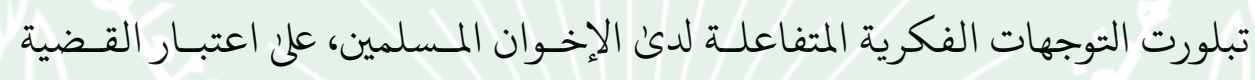

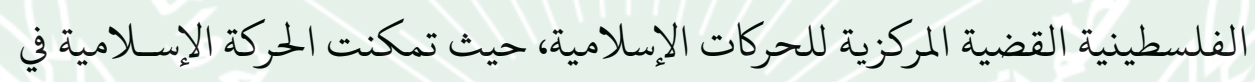

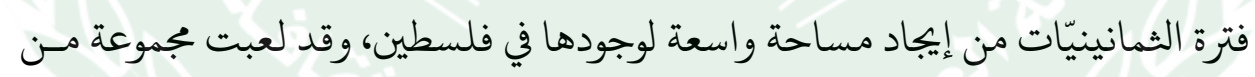

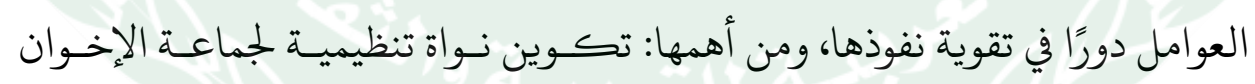

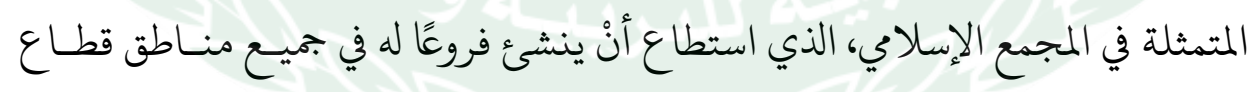

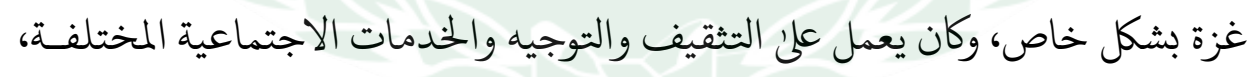

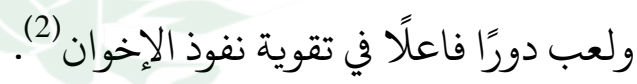

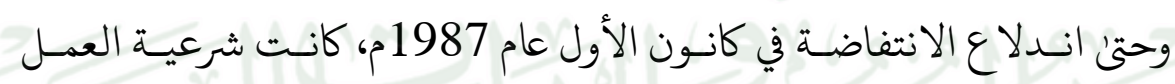

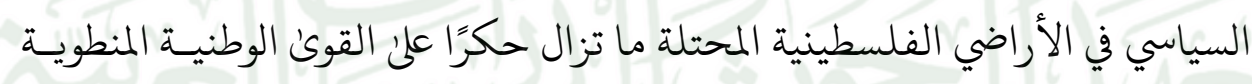

(1) إياد البرغوثي، الأسلمة والسياسة في الأراضي الفلـسطينية المحتلـة، مركز الزهـراء للدراسـات

$$
\text { (2) جواد الحمد، القرجع سابق، ص1990م، ص484. }
$$


تحت إطار منظمة الثحرير الفلسطينية، وكانت الحيـاة والثفـاعلات السياسية تـتم في

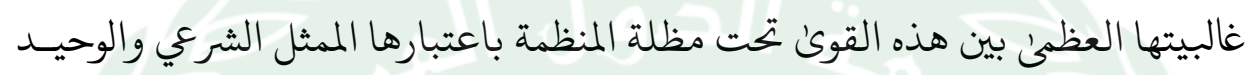

للشعب الفلسطيني (1).

وقد عمل الاختلاف بين فتح والإخوان المسلمين فـترة الثمانينيـات على مسائل

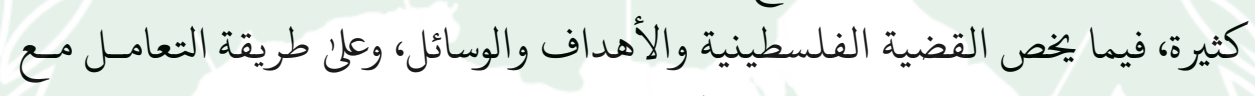

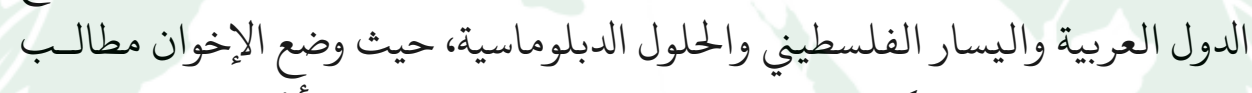

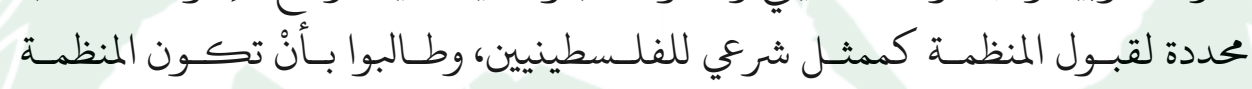

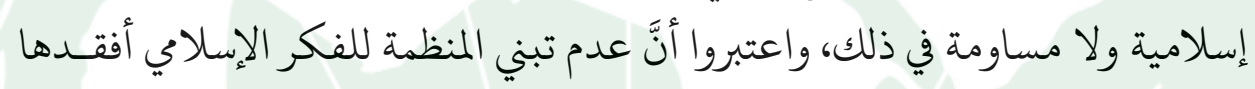

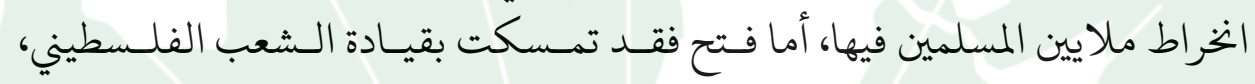

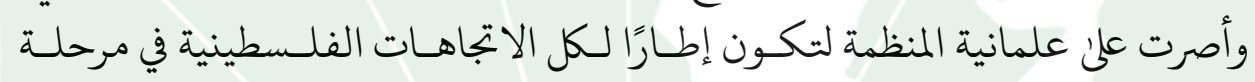
التحرير الوطني (2).

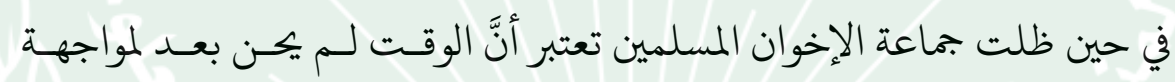

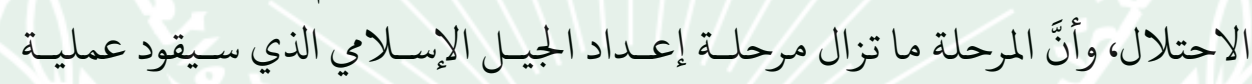

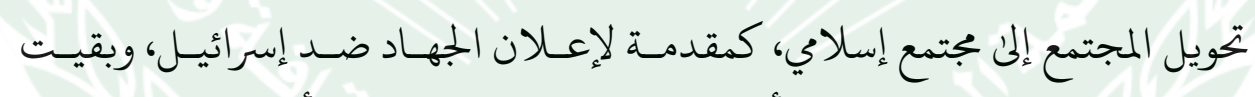

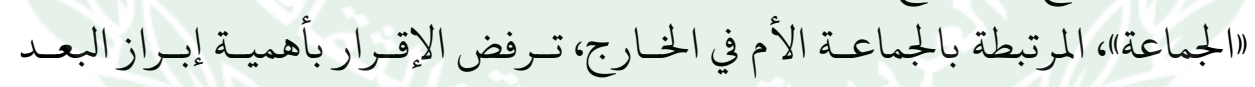

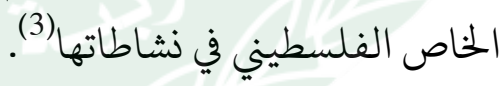

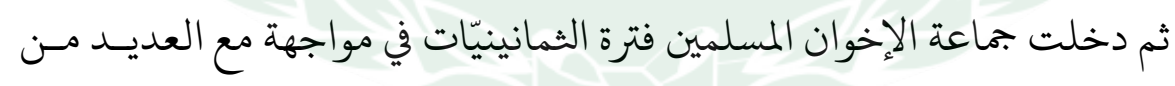

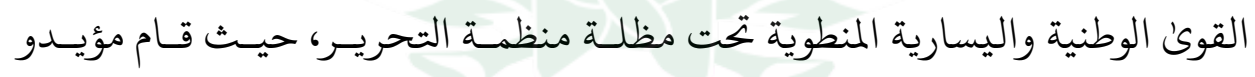

(1) علي الجرباوي، مـاس مـدخل الإخـوان المسلمين إلن الشرعية السياسية، مجلـة الدراسـات

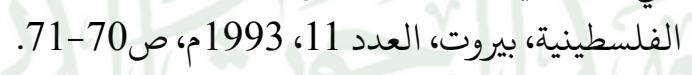

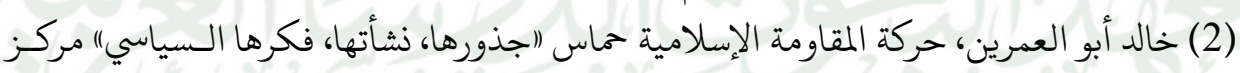

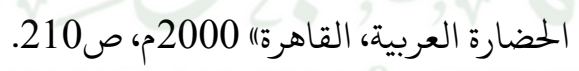

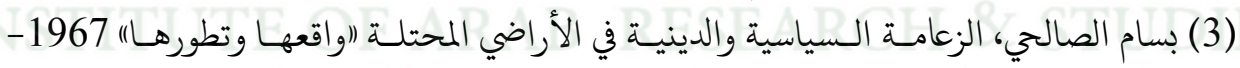

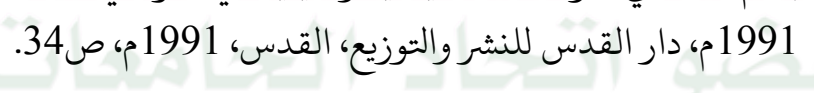


الإخوان عام 1980م، بإحراق "(جمعية الهلال الأحمر الفلسطيني") في قطاع غزة بحجـة

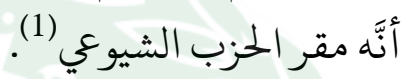

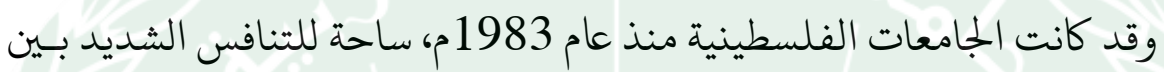

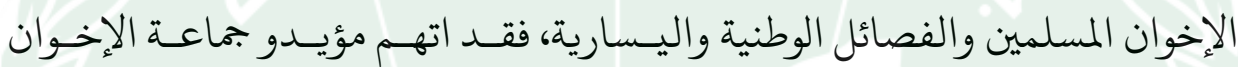

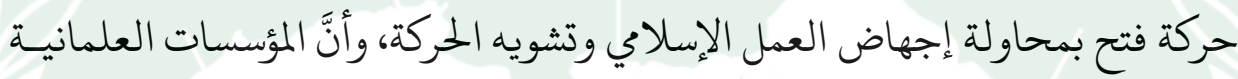

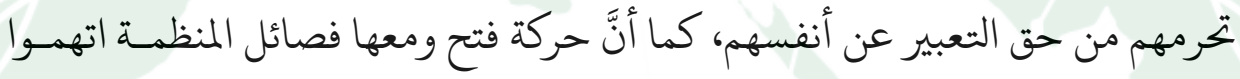

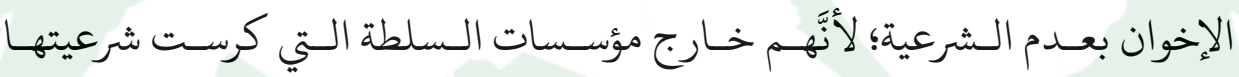

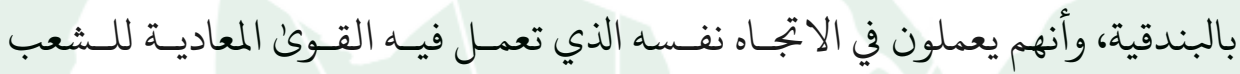

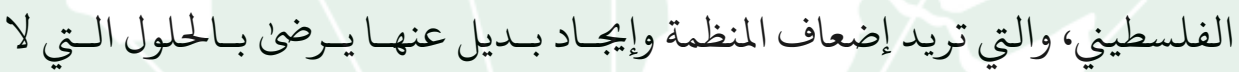

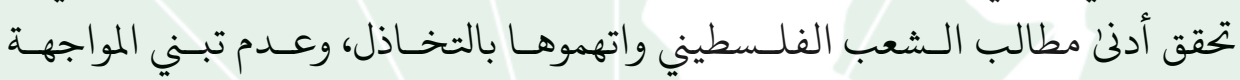

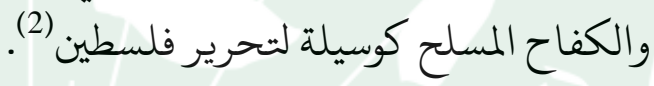

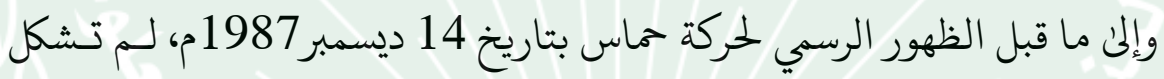

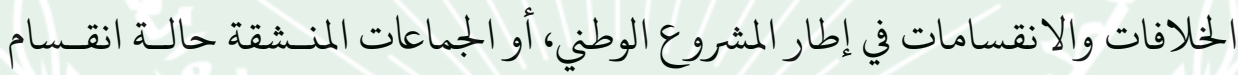

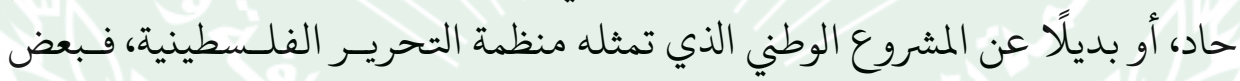

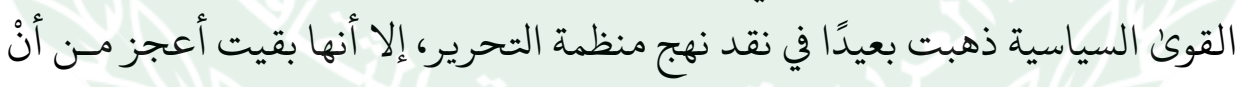

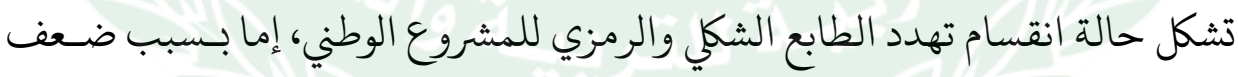

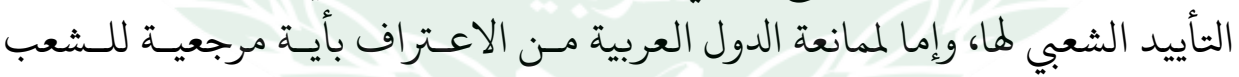

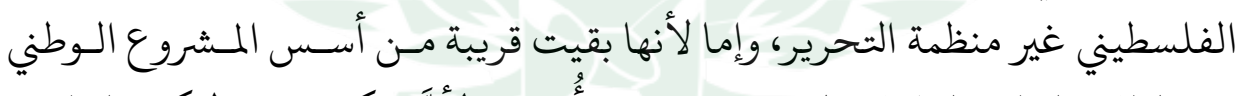

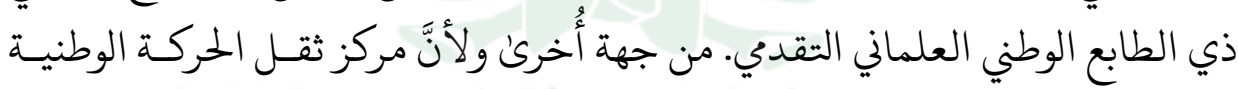

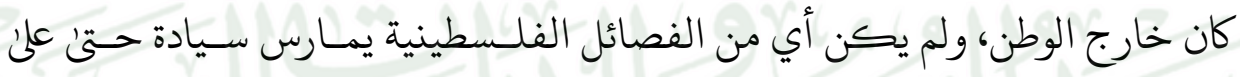

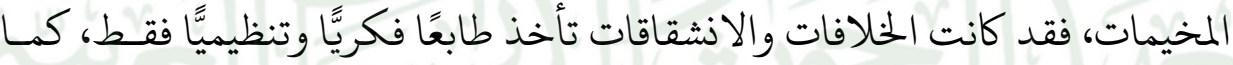

(1) زهير إبراهيم المصري، اتجاهات الفكر السياسي الفلسطيني ما بين الكفاح والتسوية، مكتبـة

$$
\text { (2) خالد أبو العمرين، غرجة، 2008م، صبق ذكري، ص210. }
$$




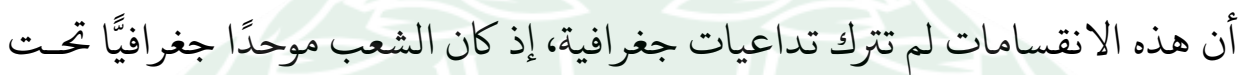

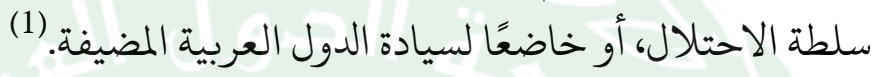

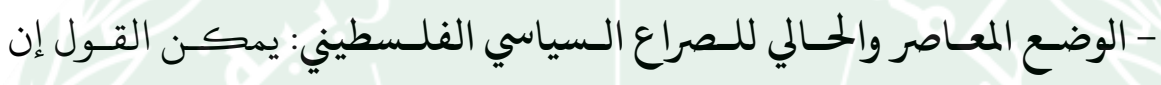

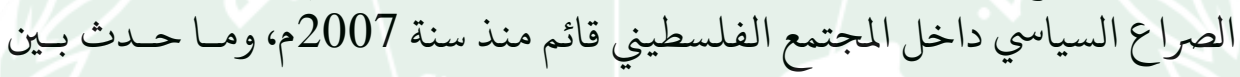

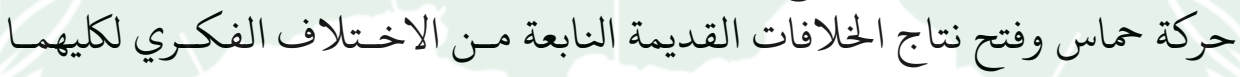

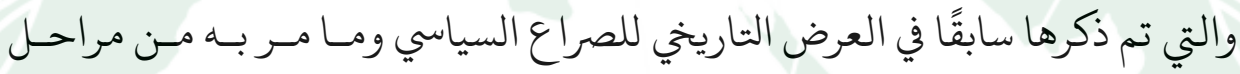

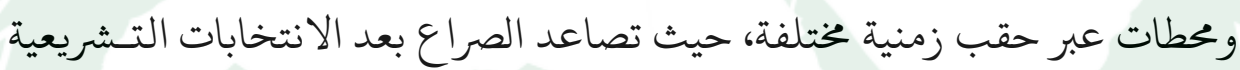

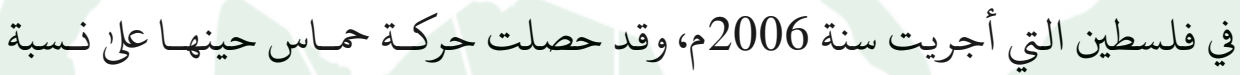

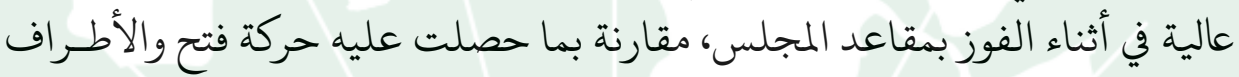

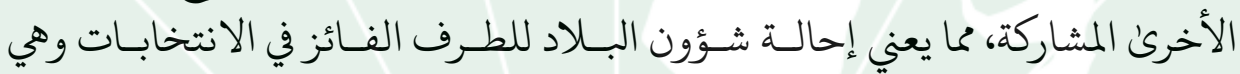

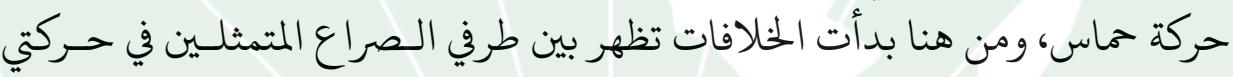

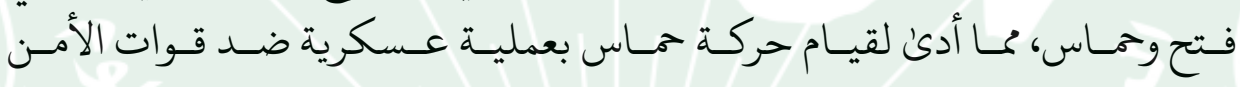

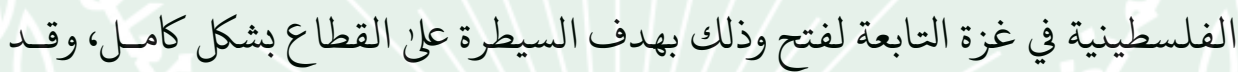

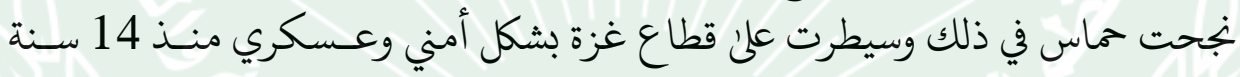

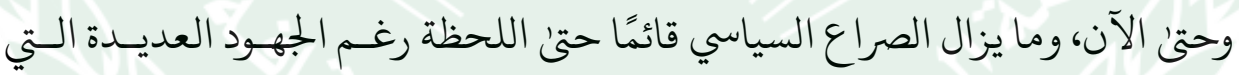

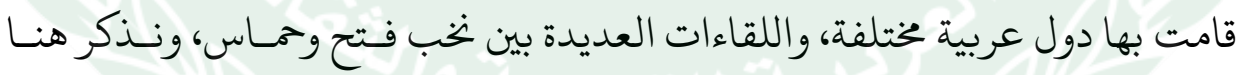

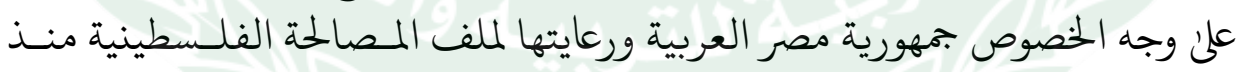

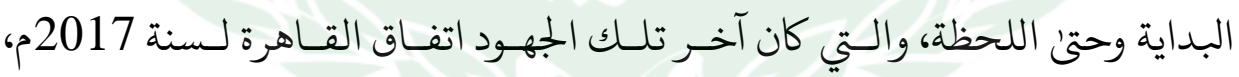

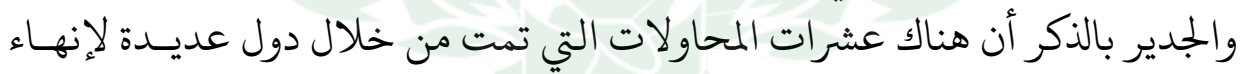

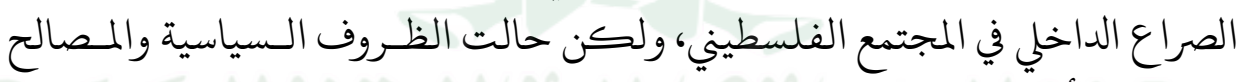

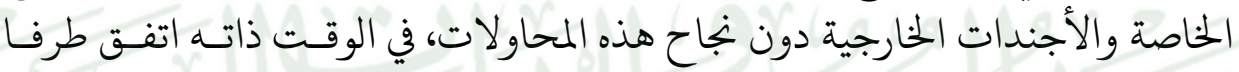

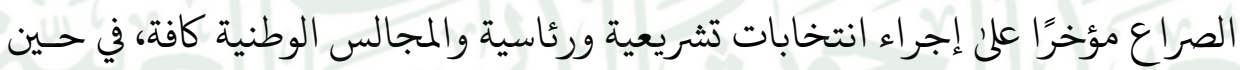

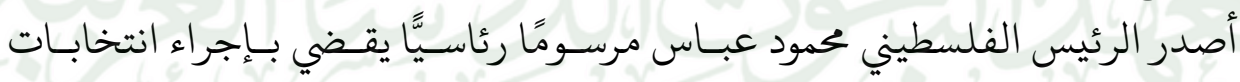

(1) إبراهيم أبراش، جذور الانقسام الفلسطيني ومخاطره على المشروع الوطني، مجلة الدراسـات

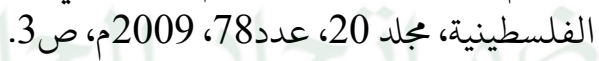


جديدة بهدف حل إشكالية الصراع والانقسام داخل المجتمع، وقد اتفق الطرفـان علئ

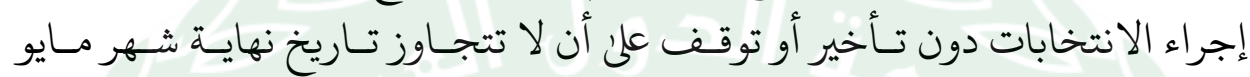

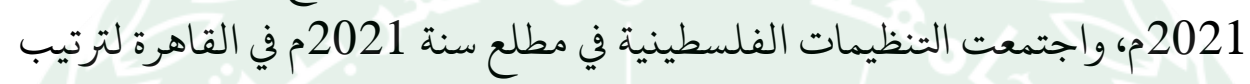

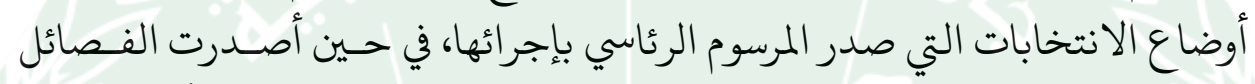

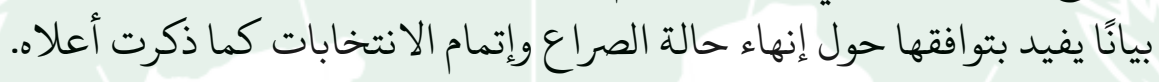

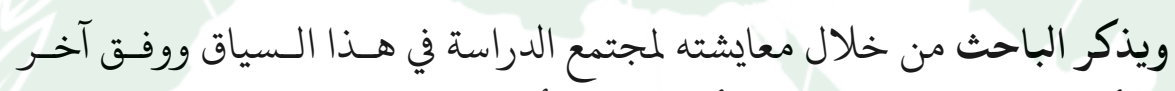

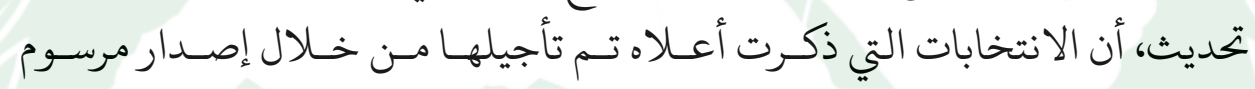

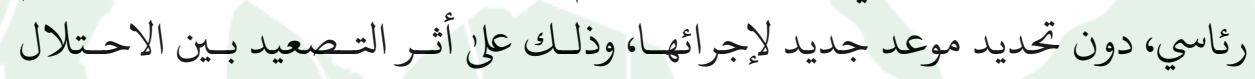

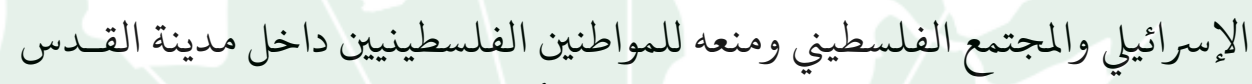

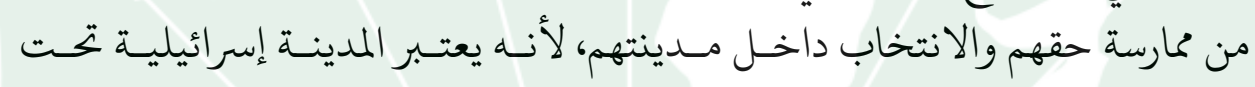

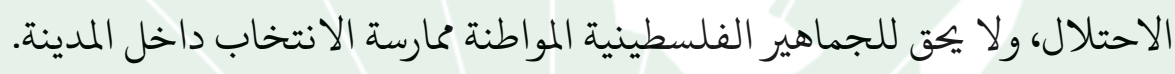
3- المواقف المحلية والدولية تجاه الصراع السياسي:

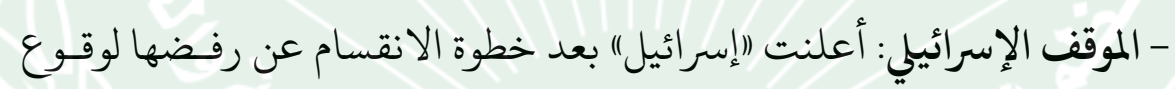

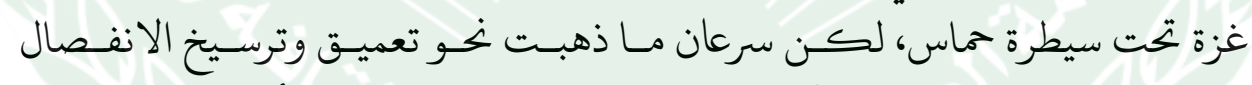

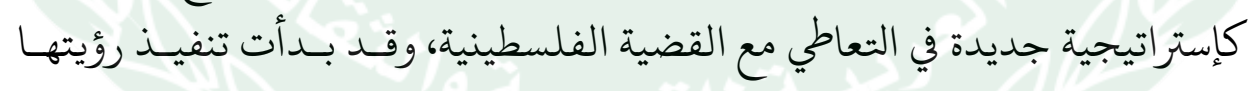

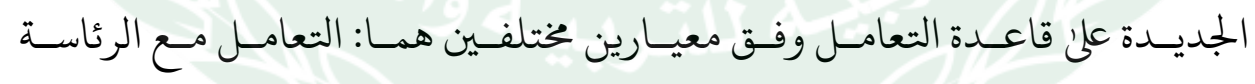

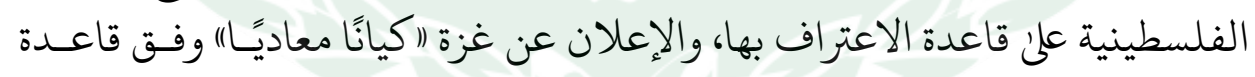

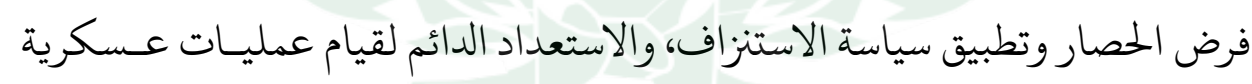

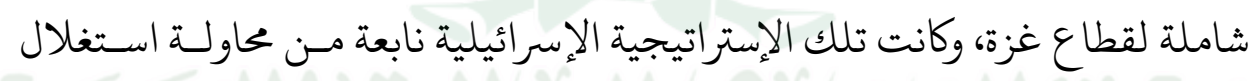

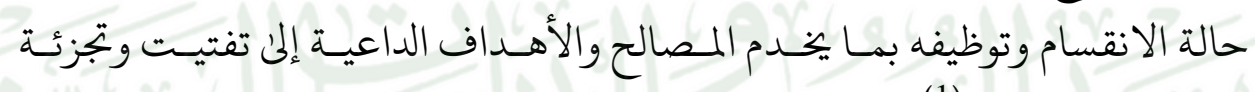
القضية الفلسطينية (1).

(1) أنطوان شلحت ومفيد وقسوم وآخرون: تقرير مدار الإسـتراتيجي 2008م المششهد الإسرائسيلي

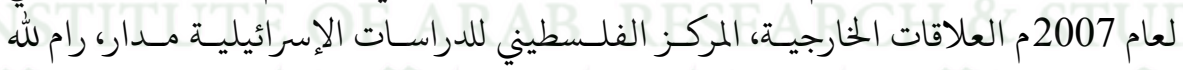

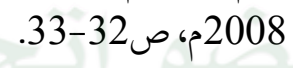




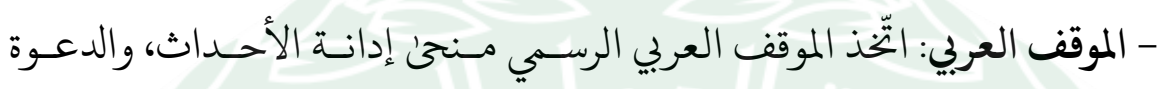

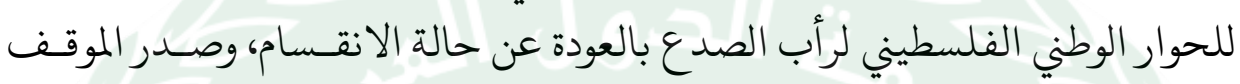

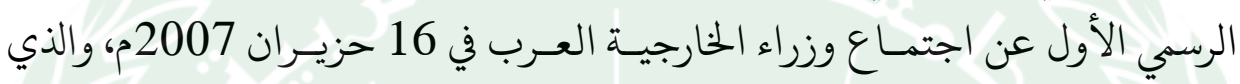

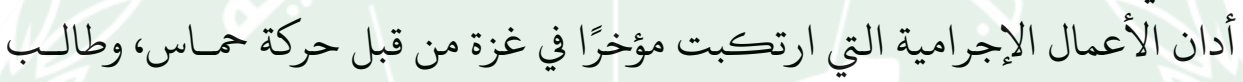

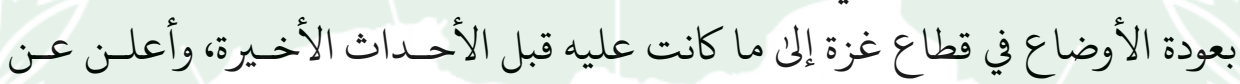
تشكيل لجنة لثقصي الحقائق.

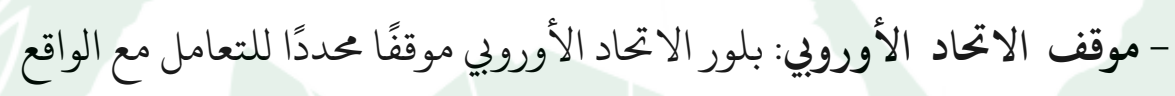

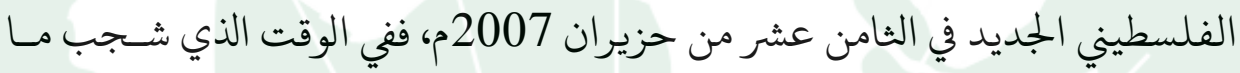

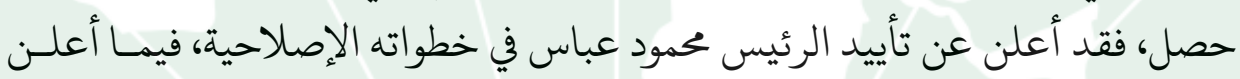

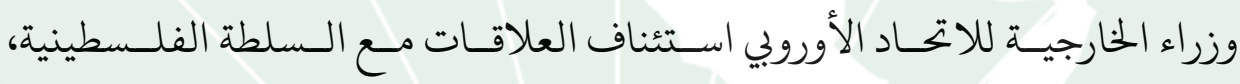

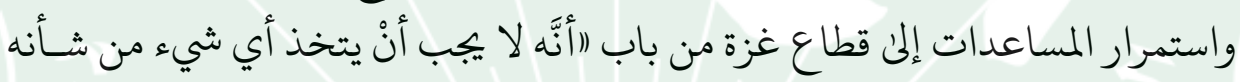

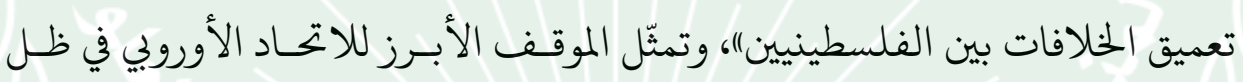

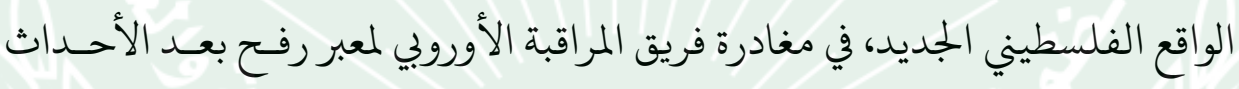
مباشرة.

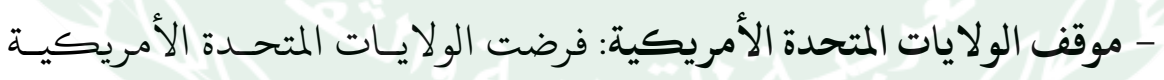

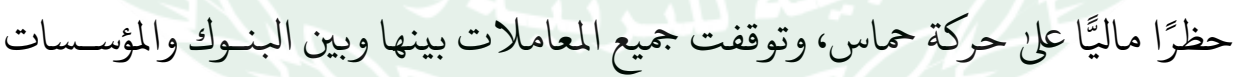

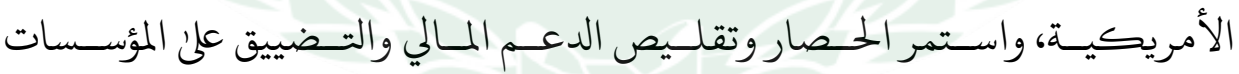

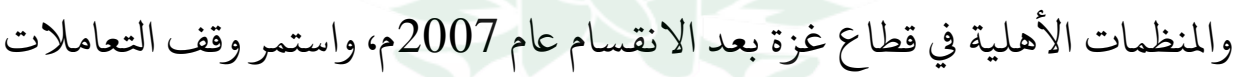

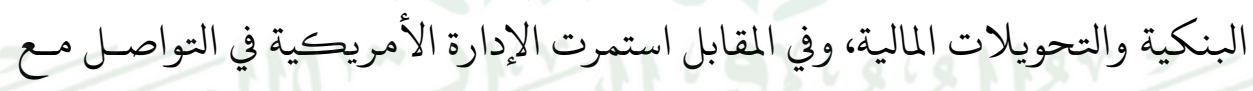

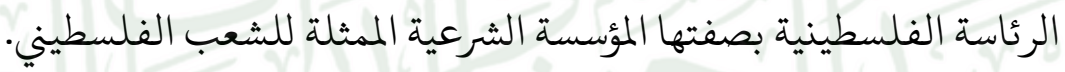

(1) معضلة الانقسام الفلسطيني وحدود الغضب العربي، موقع سويس انفو، 19 سـبتمبر 2008م.

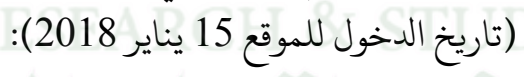
www.swissinfo.ch/ara/arabic_international/detail.html?siteSect=141\& 


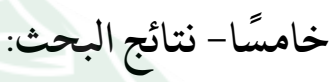

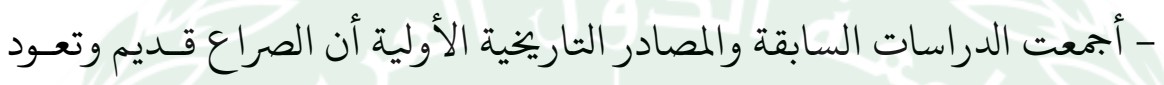
نشأته لثمانينات القرن الماضي، وما زال مستمرًا حتن اللحظة.

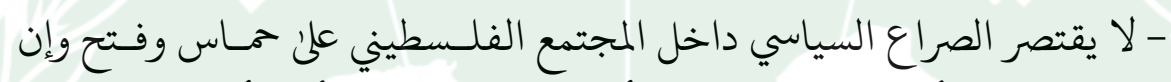

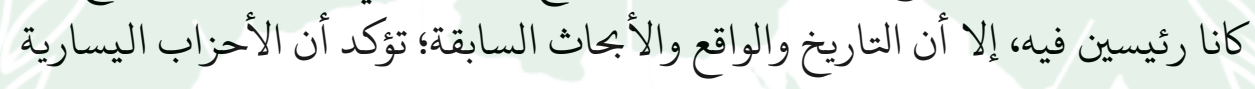

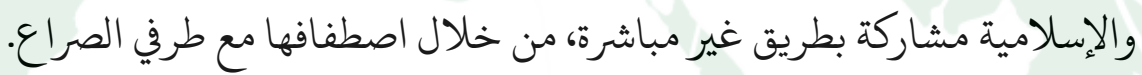

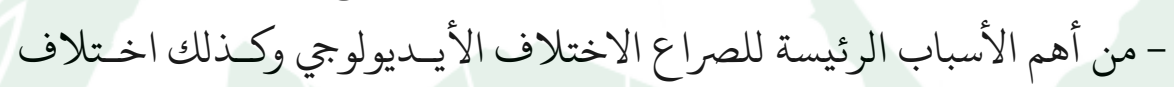

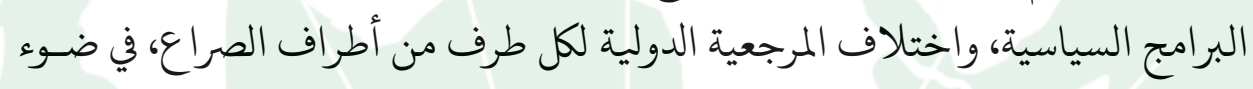
خلاف محاور كل طرف بين المربع العربي، والمربع التركي والإيراني.

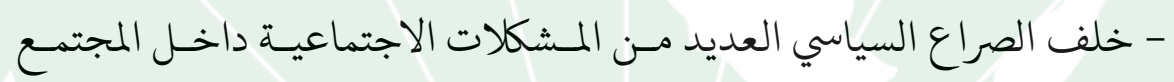

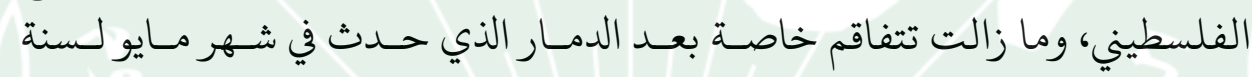

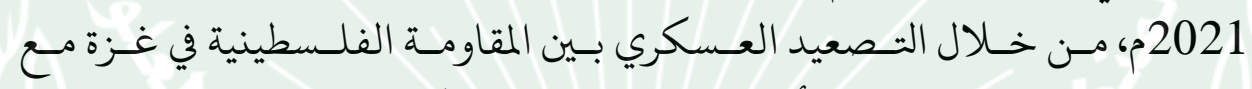

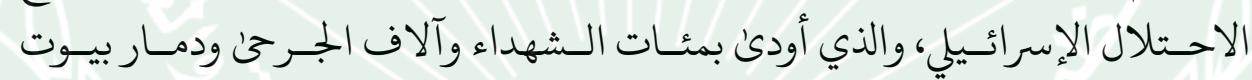

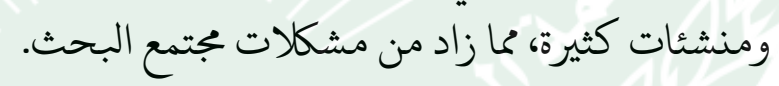

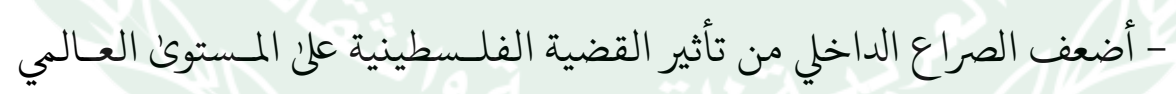
والعربي.

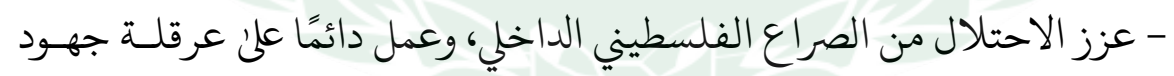
إنهاء هذا الصراع ليطيل أمده، لصالح مطامعهم الاحتلالية وبقائهم في فلسطين. * 


\section{المصادروالمراجع}

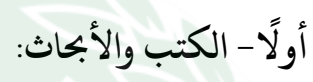

- أكرم زعيتر، الحركة الوطنيـة الفلـسطينية، 1935-1939م، مؤستسة الدراسـات الفلـسطينية،

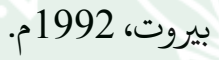

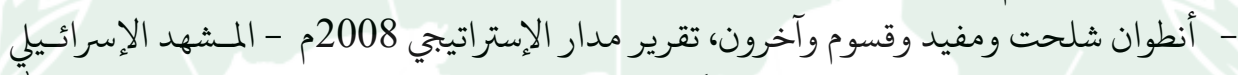

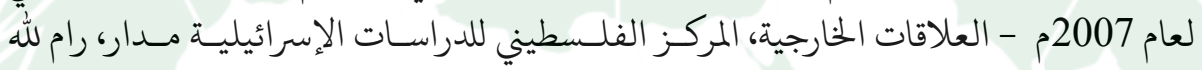

- إياد البرغوثي، الأسلمة والـسياسة في الأراضي الفلـسطينية المحتلـة، مركز الزهـراء للدراسـات

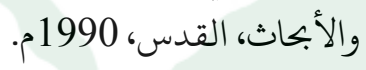

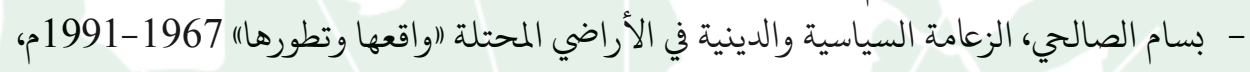

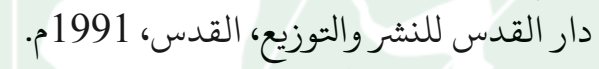

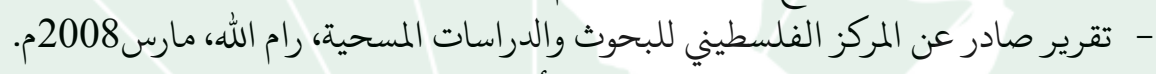

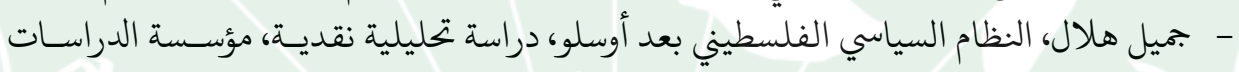

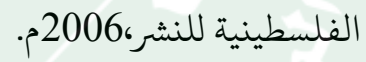
- - جواد الحمد، المدخل إلمن القضية الفلسطينية، مركز دراسات الشرق، عمان، 1907مان 1997م.

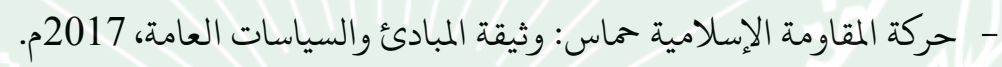

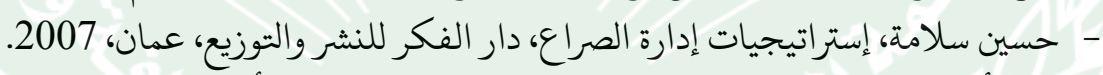

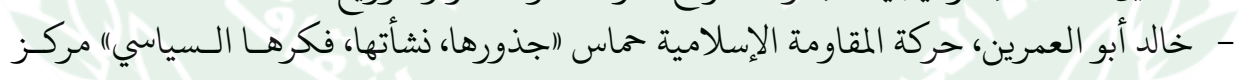

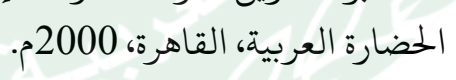

- زهير إبراهيم المصري، التجاهات الفكر السياسي الفلسطيني ما بين الكفـاح والتسوية، مكتبـة

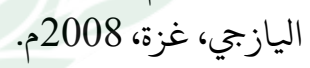

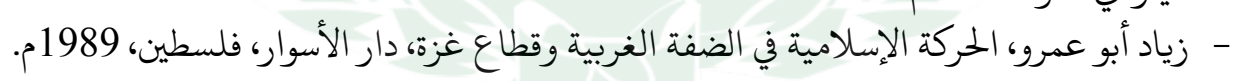

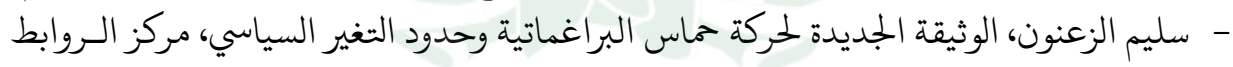

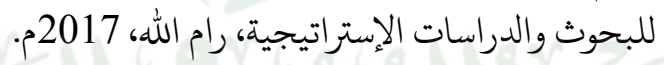

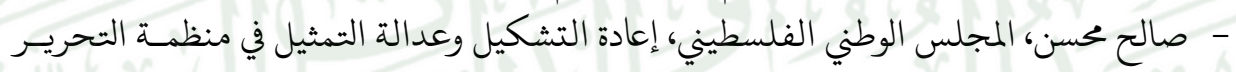

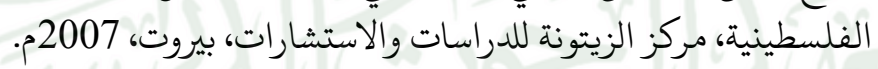
- صلاح الدين البحيري، المدخل إلى القضية الفلسطينية، مركز دراسات الشرق الأوسط، عمان، 1997 ماح المن - طلعت إبراهيم لطفي، النظرية المعاصرة في علم الاجتماع، القاهرة، دار غريب للطباعة والنشر، ط2، 2009. 
- - عبد العزيز بن علئ الغريب، نظريات علم الاجتماع، جدة، المطبعة للنشر، 2009. - عصام سخنيني، تمثيل الشعب الفلسطيني الغريني ومنظمة الثحرير الفلسطينية، مجلة شؤون فلسطينية،

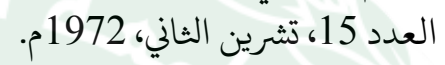

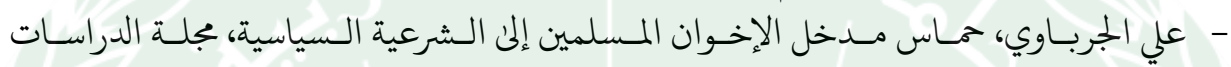

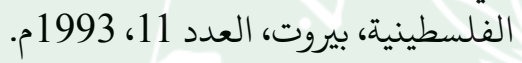

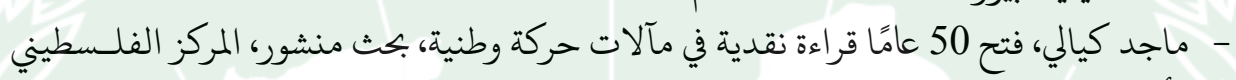

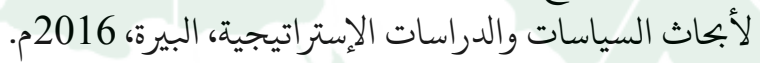

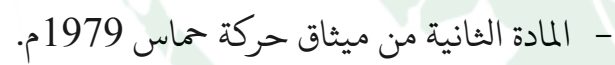

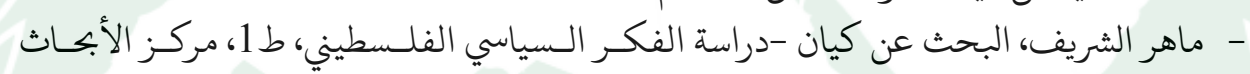

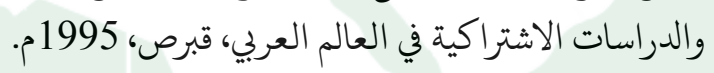

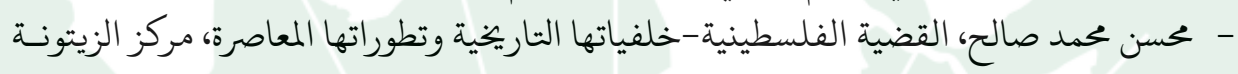

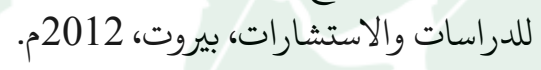
- محمد الجوهري، وعدلي السمري، المشكلات الاجتماعية، مركز البحوث والمبات والدراسات الاجتماعيـة،

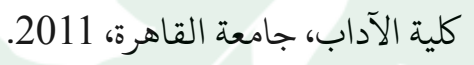

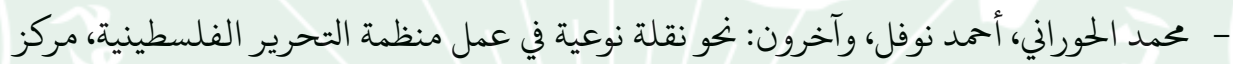

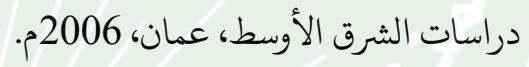

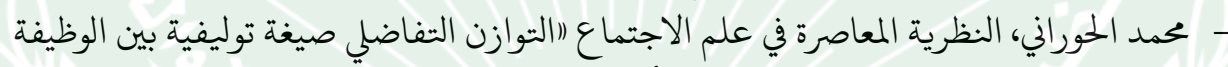

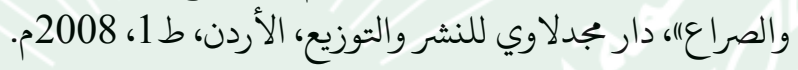

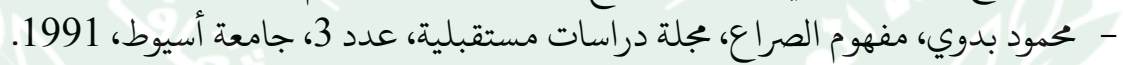

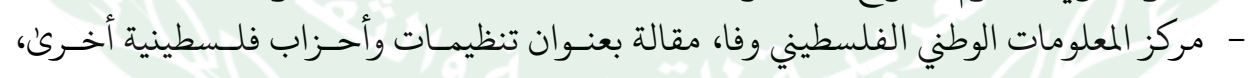
تاريخ الدخول 2019/8/28م.

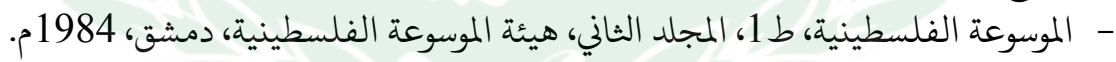

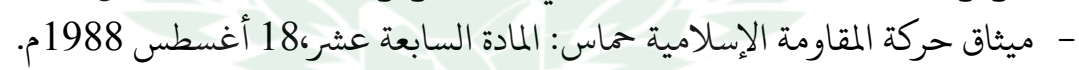

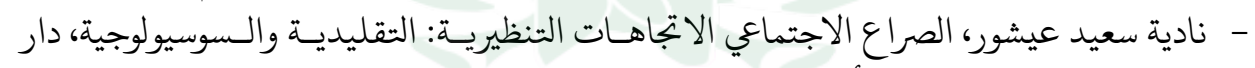
مجدلاوي للنشر والتوزيع، الأردن. - ـ واصل المومني، المناخ التنظيمي وإدارة الصراع في المؤسسات التربوية، دار الحامد للنشر والتوزيع، عمان، الأردن، 2006.

- Edward J. Murray, "Conflict: The Psychological Aspects", in IESS,. pp. 220-225.

ثانيًا- الدوريات والدراسات الخاصة:

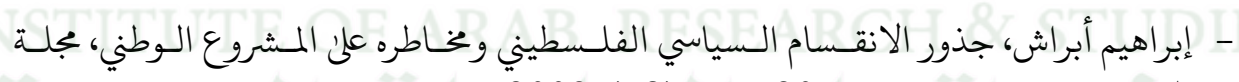
الدراسات الفلسطينية، المجلد 20، العدرد العد (78)، 2009م. 
- إبراهيم قشطة، الصراع التنظيمي وأثثه على الأوضاع والعلاقات الاجتماعية الفلسطينية، دراسة

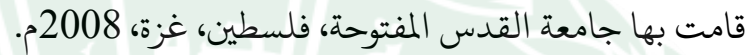

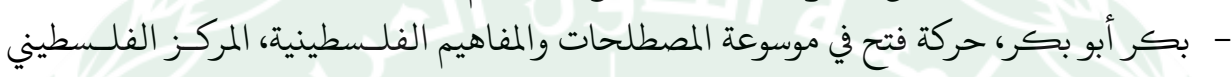

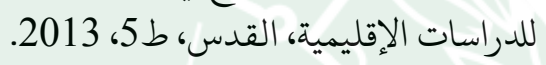
- صقر أبو فخر، حركة التحرير الوطني الفلسطيني فتح قافلة التيه الفلسطيني الطويـل، الـسفير،

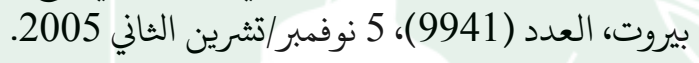

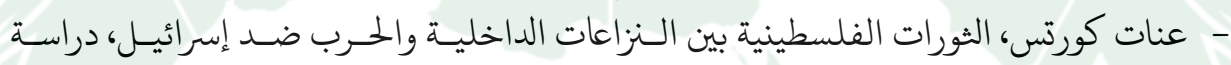

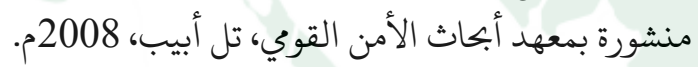

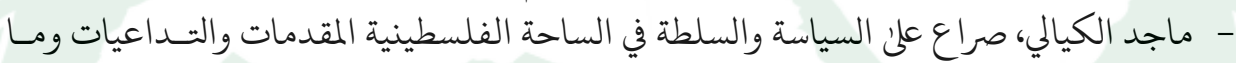

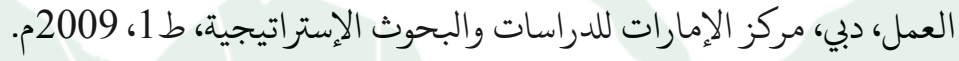

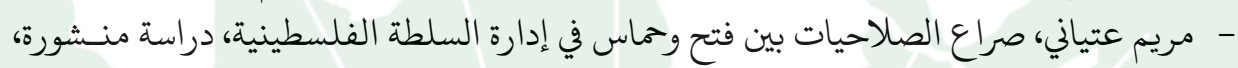

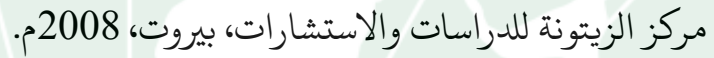

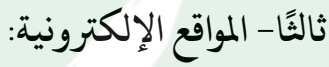

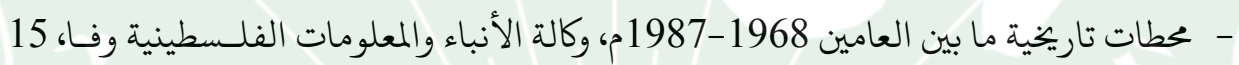
http://info.wafa.ps/ar-page.aspx?id=9102

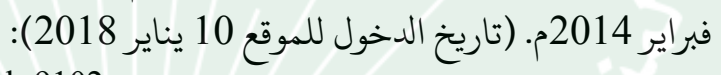

- المركز الفلسطيني لأبحاث الـسياسات والدراسـات الإسـتراتيجية- مسسارات، (تـاريخ الدخـول https://www.masarat.ps/article/4610. 2019/8/26

- معضلة الانقسام الفلسطيني وحدود الغضب العربي، موقع سـويس انفـو، 19 ســبتمبر 2008م.

$$
\text { (تاريخ الدخول للموقع } 15 \text { يناير 2018): }
$$

www.swissinfo.ch/ara/arabic-international/detail.html?siteSect=141

- مفوضية الإعلام والثقافة والثعبئة الفكرية لحركة فتح، (تاريخ الدخول 2109/7/29): https://www.fatehmedia.ps/page-69882.html

- منير شفيق، في معالجة الانقسام الفلسطيني، فلسطين اليوم، 19 يوليو 2015م. 2015 (تاريخ الدخـول

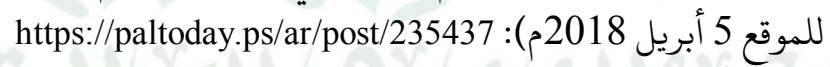

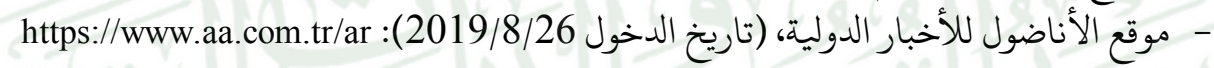

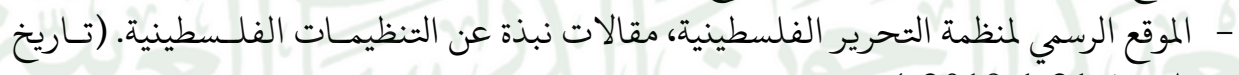

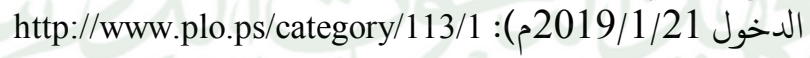




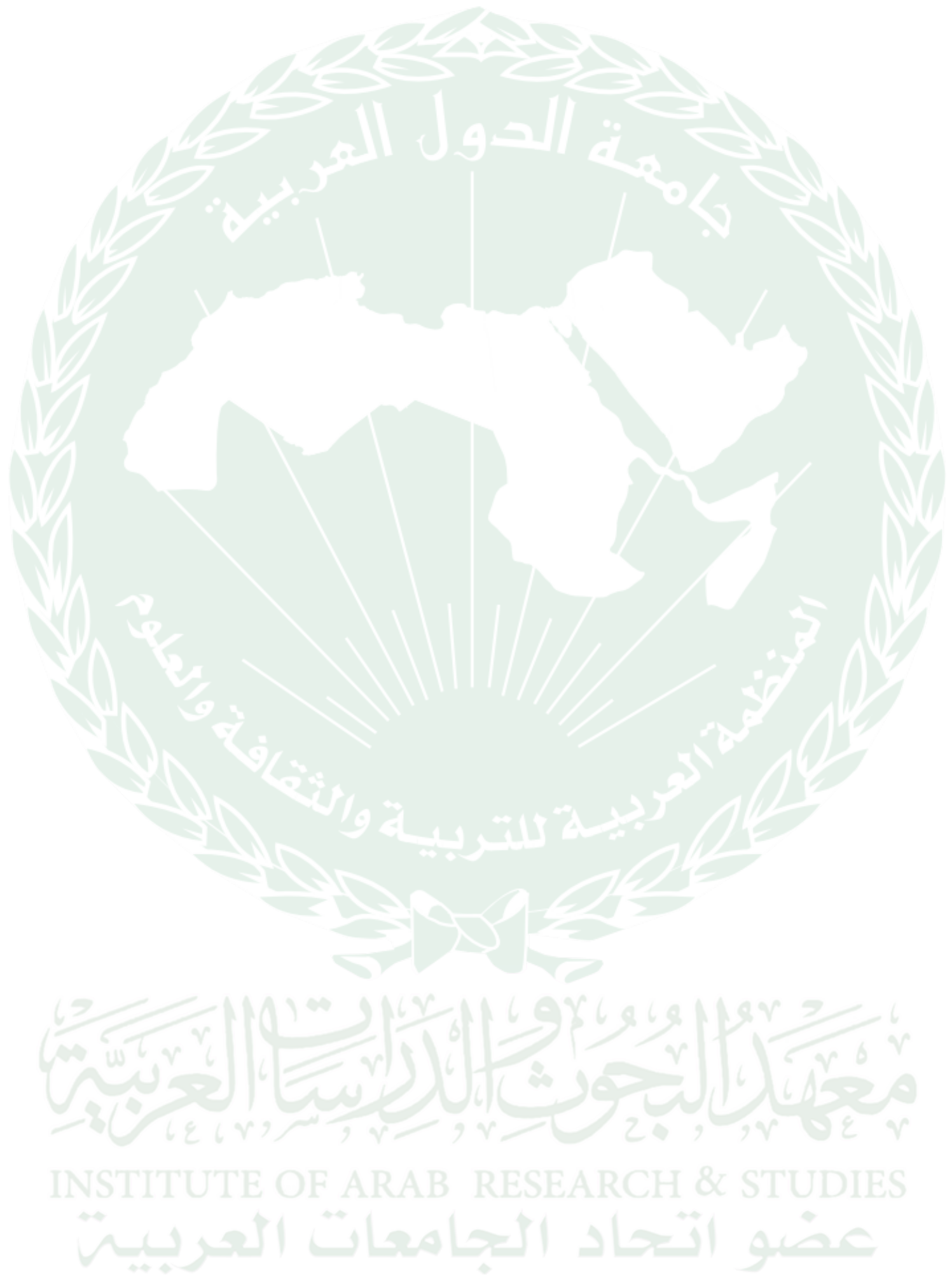

